Prepared in cooperation with the U.S. Fish and Wildlife Service

\title{
Resilience and Risk-A Demographic Model to Inform Conservation Planning for Polar Bears
}

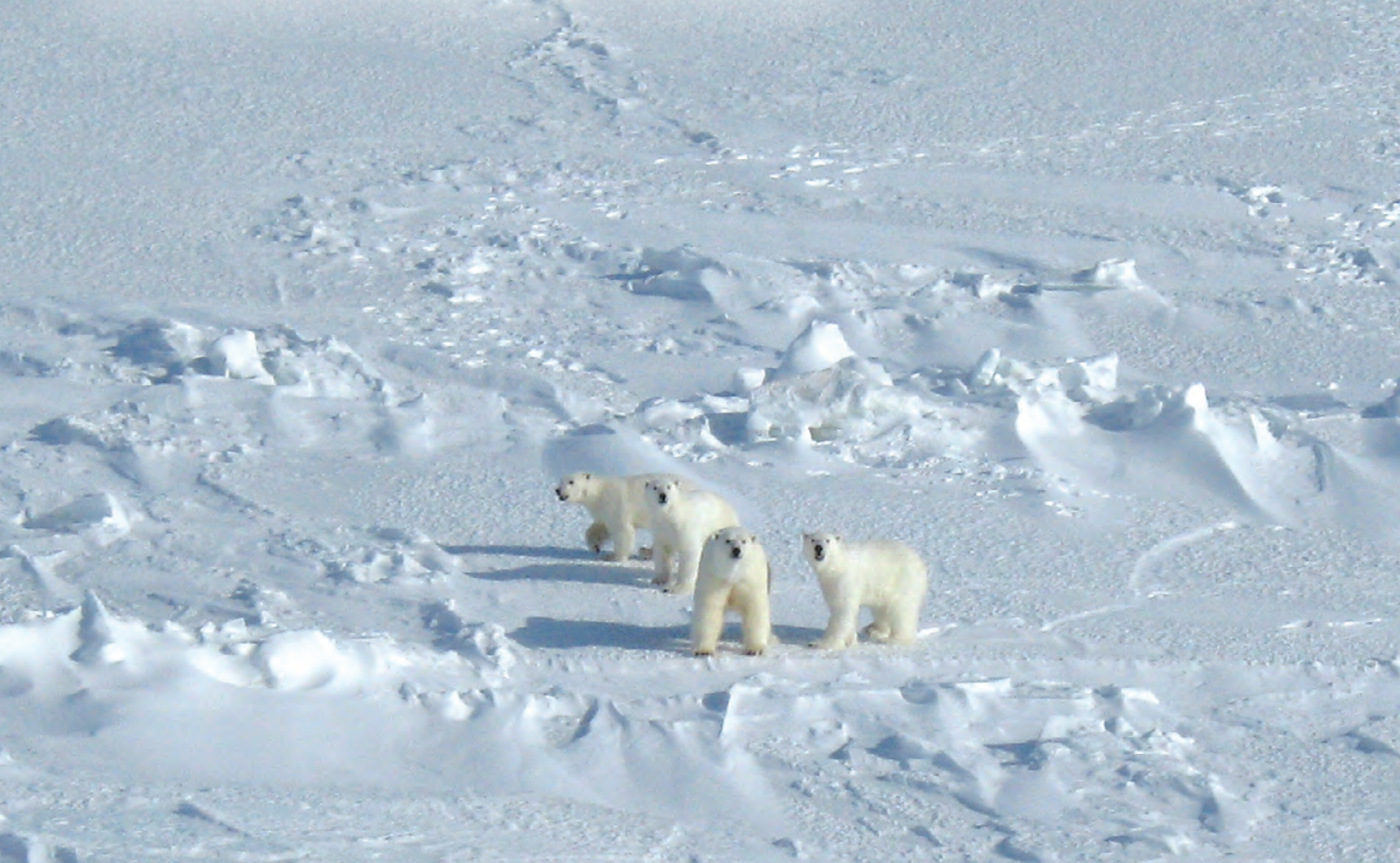

Open-File Report 2015-1029

U.S. Department of the Interior

U.S. Geological Survey 
Cover: An adult female polar bear and her three yearling cubs on the sea ice of the Chukchi Sea, spring 2010. Photograph taken by Eric V. Regehr, U.S. Fish and Wildlife Service. 


\section{Resilience and Risk-A Demographic Model to Inform Conservation Planning for Polar Bears}

By Eric V. Regehr, Ryan R. Wilson, Karyn D. Rode, and Michael C. Runge

Prepared in cooperation with the U.S. Fish and Wildlife Service

Open-File Report 2015-1029

U.S. Department of the Interior

U.S. Geological Survey 


\section{U.S. Department of the Interior \\ SALLY JEWELL, Secretary}

\section{U.S. Geological Survey \\ Suzette M. Kimball, Acting Director}

U.S. Geological Survey, Reston, Virginia: 2015

For more information on the USGS - the Federal source for science about the Earth,

its natural and living resources, natural hazards, and the environment-visit

http://www.usgs.gov or call 1-888-ASK-USGS (1-888-275-8747)

For an overview of USGS information products, including maps, imagery, and publications, visit http://www.usgs.gov/pubprod

To order this and other USGS information products, visit http://store.usgs.gov

Any use of trade, product, or firm names is for descriptive purposes only and does not imply endorsement by the U.S. Government.

Although this information product, for the most part, is in the public domain, it also may contain copyrighted materials as noted in the text. Permission to reproduce copyrighted items must be secured from the copyright owner.

Suggested citation:

Regehr, E.V., Wilson, R.R., Rode, K.D., and Runge, M.C., 2015, Resilience and risk-A demographic model to inform conservation planning for polar bears: U.S. Geological Survey Open-File Report 20151029, 56 p., http://dx.doi.org/10.3133/ofr20151029.

ISSN 2331-1258 (online) 


\section{Contents}

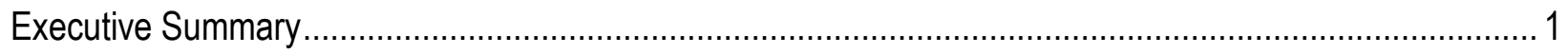

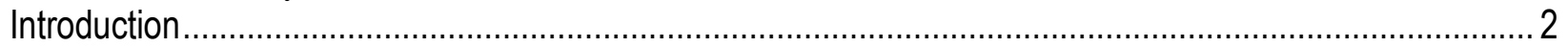

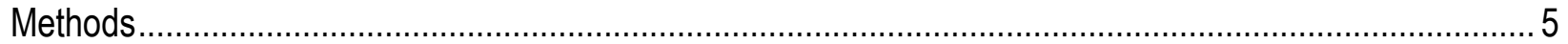

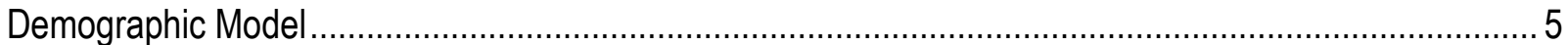

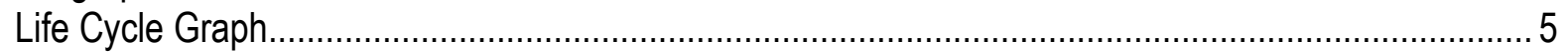

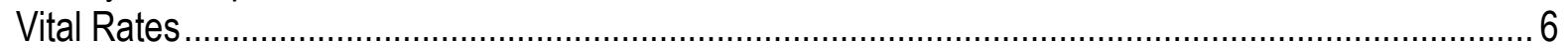

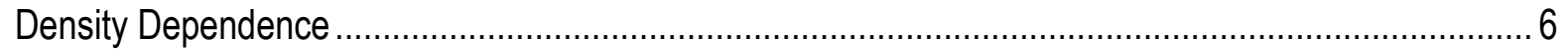

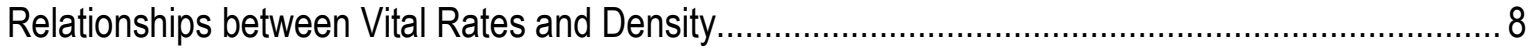

Maximum Net Productivity Level..................................................................................... 8

Metabolic Energetic Equivalents..................................................................................... 10

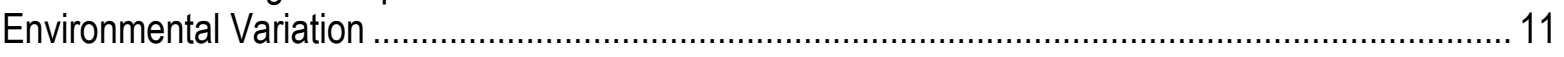

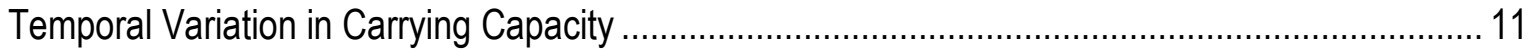

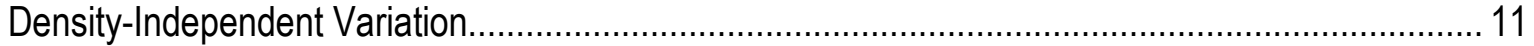

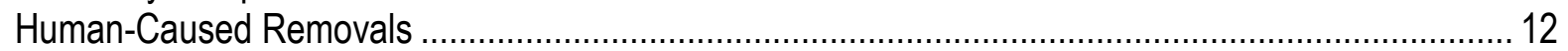

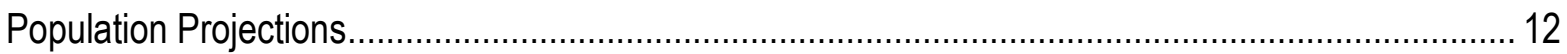

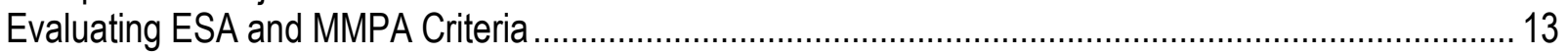

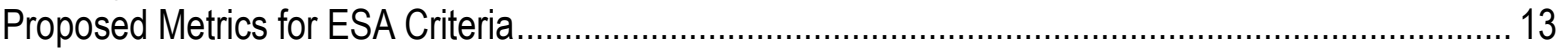

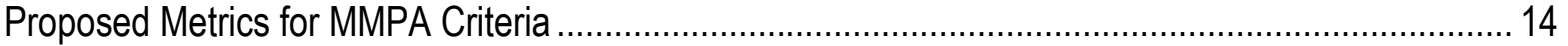

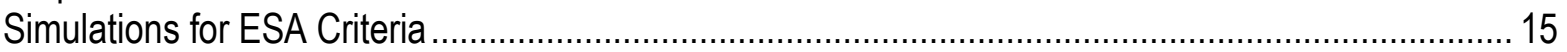

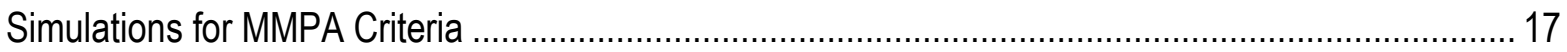

Inputs to the State-Dependent Management Framework ....................................................... 17

Robustness of the State-Dependent Management Framework ................................................ 18

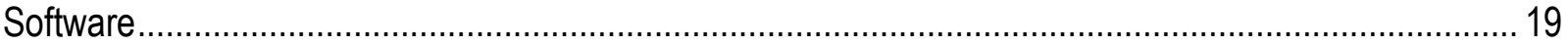

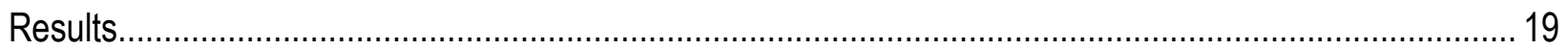

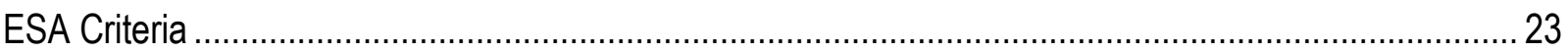

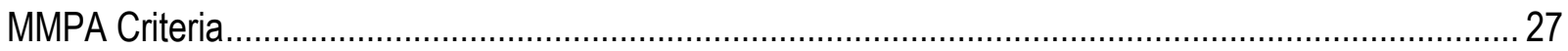

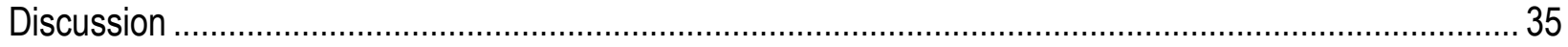

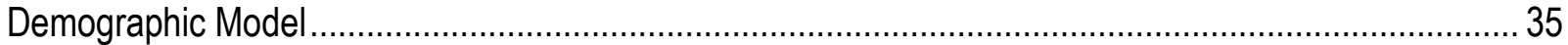

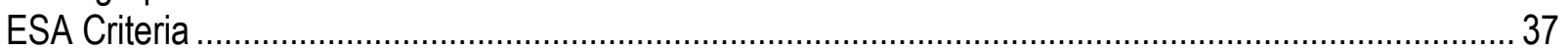

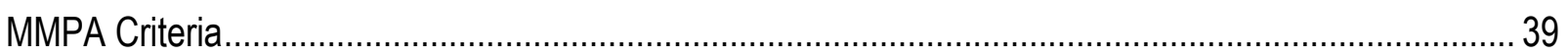

Comparison with Current Polar Bear Harvest Management............................................................ 42

Definition of Sustainability for Polar Bear Harvest Management ..................................................... 42

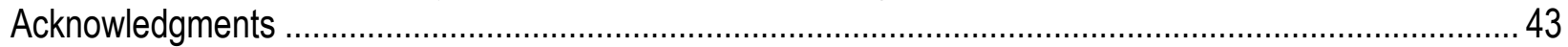

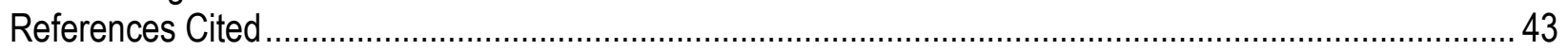

Appendix A. Methods to Adapt Published Vital Rates to the Polar Bear Life Cycle Graph ........................52

Appendix B. Methods to Generate Density-Dependent Functions for the Vital Rates ................................53

Appendix C. Methods to Generate a Sea Ice-Based Proxy for Carrying Capacity..................................... 55

Appendix D. Methods to Estimate Parameters Using Simulated Population Assessments ........................56 


\section{Figures}

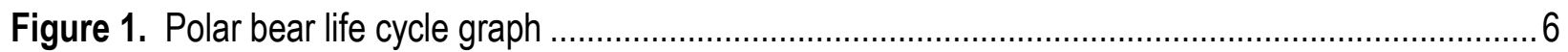

Figure 2. Graphs showing the model of density dependence for polar bears …………........................ 9

Figure 3. Contour plot of the recruitment metric as a function of survival and breeding probability ............20 Figure 4. Contour plot of maximum net productivity level (MNPL) as a function of survival and recruitment

Figure 5. Contour plot of per capita population growth rate at maximum net productivity level ( $\left.r_{M N P L}\right)$ as a function of survival and recruitment

Figure 6. Contour plot of the combinations of survival and recruitment necessary to achieve a 90-percent probability of persistence over 100 years for different levels of carrying capacity. 25

Figure 7. Graphs showing example projections for a small population with and without human-caused removals. 26

Figure 8. Graph showing probability of population size decreasing to less than $N_{M N P L}\left(P_{<M N P L}\right)$ as a function of the management factor $\left(F_{0}\right)$, for different levels of data precision.

Figure 9. Graph showing relationship between the probability of extirpation $\left(1-P_{\text {persist }}\right)$ and the probability of population size decreasing to less than $N_{M N P L}\left(P_{<M N P L}\right)$. 30

Figure 10. Graph showing annual yield as a function of time, for different levels of the management factor $\left(F_{0}\right)$

Figure 11. Graphs showing example population projections with and without human-caused removals for stable and declining carrying capacity.

\section{Tables}

Table 1. Estimated vital rates for polar bear subpopulations ................................................................

Table 2. Metabolic energetic equivalents for polar bears ............................................................... 10

Table 3. Summary of key components in simulations to evaluate Endangered Species Act (ESA) and Marine Mammal Protection Act (MMPA) criteria ............................................................................. 16

Table 4. Levels of data precision used in simulated population assessments........................................ 17

Table 5. Range of survival rates that must be maintained, in conjunction with sufficient recruitment, to achieve a 90-percent probability of persistence over 100 years

Table 6. Threshold values of the management factor $\left(F_{0}\right)$ used to calculate human-caused removals under the state-dependent management framework, which meet conservation goals based on a placeholder degree of risk tolerance.

Table 7. Increased risk of extirpation compared to no human-caused removals ( $\left.\Delta P_{\text {extirpation}}\right)$, under a sample application of the state-dependent management framework, for different rates of declining carrying capacity. 


\section{Conversion Factors}

International System of Units to Inch/Pound

\begin{tabular}{lcl}
\hline & \multicolumn{1}{c}{ Multiply } & \multicolumn{1}{c}{ To obtain } \\
\hline \multicolumn{3}{c}{ Length } \\
\hline kilometer $(\mathrm{km})$ & 0.6214 & mile (mi) \\
kilometer $(\mathrm{km})$ & 0.5400 & mile, nautical (nmi) \\
\hline \multicolumn{3}{c}{ Mass } \\
\hline kilogram $(\mathrm{kg})$ & 2.2054 & pound avoirdupois (lb) \\
\hline
\end{tabular}




\section{Abbreviations, Acronyms, and Symbols}

\begin{tabular}{|c|c|}
\hline Adult & Polar bear aged 5 or more years \\
\hline $\mathrm{CO}$ & Cub-of-the-year \\
\hline $\mathrm{C} 1$ & Yearling \\
\hline $\mathrm{C} 2$ & Two-year-old polar bear still dependent on its mother \\
\hline $\mathrm{CI}$ & Confidence interval \\
\hline CMP & Polar Bear Conservation Management Plan \\
\hline CS & Chukchi Sea \\
\hline $\mathrm{CV}$ & Coefficient of variation \\
\hline$\Delta P_{\text {extirpation }}$ & Increased risk of extirpation \\
\hline ESA & Endangered Species Act \\
\hline$F_{O}$ & $\begin{array}{l}\text { Factor that reflects management objectives and risk tolerance when calculating } \\
\text { sustainable harvest rate }\end{array}$ \\
\hline$h_{M N P L}$ & $\begin{array}{l}\text { Maximum rate of human-caused removals that still maintains populations above the } \\
\text { equilibrium population size at MNPL }\end{array}$ \\
\hline$\kappa$ & Proportional change in the number of ice-covered days \\
\hline$K$ & Carrying capacity \\
\hline mee & Metabolic energetic equivalent \\
\hline MMPA & Marine Mammal Protection Act \\
\hline MNPL & Maximum net productivity level \\
\hline$N$ & Population size \\
\hline$N_{M N P L}$ & Equilibrium population size at MNPL \\
\hline OSP & Optimum sustainable population \\
\hline$P_{<M N P L}$ & Probability that population size is less than MNPL \\
\hline PBR & Potential biological removal method for assessing take \\
\hline PBRT & Polar Bear Recovery Team \\
\hline$P_{\text {persist }}$ & Probability of persistence \\
\hline PVA & Population viability analysis \\
\hline$r$ & Per capita population growth rate \\
\hline$r_{\max }$ & $\begin{array}{l}\text { Maximum per capita population growth rate at low densities and in the absence of } \\
\text { human-caused removals }\end{array}$ \\
\hline$r_{M N P L}$ & $\begin{array}{l}\text { Per capita population growth rate at MNPL and in the absence of human-caused } \\
\text { removals }\end{array}$ \\
\hline SB & Southern Beaufort Sea \\
\hline$S R$ & Factor that specifies the male-to-female ratio in human-caused removals \\
\hline Subadult & Independent polar bear aged $2-4$ years \\
\hline Subpopulation & $\begin{array}{l}\text { One of the } 19 \text { polar bear subpopulations recognized by the International Union for } \\
\text { the Conservation of Nature }\end{array}$ \\
\hline$t$ & Annual time step in a population projection \\
\hline TK & Traditional knowledge \\
\hline USFWS & U.S. Fish and Wildlife Service \\
\hline USGS & U.S. Geological Survey \\
\hline
\end{tabular}




\title{
Resilience and Risk-A Demographic Model to Inform Conservation Planning for Polar Bears
}

\author{
By Eric V. Regehr'1, Ryan R. Wilson'1, Karyn D. Rode², and Michael C. Runge ${ }^{2}$
}

\section{Executive Summary}

Climate change is having widespread ecological effects, including loss of Arctic sea ice. This has led to listing of the polar bear (Ursus maritimus) and other ice-dependent marine mammals under the U.S. Endangered Species Act. Methods are needed to evaluate the effects of climate change on population persistence to inform recovery planning for listed species. For polar bears, this includes understanding interactions between climate and secondary factors, such as subsistence harvest, which provide economic, nutritional, or cultural value to humans.

We developed a matrix-based demographic model for polar bears that can be used for population viability analysis and to evaluate the effects of human-caused removals. This model includes densitydependence (the potential for a declining environmental carrying capacity), density-independent limitation, and sex- and age-specific harvest vulnerabilities. We estimated values of adult female survival (0.93-0.96), recruitment (number of yearling cubs per adult female; $0.1-0.3$ ), and carrying capacity ( $>250$ animals) that must be maintained for a hypothetical population to achieve a 90 -percent probability of persistence over 100 years.

We also developed a state-dependent management framework, based on harvest theory and the potential biological removal method, by linking the demographic model to simulated population assessments. This framework can be used to estimate the maximum sustainable rate of human-caused removals, including subsistence harvest, which maintains a population at its maximum net productivity level. The framework also can be used to calculate a recommended sustainable harvest rate, which generally is lower than the maximum sustainable rate and depends on management objectives, the precision and frequency of population data, and risk tolerance. The historical standard 4.5-percent harvest rate for polar bears, at a 2:1 male-to-female ratio, is reasonable under many biological and management conditions, although lower or higher rates may be appropriate in some cases.

\footnotetext{
${ }^{1}$ U.S. Fish and Wildlife Service.

${ }^{2}$ U.S. Geological Survey.
} 
Our modeling results suggest that harvest of polar bears is unlikely to accelerate population declines that result from declining carrying capacity caused by sea-ice loss, provided that several conditions are met: (1) the sustainable harvest rate reflects the population's intrinsic growth rate, and the corresponding harvest level is obtained by applying this rate to an estimate of population size; (2) the sustainable harvest rate reflects the quality of population data (e.g., lower harvest when data are poor); and (3) the level of human-caused removals can be adjusted. Finally, our results suggest that stopgap measures (e.g., further reduction or cessation of harvest when the population size is less than a critical threshold) may be necessary to minimize the incremental risk associated with harvest, if environmental conditions are deteriorating rapidly. We suggest that the demographic model and approaches presented here can serve as a template for conservation planning for polar bears and other species facing similar challenges.

\section{Introduction}

Climate change is expected to be a primary driver of ecological change and biodiversity loss in the foreseeable future (Groffman and others, 2014). This may be especially true in the Arctic (Post and others, 2009; Convey and others, 2012) where the rate of warming has been approximately twice the global mean (Intergovernmental Panel on Climate Change, 2013). In the Arctic marine environment, warming temperatures and changing circulation patterns have led to declines in the extent, temporal availability, and thickness of sea ice (Maslanik and others, 2007; Stroeve and others, 2012). Sea-ice loss is expected to continue throughout the 21 st century with some models predicting a nearly ice-free Arctic in the summer within 20 years (Overland and Wang, 2013). Arctic marine mammals depend on sea ice for many aspects of their life history (Laidre and others, 2008; Kovacs and others, 2011). In recent years, several species of Arctic marine mammals have been listed under the U.S. Endangered Species Act (ESA) prior to the occurrence of range-wide population declines, based on climate change concerns (Schliebe and others, 2006; Cameron and others, 2010; Kelly and others, 2010). These listings present new challenges, including the fact that the government agencies primarily responsible for implementing recovery plans do not have the regulatory authority to address global greenhouse gas emissions (e.g., U.S. Fish and Wildlife Service, 2013), the primary cause of anthropogenic climate change. Near-term recovery actions likely will focus on addressing secondary factors or threats, with the goal of increasing the chances of persistence until global action leads to a stabilized climate system (Ruhl, 2008; Seney and others, 2013). Demographic models can be used to evaluate the effects of climate change on persistence, including interactions between climate and secondary factors. Such models also can establish links between conservation goals and specific metrics for monitoring, provide an objective assessment of the benefits of recovery actions, and inform decisions about the tradeoffs that will necessarily be part of recovery planning.

Polar bears (Ursus maritimus) exemplify the challenges discussed here. The species was listed as "threatened" under the ESA in 2008 based on observed and forecasted population declines owing to sea-ice loss (U.S. Fish and Wildlife Service, 2008). Of the 19 recognized polar bear subpopulations (Obbard and others, 2010), multiple lines of evidence suggest that 2 subpopulations have experienced sea ice-related declines to date (Stirling and others 1999; Regehr and others, 2007, 2010; Bromaghin and others, in press). Several subpopulations apparently are either productive or stable despite sea-ice loss (Obbard and others, 2007; Stirling and others, 2011; Stapleton and others, 2012; Peacock and others, 2013; Rode and others, 2014), and many subpopulations are data deficient (Obbard and others, 2010). Although the current status of polar bear subpopulations is variable, all polar bears depend on sea ice for fundamental aspects of their life history (Amstrup, 2003), including access to their primary prey, 
ringed seals (Phoca hispida) and bearded seals (Erignathus barbatus). The long-term ecological effects of continued climate change are expected to be negative for most subpopulations (Stirling and Derocher, 2012). Effective conservation planning will require consideration of regional and temporal variation in the manifestation of such effects.

Polar bears represent an important cultural, nutritional, and in some regions economic resource for native people throughout the Arctic (Dowsley, 2009; Born and others, 2011; Voorhees and others, 2014). Fifteen polar bear subpopulations, including the two subpopulations that occur partially within United States territory, currently support a legal subsistence harvest (Laidre and others, 2015). When polar bears were listed under the ESA, the species was classified as "depleted" under the U.S. Marine Mammal Protection Act (MMPA; 16 USC $\$ 1361$ et seq.). Both the ESA and MMPA prohibit taking (i.e., to harass, hunt, capture, or kill) protected species, with several exemptions including take by coastal-dwelling Alaskan Natives for subsistence purposes including making and selling handicrafts. Concurrent with the ESA listing, the U.S. Fish and Wildlife Service (USFWS, 2013) published a Section 4(d) "Special Rule," establishing that take regulations for polar bears would continue as determined by the MMPA prior to listing. Although the ESA listing concluded that overutilization (i.e., excessive take) does not currently threaten polar bears, future interactions between climate change and human-caused removals are less clear. For example, habitat loss could increase vulnerability to overutilization due to smaller population sizes or reduced intrinsic population growth rates. Climate change also could lead to increased human-bear conflicts (Dyck, 2006) if longer ice-free seasons result in more polar bears on shore for longer periods (Schliebe and others, 2008; Towns and others, 2009; U.S. Geological Survey, unpub. data, 2014). In addition to the biological considerations listed here, how polar bears are managed likely will be subject to increased international attention and politicization in coming years (Peacock and others, 2011). Thus, although loss of Arctic sea ice is the primary long-term threat to polar bears, subsistence harvest likely will represent a key secondary factor in future discussions about the species.

In this report, we develop a demographic model for polar bears that can be used to perform population viability analysis (PVA; Beissinger and McCullough, 2002) and to evaluate the effects of human-caused removals (i.e., the combination of subsistence harvest, animals killed in conflicts, and other sources of human-caused mortality). The model extends previous work for polar bears (Hunter and others, 2010) by (1) including density-dependent functions to link vital rates (e.g., survival and recruitment) to changes in population size and environmental carrying capacity; (2) including sex- and age-specific harvest vulnerabilities; and (3) linking the demographic model to simulated population assessments, so that management strategies can be evaluated in light of uncertain information and time lags (e.g., Milner-Gulland, 2011).

A primary motivation for developing this demographic model was to inform conservation planning for polar bears currently underway within the United States. In 2013, the USFWS convened a Polar Bear Recovery Team (PBRT) to fulfill statutory requirements of the ESA and MMPA. The team was tasked with developing a plan that includes "objective, measurable" criteria for the recovery of polar bears under the ESA, as well as measures to conserve and restore the species to its optimum sustainable population (OSP) under the MMPA. Optimal sustainable population is defined as being greater than the maximum net productivity level (MNPL), which is the number of animals that results in maximum sustainable yield (Wade, 1998). Development of criteria that meet these ESA and MMPA requirements, and strategies for achieving the criteria, are being combined into a single plan referred to as the Polar Bear Conservation Management Plan (CMP). An initial draft of the CMP is being developed by the PBRT and is scheduled to be released for public comment in 2015. 
The PBRT has approached conservation planning for polar bears using a three-tier framework. Fundamental goals are at the highest tier and reflect overarching desires for the species, including maintaining population persistence, diversity (e.g., genetic, behavioral, ecological), and opportunities for subsistence use. Within the draft CMP, these fundamental goals are expressed as recovery criteria, which define conditions under which protection of the ESA is no longer needed, and conservation criteria, which reflect management goals under the MMPA. One tier below the fundamental goals and associated ESA and MMPA criteria are quantitative demographic criteria. The demographic criteria are more proximate, measurable, and specific expressions of the ESA and MMPA criteria. The demographic criteria can serve as proxies for achieving the fundamental goals, and can be used to guide recovery actions. A third and final tier consists of specific threats-based criteria that must be addressed to achieve recovery.

As members of the Science and Traditional Ecological Knowledge Working Group of the PBRT, the authors of this report were asked to develop a demographic model for polar bears, and to demonstrate how to estimate demographic criteria that correspond to higher level ESA and MMPA criteria. To do this, we first estimated combinations of vital rates that could serve as proxies for population persistence, a potential metric for expressing fundamental goals under the ESA. These vital rates are easier to measure than the probability of persistence and can be used as an initial indicator of whether, if conditions are maintained, a specified target for persistence is likely to be met. They also can be used to evaluate tradeoffs and efficiencies when planning recovery actions - for example, whether to focus on improving recruitment or survival (Runge and others, 2004). Second, we estimated the sustainable rate of human-caused removals that could maintain populations greater than the MNPL, as required by the MMPA. We expected this rate to vary as a function of population status, uncertainty in the information available for management, time lags in the management system, and risk tolerance (i.e., how certain that managers want to be of population size remaining greater than the MNPL). Therefore, rather than estimating a unique sustainable rate, we developed a state-dependent management framework that can be used to estimate the sustainable rate of human-caused removals under different conditions. State-dependent management refers to using updated information on the state of a system to inform decisions about management of the system (Lyons and others, 2008).

In this report, we present the polar bear demographic model, proposed metrics for demographic criteria that correspond to candidate ESA and MMPA criteria, and estimates of threshold values for these metrics. Our intention was not to predict the future status of polar bears; we projected hypothetical polar bear populations forward in time under different conditions, for the purpose of evaluating ESA criteria, but did not use the model for inference about the future of specific subpopulations (e.g., Hunter and others, 2010) or of the species (e.g., Amstrup and others, 2008). Furthermore, our intention was not to prescribe a specific management approach. We, therefore, estimated metrics related to human-caused removals based on a placeholder degree of risk tolerance. Several structural elements of the demographic model were informed by data for the Chukchi Sea (CS) and Southern Beaufort Sea (SB) polar bear subpopulations, because these subpopulations occur within U.S. territory (Obbard and others, 2010) and are a focus of the draft CMP. We intend for the structure and application of the demographic model to be refined in an adaptive manner as information on polar bears improves and recovery actions are implemented. 


\section{Methods}

We first describe the demographic model and how it can be used to project hypothetical polar bear populations forward in time. We then propose demographic metrics to serve as proximate measures of ESA and MMPA criteria, and finally describe simulations consisting of multiple population projections with different combinations of vital rates, environmental conditions, and management approaches, which were used to estimate threshold values for these metrics.

\section{Demographic Model}

\section{Life Cycle Graph}

We constructed a matrix-based population model (Caswell, 2001), based on a life cycle graph (fig. 1) developed previously for a multistate capture-recapture analysis (Regehr and others, 2010) and demographic assessment (Hunter and others, 2007, 2010) of the SB polar bear subpopulation. The life cycle graph is based on a post-breeding census from the spring of year $t$ to the spring of year $t+1$. It includes six female stages representing age and reproductive status, and four male stages representing age. Transitions between stages are defined by the following vital rates:

- $\sigma_{i}$ is the probability that an individual in stage $i$ survives from time $t$ to $t+1$;

- $\sigma_{L 0}$ and $\sigma_{L l}$ are the probabilities that at least one member of a cub-of-the-year (C0) or yearling (C1) litter, respectively, survives from time $t$ to $t+1$;

- $f$ is the expected size of a $\mathrm{C} 1$ litter that survives to 2 years; and

- $\quad \beta_{i}$ is the conditional probability, given survival, of an individual in stage $i$ breeding and thereby producing a $\mathrm{C} 0$ litter with at least one member surviving until the following spring. All survival rates in the life cycle graph represent natural (i.e., unharvested) survival.

For the current analysis, we modified the life cycle graph from Hunter and others $(2007,2010)$ by adding a transition between stages 3 and 5 , to allow 4-year-old females to breed and produce a C0 litter in the following year. Although uncommon in the SB, this occurs in some other subpopulations (e.g., Lunn and others, 2014). 


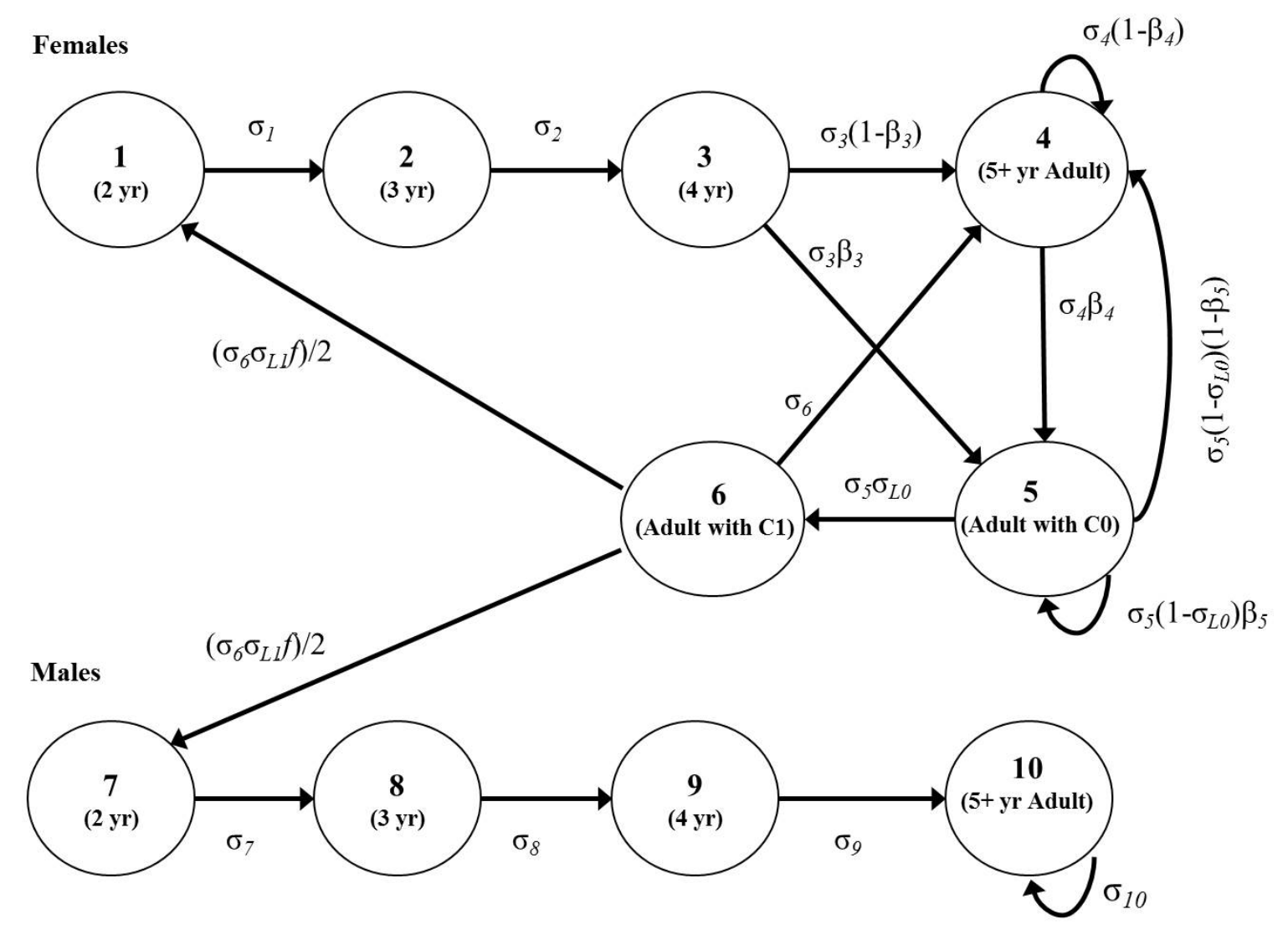

Figure 1. Polar bear life cycle graph (modified from Hunter and others, 2010, fig. 2). Stages 1-6 are females and stages $7-10$ are males. $\sigma_{i}$ is the probability of survival of an individual in stage $i, \sigma_{L O}$ and $\sigma_{L 1}$ are the probabilities of at least one member of a cub-of-the-year ( $\mathrm{C} 0$ ) or yearling (C1) litter surviving to the following spring, $f$ is the expected size of $C 1$ litters that survive to 2 years, and $\beta_{i}$ is the conditional probability, given survival, of an individual in stage $i$ breeding, thereby producing a $\mathrm{CO}$ litter with at least one member surviving until the following spring.

\section{Vital Rates}

We obtained time-invariant estimates of vital rates for polar bears (table 1) from the scientific literature and from proceedings of the Polar Bear Specialist Group of the International Union for the Conservation of Nature (Obbard and others, 2010). These vital rates were used to inform some aspects of the demographic model and to define the range of conditions under which hypothetical polar bear populations were projected, as described throughout section, "Methods." We adapted the published vital rates, which were derived from capture-recapture models with different structures, to the life cycle graph using conventions described in appendix $\mathrm{A}$.

\section{Density Dependence}

It is necessary to include density dependence in a demographic model, if the model will be used to evaluate persistence relative to changing carrying capacity or human-caused removals (Guthery and Shaw, 2013). We developed density-dependent functions based on polar bear biology, population dynamics theory, and the nutritional requirements of polar bears. 
Table 1. Estimated vital rates for polar bear subpopulations.

[Survival rates are estimates of natural (i.e., unharvested) survival unless otherwise noted. Age classes are cub-of-the-year (C0), yearling (C1), subadult (2-4 yr) and adult ( $\geq 5$ yr). Litter production rate is defined in Obbard and others (2010). yr, year; $\geq$, greater than or equal to]

\begin{tabular}{|c|c|c|c|c|c|c|c|c|c|c|c|c|}
\hline \multirow{3}{*}{ Subpopulation } & \multicolumn{8}{|c|}{ Survival } & \multicolumn{3}{|c|}{ Reproduction } & \multirow{3}{*}{ Reference } \\
\hline & \multicolumn{4}{|c|}{ Female } & \multicolumn{4}{|c|}{ Male } & \multicolumn{2}{|c|}{ Litter production rate } & \multirow{2}{*}{$\begin{array}{l}\text { Co litter } \\
\text { size }\end{array}$} & \\
\hline & $\mathrm{CO}$ & C1 & Subadult & Adult & CO & C1 & Subadult & Adult & $5 \mathrm{yr}$ & $\geq 6 \mathrm{yr}$ & & \\
\hline Baffin Bay & 0.62 & 0.94 & 0.94 & 0.95 & 0.57 & 0.94 & 0.94 & 0.95 & 0.88 & 1.00 & 1.59 & $\begin{array}{l}\text { Taylor and others, } \\
2005\end{array}$ \\
\hline Davis Strait-Central ${ }^{1}$ & 0.92 & 0.94 & 0.94 & 0.96 & 0.92 & 0.94 & 0.94 & 0.97 & 0.54 & 0.44 & 1.49 & $\begin{array}{l}\text { Peacock and others, } \\
2013\end{array}$ \\
\hline $\begin{array}{l}\text { Davis Strait- } \\
\text { Northern }\end{array}$ & 0.89 & 0.92 & 0.92 & 0.95 & 0.89 & 0.92 & 0.90 & 0.94 & 0.54 & 0.44 & 1.49 & $\begin{array}{l}\text { Peacock and others, } \\
2013\end{array}$ \\
\hline $\begin{array}{l}\text { Davis Strait- } \\
\text { Southern }^{1}\end{array}$ & 0.90 & 0.93 & 0.92 & 0.96 & 0.90 & 0.93 & 0.91 & 0.94 & 0.54 & 0.44 & 1.49 & $\begin{array}{l}\text { Peacock and others, } \\
2013\end{array}$ \\
\hline Gulf of Boothia & 0.89 & 0.90 & 0.90 & 0.96 & 0.89 & 0.90 & 0.90 & 0.96 & 0.19 & 0.97 & 1.65 & $\begin{array}{l}\text { Taylor and others, } \\
2009\end{array}$ \\
\hline Kane Basin & 0.41 & 0.76 & 0.76 & 1.00 & 0.35 & 0.66 & 0.66 & 1.00 & 0.00 & 0.98 & 1.67 & $\begin{array}{l}\text { Taylor and others, } \\
2008 \mathrm{a}\end{array}$ \\
\hline Lancaster Sound & 0.75 & 0.90 & 0.90 & 0.95 & 0.63 & 0.84 & 0.84 & 0.97 & 0.11 & 0.95 & 1.69 & $\begin{array}{l}\text { Taylor and others, } \\
2008 \mathrm{~b}\end{array}$ \\
\hline McClintock Channel & 0.62 & 0.98 & 0.98 & 0.98 & 0.62 & 0.98 & 0.98 & 0.92 & 0.11 & 0.93 & 1.70 & $\begin{array}{l}\text { Taylor and others, } \\
\text { 2006; Obbard } \\
\text { and others, } 2010\end{array}$ \\
\hline $\begin{array}{l}\text { Northern Beaufort } \\
\text { Sea }^{2}\end{array}$ & 0.52 & 0.33 & 0.91 & 0.91 & 0.52 & 0.32 & 0.83 & 0.83 & 0.28 & 0.88 & 1.76 & $\begin{array}{l}\text { Stirling and others, } \\
2011\end{array}$ \\
\hline Norwegian Bay & 0.75 & 0.90 & 0.90 & 0.95 & 0.63 & 0.84 & 0.84 & 0.97 & 0.54 & 0.54 & 1.71 & $\begin{array}{l}\text { Taylor and others, } \\
2008 \mathrm{~b}\end{array}$ \\
\hline $\begin{array}{l}\text { Southern Beaufort } \\
\text { Sea }\end{array}$ & 0.34 & 0.93 & 0.93 & 0.97 & 0.34 & 0.90 & 0.90 & 0.96 & 0.44 & 0.44 & 1.72 & $\begin{array}{l}\text { Obbard and others, } \\
\text { 2010; Regehr } \\
\text { and others, } 2010\end{array}$ \\
\hline $\begin{array}{l}\text { Southern Hudson } \\
\text { Bay }^{2}\end{array}$ & 0.73 & 0.72 & 0.92 & 0.91 & 0.59 & 0.58 & 0.86 & 0.86 & 0.97 & 0.97 & 1.58 & $\begin{array}{l}\text { Obbard and others, } \\
2007,2010\end{array}$ \\
\hline Viscount Melville & 0.69 & 0.96 & 0.96 & 0.96 & 0.45 & 0.92 & 0.92 & 0.92 & 0.62 & 0.87 & 1.64 & $\begin{array}{l}\text { Taylor and others, } \\
2002\end{array}$ \\
\hline Western Hudson Bay & 0.73 & 0.73 & 0.92 & 0.93 & 0.71 & 0.71 & 0.94 & 0.94 & 0.26 & 0.79 & 1.54 & $\begin{array}{l}\text { Regehr and others, } \\
\text { 2007; Obbard } \\
\text { and others, } 2010\end{array}$ \\
\hline
\end{tabular}

${ }^{1}$ Peacock and others (2013) estimated vital rates for three regions within the Davis Strait subpopulation.

${ }^{2}$ Estimates of total survival not corrected for harvest mortality. 
For long-lived species, relationships between vital rates and density are decreasing, likely convex, and have been represented in various ways including the theta-logistic and Ricker equations (Morris and Doak, 2002). We defined these relationships using a logistic equation as described in appendix B. Sample density-dependent curves for several vital rates are shown in figure $2 \mathrm{a}$. In the absence of empirical data for polar bears (Taylor, 1994), we used insights from population and evolutionary ecology to develop the functions. For large mammals, density-dependent effects typically appear first in subadult survival rates, then in breeding rates and juvenile survival, and finally in adult survival (Fowler, 1987). The relative positions of the inflection points of the curves for each vital rate were determined by the order in which polar bear life-history events are affected by density (e.g., $\sigma_{L 0}$ typically decreases before $\beta_{4}$ ). Studies in evolutionary ecology show that there is a negative correlation between the variance of a vital rate and its importance to population growth ("demographic buffering"; Pfister, 1998). Thus, the sensitivity of each vital rate to density was inversely proportional to its elasticity, as calculated using a matrix population model based on the life cycle graph (Caswell, 2001).

To evaluate the sensitivity of the results to the form of density dependence, we developed an alternative linear density-dependent function (sample curves in fig. 2d). This function represented the classic logistic growth model for populations (Ross, 2009), which is unrealistic for polar bears (Taylor, 1994) but was useful for two reasons. First, the classic logistic growth model has been widely used in wildlife management (Caughley and Sinclair, 1994) and thus provided a benchmark for comparison with our density-dependent functions. Second, we expected the model to provide a more conservative assessment of human-caused removals because linear relationships between vital rates and density would result in lower MNPL and weaker density-dependent changes in vital rates at population sizes close to MNPL.

\section{Maximum Net Productivity Level}

The density-dependent functions of the vital rates (figs. 2a and 2d) underlie several key demographic behaviors. For each set of curves, there is a unique combination of vital rates that produces a per capita population growth rate $(r)$ equal to 0 . By definition, this unique combination of vital rates corresponded to a location on the $x$-axis representing the equilibrium population size $(N)$ at carrying capacity $(K)$, at which the dimensionless ratio $N / K=1.0$ (figs. $2 \mathrm{a}$ and $2 \mathrm{~d}$ ). We used the densitydependent functions to derive yield curves, which describe the relationship between population density and sustainable removals. Maximum net productivity level is defined as the ratio $N / K$ at which the annual sustainable removals were maximized (figs. $2 \mathrm{~b}$ and 2e). When performing population projections, equilibrium population size at MNPL was calculated as $N_{M N P L}(t)=\mathrm{MNPL} \times K(t)$; where $K$ is carrying capacity, expressed as a number of animals, and referenced to time $(t)$ because projections included temporal variation in $K$, as described in subsequent sections. The per capita growth rates $r_{\max }$ and $r_{M N P L}$ provide measures of a population's capacity for growth, at small population sizes and at $N_{M N P L}$, respectively (figs. $2 \mathrm{c}$ and $2 \mathrm{f}$ ). In this report, we use $r_{M N P L}$ as a measure of a population's resilience, defined as its capacity to grow (in the absence of human-caused removals) following reduction to a population size of less than $K$. Reported estimates of $r_{M N P L}$ were calculated assuming a stable stage distribution and asymptotic population dynamics (Caswell, 2001); potential departures from these assumptions are discussed where they occur. 
(a)

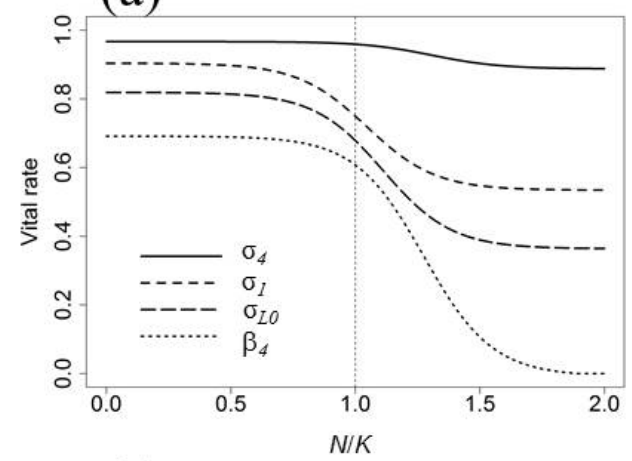

(b)

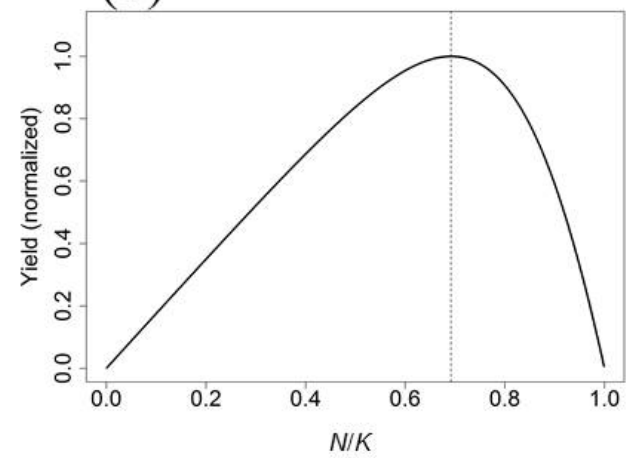

(c)

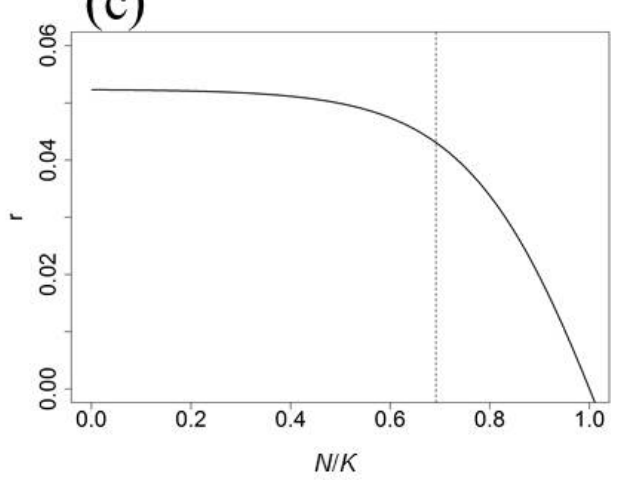

(d)

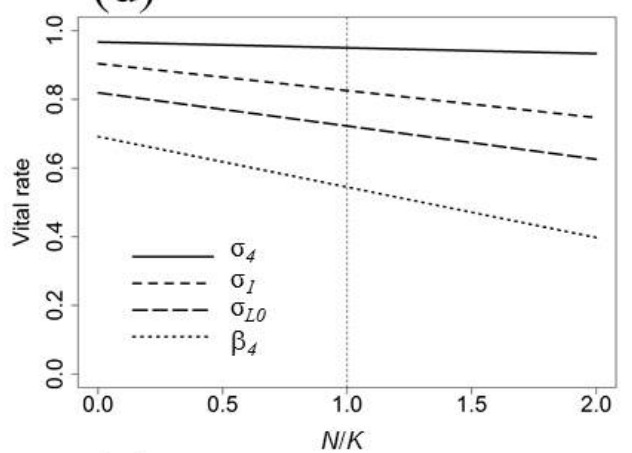

(e)

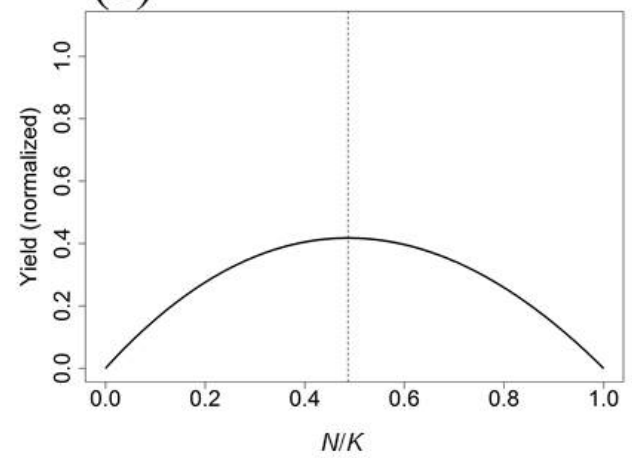

(f)

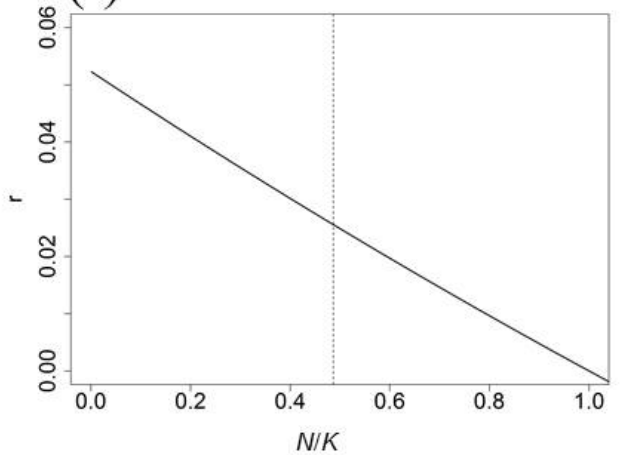

Figure 2. Graphs showing the model of density dependence for polar bears. Sample results are shown for a population with medium resilience; the per capita growth rate at a population density corresponding to maximum net productivity level $\left(r_{M N P L}\right)$ was 0.043 . Density is expressed as the ratio of population size $(N)$ to carrying capacity $(K)$. $\sigma_{4}$ is the probability of survival of an individual in stage $4, \sigma_{L 0}$ and $\sigma_{L 1}$ are the probability of at least one member of a cub-of-the-year ( $\mathrm{C} 0$ ) or yearling ( $\mathrm{C} 1$ ) litter surviving to the following spring, and $\beta_{4}$ is the conditional probability, given survival, of an individual in stage 4 breeding, thereby producing a $\mathrm{C} 0$ litter with at least one member surviving until the following spring. The parameter $r$ is the asymptotic per capita population growth rate. Vital rates were nonlinear (left column of panels) or linear (right column of panels) functions of density. Panels (a) and (d) are sample density-dependent curves of the vital rates. The dashed vertical lines correspond to $N / K=1$ at carrying capacity. Panels (b) and (e) are yield curves, which show normalized annual sustainable removals as a function of density. The vertical lines correspond to $N / K=0.69$ at maximum net productivity level. Panels $(c)$ and (f) show per capita growth rate as a function of density. 
We hypothesized that density dependence in polar bears is largely the result of direct (e.g., contest) and indirect (e.g., scramble) competition for nutritional resources (Taylor, 1994; Rode and others, 2012). However, individual polar bears vary greatly in body size and nutritional requirements (Stirling and Oritsland, 1995), and, therefore, can be expected to vary in their contributions to competitive effects. To account for this variation, we calculated metabolic energetic equivalent (mee) values as the mean body mass for each sex and age class, raised to the $2 / 3$ power to convert from actual body mass to metabolic body mass (White and Seymour, 2003; Capellini and others, 2010), and standardized to give a mee value of 1.0 for solitary adult females. We used data on polar bear mass from the CS and SB subpopulations (Rode and others, 2014; U.S. Fish and Wildlife Service and U.S. Geological Survey, unpub. data, 2014). We further modified mee values to reflect sex- and age-based variation in polar bear diet. Nutritional ecology studies suggest that 10-20 percent of the diet of adult male polar bears consists of large prey items - for example, bearded seals and beluga whales (Delphinapterus leucas), which are less accessible to females and younger bears (Thiemann and others, 2008; Cherry and others, 2011). Therefore, we reduced the mee value for adult males by 15 percent to reflect the portion of male diet that does not overlap with, or cause competition with, polar bears in other sex and age classes. The resulting mee values (table 2) represent the energetic requirements of each animal, relative to the requirements of solitary adult females.

Carrying capacity at the beginning of each population projection [i.e., $K(t=1)]$ was specified as a number of animals, and subsequently was transformed into energetic equivalents based on the starting stage distribution (see section, "Population Projections") and the sex- and age-specific mee values (table 2). To accommodate the different energetic demands of individual polar bears, population density at each time step $t=1,2 \ldots k$ was based on the sum of mee values for the individuals in the population (rather than the number of individuals) divided by $K(t)$ expressed as energetic equivalents. Thus, $K$ within the demographic model can be understood as the total amount of energy accessible to polar bears at any given point in time, and population density can be understood as the fraction of that energy being used by polar bears.

Table 2. Metabolic energetic equivalents for polar bears.

[Values estimated using body mass data for the Chukchi Sea and Southern Beaufort Sea polar bear subpopulations. Age classes are cub-ofthe-year $(\mathrm{C} 0)$, yearling $(\mathrm{C} 1)$, 2-year-old $(\mathrm{C} 2)$, subadult $(2-4 \mathrm{yr})$ and adult ( $\geq 5 \mathrm{yr})$. yr, year; $\geq$, greater than or equal to]

\begin{tabular}{|c|c|c|c|c|c|c|c|}
\hline CO & C1 & \multicolumn{2}{|c|}{ C2 } & \multicolumn{2}{|c|}{ Subadult } & \multicolumn{2}{|c|}{ Adult } \\
\hline both sexes & both sexes & female & male & female & male & female & male \\
\hline 0.2 & 0.6 & 0.7 & 0.9 & 0.8 & 1.0 & 1.0 & 1.3 \\
\hline
\end{tabular}




\section{Environmental Variation}

The Arctic marine environment is highly variable (Walsh, 2008), which can influence persistence even when population sizes are large (Boyce and others, 2006). Given the primary threat to polar bears of climate change, methods to evaluate persistence should incorporate relationships between environmental variation and vital rates. We represented environmental variation as the additive effects of two components: (1) temporal variation in $K$, which operated on vital rates through the densitydependent functions; and (2) density-independent temporal variation in vital rates.

\section{Temporal Variation in Carrying Capacity}

We included temporal variation in $K$ in a manner that was biologically relevant to polar bears. As described in appendix C, we used satellite imagery for the CS and SB regions to calculate the number of days per year (1979-2013) that sea ice covered greater than ( $>$ ) 50 percent of the mean sea ice area in March, when maximum ice extent usually occurs. We then projected the proportional change in the number of ice-covered days, relative to a baseline period. The resulting dimensionless metric $(\kappa)$ captures the variance and trend in the duration of the period that polar bears likely have greatest access to their prey, and is similar to metrics used to link sea ice to polar bear demography and nutritional status (Regehr and others, 2010; Peacock and others, 2013; Rode and others, 2014; Lunn and others, 2014).

When performing population projections, carrying capacity at any point in time was calculated as $K(t)=K(t=1) \times \kappa(t)$. The resulting values of $K(t)$ represent a proxy for true environmental carrying capacity, which is unknown, and were used only for the purpose of exploring the demographic consequences of variation in the Arctic environment. All population projections included interannual variation in $\kappa$. As described subsequently, population projections included several multiples of the temporal trend in $\kappa$, ranging from 0 to 2 times the observed sea-ice trend within the CS and SB subpopulation boundaries, depending on whether the goal of the projection was to evaluate populations under conditions of stable or decreasing $K$. We did not use the demographic model to infer actual probabilities of persistence for the CS and SB subpopulations because that would require the additional assumption that values of $K(t)$ were accurate predictors of future environmental carrying capacity.

\section{Density-Independent Variation}

Density-independent variation in vital rates for polar bears can arise from weather fluctuations (Stirling and Smith, 2004), changes in prey populations (Stirling and Lunn, 1997), or other factors. We assumed that such variation constitutes 25 percent of total uncertainty (i.e., temporal variation plus sampling uncertainty) in estimated vital rates (table 1), following the example of Taylor and others (2002). The resulting estimate of the temporal coefficient of variation for $\sigma_{4}$, the most important vital rate, was 0.014 . Because population persistence is influenced by both the magnitude and correlation structure of variation (Doak and others, 2005), we derived a correlation matrix from annual estimates of vital rates for the SB subpopulation (Regehr and others, 2010), and used this correlation matrix for all population projections. We determined that there was nearly complete correlation among survival rates (e.g., a mean correlation coefficient of 0.99 between $\sigma_{4}$ and other survival rates) and positive correlation between survival and reproductive rates (e.g., 0.67 between $\sigma_{4}$ and $\beta_{4}$ ). 
We used correlated non-normal distributions to capture density-independent temporal variation in vital rates. To simulate these distributions, we used methods described in Morris and Doak (2002, p. 282-287) to transform correlated standard normal deviates into correlated values, from either a multivariate beta distribution (for all vital rates in the life cycle graph except $f$ ) or a stretched beta distribution (for $\mathrm{C} 0$ litter size, which was used to calculate $f$ ). For the vital rates $\beta_{3}$ and $\beta_{4}$, shape parameters for the beta distribution were occasionally inestimable due to high variances. In such cases, these vital rates were randomly selected from a uniform distribution with a range $[0,0.5]$ or $[0.5,1.0]$ depending on whether the standard normal deviate was less than or greater than 0.5 , respectively.

\section{Human-Caused Removals}

Human-caused removals were implemented annually at a specified rate (i.e., fraction of population size) or level (i.e., number of animals) depending on the management scenario included in a given projection. The reproductive value of polar bears varies with sex and age (Hunter and others, 2007). Furthermore, subsistence harvests generally are sex-selective, and young polar bears are more likely than older bears to be killed by humans due to behavioral and nutritional factors (Derocher and others, 1997; Dyck, 2006). To reflect this variation, the demographic model included stage-specific harvest vulnerabilities (e.g., Taylor and others, 2005) so that removals could be allocated accurately over life cycle stages. We estimated harvest vulnerability for subadults compared to adults using the stage distribution for the SB subpopulation from 2001 to 2006 (Regehr and others, 2010) and hunterreported age classes of harvested bears during the same period (U.S. Fish and Wildlife Service, unpub. data 2010). This suggested that subadults of both sexes (stages 1-3 and 7-10) were twice as likely to be killed by humans, relative to their stage distribution, compared to adults (stages 6 and 10). Similar harvest vulnerabilities have been estimated using 28 years of data for the western Hudson Bay subpopulation (Derocher and others, 1997). We set harvest vulnerability to 0.1 (relative to single adult females in stage 4) for stages 5 and 6 , because taking adult females with dependent young is restricted and occurs rarely in most subpopulations (Brower and others, 2002).

\section{Population Projections}

For a given population projection, inputs included maximum values of vital rates (i.e., survival and reproductive rates at low density), the starting value of $K$ expressed as a number of animals, and the rate of human-caused removals. Populations started with a stable stage distribution at a population size equal to $N_{M N P L}$, which was calculated from the starting value of $K$ [e.g., $N_{M N P L} \approx 0.69 \times K(t=1)$, as described in section, "Results"]. Density-dependent curves for the vital rates were generated as described in section, "Density Dependence". At each time step $t=2,3, \ldots k$, the following operations were performed.

First, populations were projected forward 1 year using a stage-structured matrix model: $\boldsymbol{n}(\mathrm{t}+1)=$ $\boldsymbol{A}(\mathrm{t}) \times \boldsymbol{n}(\mathrm{t})$, where $\boldsymbol{n}(\mathrm{t})$ is a stage distribution vector representing the number of animals in each life cycle stage at time step $t$, and $A(\mathrm{t})$ is a $10 \times 10$ matrix that projects the population from time $t$ to $t+1$ (Caswell, 2001). Entries in $\boldsymbol{A}(t)$ were defined in terms of vital rates in the life cycle graph (fig. 1). Second, humancaused removals were allocated among stages using a multinomial distribution with the probability for each stage calculated as the product of its proportional stage distribution and harvest vulnerability. If the target removal level for a particular stage exceeded the number of bears in that stage, excess removals were allocated to the more populous stages 4 or 10 , for females or males, respectively. If the male segment of the population was exhausted, which happened occasionally for male-biased removals at high rates, excess male removals were allocated to stage 4 females. Third, population density, $N / K$, was 
calculated by summing mee values across animals in the population, then dividing by the total mee values available at carrying capacity. The survival and reproductive rates corresponding to this density were determined from the density-dependent curves. Fourth, these vital rates were subject to densityindependent variation, as described previously. Finally, the resulting vital rates were used to construct a projection matrix for the next time step $\boldsymbol{A}(t+1)$.

For each set of conditions under which a population was projected, we performed 1,000 iterations to assess variability. For each iteration, we recorded (1) demographic outputs including the time-constant values of MNPL, $r_{M N P L}$, and $r_{\max } ; \boldsymbol{n}(t)$ and a vector of stage-specific removals at each time step; and (2) whether the population persisted or the time step at which it was extirpated. We defined persistence as maintaining a population size greater than a quasi-extinction threshold of 15 percent of starting population size or 100 animals, whichever was larger. We used a proportional quasi-extinction threshold because of potential Allee effects caused by reduced breeding encounters and mating success at low population densities (Molnár and others, 2008). Low population densities could result if $N$ declines while the amount of habitat during the breeding season remains stable. This could occur for polar bears because they mate in April and May (Amstrup, 2003), and projected sea-ice loss at that time of the year is relatively small (Stroeve and others, 2012). We used the lower quasi-extinction threshold of 100 animals because demographic stochasticity, which our model did not include, and other smallpopulation effects can become important below this level (Wieglus and others, 2001; Morris and Doak, 2002).

\section{Evaluating ESA and MMPA Criteria}

In this section, we propose metrics for demographic criteria that correspond to higher-level ESA and MMPA criteria. We then demonstrate how the demographic model can be used to estimate threshold values for these metrics.

\section{Proposed Metrics for ESA Criteria}

We consider the following candidate criterion for recovery under the ESA: "the probability of persistence in each ecoregion is at least 90 percent over 100 years." Ecoregions refer to the four grouping of polar bears defined by Amstrup and others (2008) based on spatial and temporal dynamics of sea ice, which are consistent with broad patterns of life history and genetic diversity for polar bears (Peacock and others, 2015). The following three metrics were defined to serve as proxies for persistence, and, taken together, can be used to infer whether the goal for persistence is met:

1. Natural (i.e., unharvested) survival of adult females. Adult female survival is the most important determinant of population growth for polar bears (Eberhardt, 1990) and is often a focus of demographic studies (Amstrup and Durner, 1995).

2. Recruitment, measured as the ratio of $\mathrm{C} 1 \mathrm{~s}$ to adult females in the population. This metric integrates breeding success and C0 survival (Rode and others, 2014). Populations need recruitment to persist. Furthermore, recruitment may vary more than adult survival for long-lived animals and thus drive most of the observed changes in population growth (Mitchell and others, 2009).

3. Carrying capacity $(K)$ expressed as a number of animals. This represents an approximate lower limit on the number of animals that the environment must be able to support, for a subpopulation with sufficient survival and recruitment (as defined by the first two metrics) to persist in the face of environmental variation and other chance events (Flather and others, 2011). 
We chose these three metrics in light of several considerations. First, climate change is leading to unprecedented ecological changes in the Arctic (Hinzman and others, 2013), including the potential for declining polar bear populations (Stirling and Derocher, 2012). In this report, we estimate threshold values for these metrics, which are values that must be met for populations to persist in accordance with the candidate ESA recovery criterion. Additional work is necessary to evaluate whether, and for how long, specific subpopulations are likely to meet these threshold values. Second, recruitment and survival are functions of population density for large mammals, including bears (Taylor, 1994; Zedrosser and others, 2006; Czetwertynski and others, 2007). To be meaningful, threshold values for these metrics must be associated with a particular population size relative to carrying capacity. We reference survival and recruitment to population size at MNPL (i.e., $N_{M N P L}$ ) because this population size is relevant to harvest theory (Runge and others, 2009) and requirements under the MMPA (Wade, 1998). Third, for populations subject to human-caused removals, total survival is a function of natural (i.e., unharvested) survival and direct human-caused mortality (e.g., Peacock and others, 2013). The metric proposed here is natural survival, which — in conjunction with recruitment — determines a population's capacity for growth. For natural survival to be a meaningful predictor of persistence, human-caused removals must be conducted at a sustainable rate that does not drive populations far below $N_{M N P L}$.

\section{Proposed Metrics for MMPA Criteria}

We consider the following candidate criterion for conservation under the MMPA: "each subpopulation is managed so that its population size is at least at the maximum net productivity level relative to carrying capacity, both currently and as forecast over the next 50 years." We define the metric $h_{M N P L}$ as the maximum rate of human-caused removals that still achieves this goal. Our framework for estimating $h_{M N P L}$ extends the formula for allowable take in Runge and others (2009), which was based on the potential biological removal (PBR) method (Wade, 1998) and harvest theory (Caughley and Sinclair, 1994). We calculated human-caused removal levels for females and males as follows:

$$
\begin{gathered}
H^{\text {female }}(t)=F_{O} \times \tilde{r}_{M N P L}(t) \times 0.5 \times \widetilde{N}(t), \text { and } \\
H^{\text {male }}(t)=H^{\text {female }}(t) \times S R,
\end{gathered}
$$

where $H^{\text {female }} \quad$ is the number of females that can be removed annually while meeting the conservation goal;

$F_{O} \quad$ is a factor that reflects management objectives and risk tolerance;

$\tilde{r}_{M N P L} \quad$ is an estimate of the per capita population growth rate referenced to population density at MNPL (i.e., $r_{M N P L}$ ), selected from its sampling distribution to represent risk tolerance;

0.5 is a factor to calculate female removals assuming an equal sex ratio in the population;

$\widetilde{N} \quad$ is an estimate of $N$ selected from its sampling distribution to represent risk tolerance;

$H^{\text {male }} \quad$ is the number of males that can be removed annually; and

$S R \quad$ is a factor that specifies the male-to-female ratio in removals.

The notation for time $(t)$ indicates that parameters change annually or as new information becomes available. Equations 1 and 2 are written in terms of removal levels (i.e., numbers of animals) for convenience. The removal rate $h_{M N P L}$ for females is the right side of equation 1 before multiplying by population size [i.e., $\left.h_{M N P L}^{\text {female }}=F_{O} \times \tilde{r}_{M N P L}(t)\right]$. 
The management factor $F_{O}$ directly adjusts the removal rate, and is conceptually similar to the "recovery factor" in the PBR method (Wade, 1998). Under ideal conditions, populations will stabilize at approximately $N_{M N P L}$ when $F_{O}=1$. Increasing $F_{O}$ will result in an equilibrium population size of less than $N_{M N P L}$, until an upper limit on $F_{O}$ is reached. Beyond the upper limit, the removal rate will exceed the maximum per capita growth rate $\left(r_{\max }\right)$ and is no longer sustainable. This upper limit is $F_{O}=2$ for the classic logistic model of population growth (Runge and others, 2009), and in reality is expected to vary among species based on life history (Williams, 2013). The practical use of $F_{O}$ is to direct a population toward a target size, and to specify risk tolerance with respect to missing that target or achieving some other undesired outcome, such as extirpation. Such risks can result from stochasticity, uncertain information about population status, time lags in management actions, and other imperfections in the modeling or management framework.

The parameter $\widetilde{N}$ makes this approach state-dependent with respect to population size. This ensures that a constant removal rate will be maintained in the face of density-dependent effects-for example, declining carrying capacity due to habitat loss. The parameter $\tilde{r}_{M N P L}$ makes this approach state-dependent with respect to density-independent effects that could limit a population's capacity for growth. It also bases the approach on a parameter that is more relevant and readily measured for populations that are managed for maximum sustainable yield, compared to previous formulations that included a time-constant value of $r_{\max }$ (Runge and others, 2009). Both $r_{M N P L}$ and $N$ must be estimated and, therefore, will include sampling uncertainty. Furthermore, if a direct estimate of $r$ is available from a population assessment, it may need to be adjusted to approximate $r_{M N P L}$ if population density is not close to MNPL. Selection of $\tilde{r}_{M N P L}$ and $\widetilde{N}$ from within their sampling distributions is a decision reflecting the risk tolerance of managers, which will affect the removal level and thus the probability of meeting conservation goals.

The parameter $S R$ can be used to implement sex-specific removals, which is practical for polar bears because most subsistence harvests are designed for a male-to-female removal ratio greater than 1 (Taylor and others, 2008c). The term 0.5 in equation 1 could be replaced with an estimate of the proportion of females in the population. We have included 0.5 as a conservative management rule because most polar bear harvests select for males and the resulting proportion of females in populations tends to be greater than 0.5

\section{Simulations for ESA Criteria}

We estimated threshold values for the survival, recruitment, and carrying capacity metrics by projecting populations under the conditions described below. For each projection, the key outcome was the probability of persistence $\left(P_{\text {persist }}\right)$, calculated as the proportion of iterations that did not cross below the quasi-extinction threshold between the start of the projection and the final time step $t=100$. Projections were performed for all combinations of the following inputs:

- 400 sets of input vital rates. This parameter space was intended to broadly represent the range of vital rates that polar bears could exhibit. It was constructed by combining 20 equal-increment intervals in natural survival, from 3 percent less than the minimum values to the maximum values observed in case studies (table 1); with 20 equal-increment intervals in breeding probability and $\mathrm{C} 0$ litter size, from 30 percent less than the minimum values to the maximum values observed in case studies (table 1 ).

- 6 values for carrying capacity, $K(t=1)=4,000 ; 2,000 ; 1,000 ; 500 ; 250$; and 150 animals; with populations starting at a stable stage distribution and a population size corresponding to $N_{M N P L}$ relative to $K$. 
- Two approaches to human-caused removals: (1) Removals at a constant rate $r_{M N P L}$, using $S R=1$ and with removals implemented in direct proportion to stage distribution (i.e., without databased harvest vulnerability), and (2) No removals.

These input combinations resulted in $400 \times 6 \times 2=4,800$ projections. Threshold values for the metrics were the values of survival, recruitment, and $K$ that resulted in $P_{\text {persist }}>0.90$. Inference for these metrics was based on projections with human-caused removals at $r_{M N P L}$. Including human-caused removals referenced survival and recruitment to $N_{M N P L}$, making the estimated threshold values for these metrics broadly relevant to subpopulations that are harvested. It also ensured that estimates of $P_{\text {persist }}$ reflected low equilibrium population sizes that result from harvest. Comparison of threshold values for the metrics, estimated from projections with and without human-caused removals, served as an initial evaluation of how removals at a sustainable rate affect population persistence. Key components of this and subsequent simulations are summarized in table 3.

Table 3. Summary of key components in simulations to evaluate Endangered Species Act (ESA) and Marine Mammal Protection Act (MMPA) criteria.

\begin{tabular}{|c|c|c|c|}
\hline \multirow[b]{2}{*}{ Component } & \multicolumn{3}{|c|}{ Simulation } \\
\hline & ESA Criteria & $\begin{array}{c}\text { MMPA Criteria } \\
\text { (Inputs to the state-dependent } \\
\text { management framework) }\end{array}$ & $\begin{array}{c}\text { MMPA Criteria } \\
\text { (Robustness of the state-dependent } \\
\text { management framework) }\end{array}$ \\
\hline \multicolumn{4}{|c|}{ Population projections: } \\
\hline Parameter space & 400 sets of vital rates & $\begin{array}{c}3 \text { sets of vital rates corresponding to } \\
\text { high, medium, and low resilience }\end{array}$ & 400 sets of vital rates \\
\hline Density dependence & $\begin{array}{l}\text { density-dependent functions } \\
\text { using logistic equation (e.g., fig. 2a, } \\
\text { b, and c) }\end{array}$ & $\begin{array}{l}\text { density-dependent functions using } \\
\text { logistic equation (e.g., fig. } 2 \mathrm{a}, \mathrm{b} \text {, } \\
\text { and c) }\end{array}$ & $\begin{array}{l}\text { density-dependent functions using } \\
\text { logistic equation (e.g., fig. } 2 \mathrm{a}, \mathrm{b} \text {, } \\
\text { and c) }\end{array}$ \\
\hline Starting carrying capacity $[K(t=1)]$ & $\begin{array}{l}4000,2000,1000,5000,205 \\
\quad \text { and } 150\end{array}$ & 1000 & 1000 \\
\hline Interannual variation in $K$ & yes & yes & yes \\
\hline Temporal trend in $K$ & no & no & 3 trends \\
\hline \multicolumn{4}{|c|}{ Human-caused removals: } \\
\hline Management factor $\left(F_{O}\right)$ & 1 & 31 values from 0.5 to 1.25 & 0.75 \\
\hline $\begin{array}{l}\text { Data precision in simulated } \\
\text { population assessments (table } 4 \text { ) }\end{array}$ & true & levels 1 to 4 & level 3 \\
\hline Sex ratio $(S R)$ & 1 & 2 & 2 \\
\hline Data-based harvest vulnerability & no & yes & yes \\
\hline \multicolumn{4}{|c|}{ Other: } \\
\hline Key outcome & probability of persistence $\left(P_{\text {persist }}\right)$ & $\begin{array}{l}\text { probability that population size is } \\
\text { less than maximum net productivity } \\
\text { level }\left(P_{<M N P L}\right)\end{array}$ & $\begin{array}{l}\text { increased risk of extirpation compared } \\
\text { to no human-caused removals } \\
\left(\Delta P_{\text {extirpation }}\right)\end{array}$ \\
\hline
\end{tabular}




\section{Simulations for MMPA Criteria}

We explored the framework for the candidate MMPA criterion by performing two simulations. First, we demonstrated how to calculate inputs to the state-dependent management framework necessary to meet conservation goals in the presence of uncertain information on population status and time lags in management. Second, we demonstrated how to evaluate the robustness of the state-dependent management framework by using a single set of inputs to calculate harvest levels that were applied to populations with different vital rates and under conditions of stable and declining $K$.

\section{Inputs to the State-Dependent Management Framework}

We calculated inputs to the state-dependent management framework by projecting populations under the conditions described below. For each projection, the key outcome was the probability of violating the candidate MMPA criterion, calculated as the proportion of iterations for which $N<N_{M N P L}$ at the final time step $t=50$ (i.e., $P_{<M N P L}$ ). Projections were performed for all combinations of the following inputs:

- Three levels of population resilience corresponding to $r_{M N P L}=0.085,0.043$, and 0.015 ; subsequently referred to as high, medium, and low resilience, respectively. These values are within the range of $r$ values estimated using the vital rates in table 1, and, therefore, are representative of observed per capita growth rates for polar bears.

- Five levels of data precision. During population projections, $\widetilde{N}$ and the vital rates used to estimate $\tilde{r}_{M N P L}$ were derived from simulated population assessments that included sampling uncertainty (table 4). The first level of data precision corresponded to true values of $N$ and the vital rates, updated on an annual basis, to evaluate the effects of human-caused removals under perfect sampling and management. Other levels of data precision were based on the amount of sampling uncertainty in case studies for polar bears, using the methods described in appendix D. These provided a realistic assessment of the effects of imperfect information on polar bear management.

Table 4. Levels of data precision used in simulated population assessments.

[Coefficients of variation $(\mathrm{CV})$ for adult female survival $\left(\sigma_{4}\right)$ and population size $(N)$, representing the amount of sampling uncertainty in simulated population assessments.]

\begin{tabular}{lcc}
\hline $\begin{array}{c}\text { Data } \\
\text { precision } \\
\text { level }\end{array}$ & $\begin{array}{c}\text { Adult female } \\
\text { survival } \\
\mathbf{C V}\left(\sigma_{4}\right)\end{array}$ & $\begin{array}{c}\text { Population size } \\
\mathbf{C V}(\boldsymbol{N})\end{array}$ \\
\hline true $^{1}$ & 0.000 & 0.00 \\
1 & 0.003 & 0.04 \\
2 & 0.008 & 0.08 \\
3 & 0.018 & 0.15 \\
4 & 0.089 & 0.25 \\
\hline
\end{tabular}

${ }^{1}$ Simulated population assessments used the true values of all population parameters, updated annually instead of on a 10-year management interval. 
- Thirty-one equal-increment values of $F_{O}$ from 0.5 to 1.25 . We expected that the lower limit of 0.5 would result in conservative removal rates because the conceptually related recovery factor in the PBR method often is set to 0.5 for threatened stocks (Wade and Angliss, 1997). We expected that the upper limit of 1.25 would encompass most sustainable removal rates.

- Three methods to select $\widetilde{N}$, corresponding to the lower 5th, lower 15 th, and 50th percentiles of the sampling distribution for $N$ from simulated population assessments. Using a lower percentile of $N$ to calculate removal levels, as opposed to using the mean value, protects against overestimates when uncertainty is large (Wade, 1998).

These input combinations resulted in $3 \times 5 \times 31 \times 3=1,395$ projections. Threshold values for the candidate MMPA criterion were the values of $F_{O}$, and the method to select $\widetilde{N}$ that achieved the conservation goal described below. Simulated population assessments were performed at 10-year management intervals, and the annual number of human-caused removals remained constant between management intervals. Removals were implemented using $S R=2$ and data-based harvest vulnerability. All projections used starting carrying capacity $K(t=1)=1,000$ animals. The parameter $\tilde{r}_{M N P L}$ was selected as the 50th percentile of the sampling distribution for $r_{M N P L}$. We included a management rule constraining $\tilde{r}_{M N P L} \leq 0.10$, to protect against excessive removal rates when per capita growth rates were high and data precision was low.

In the face of uncertainty, any management framework carries a risk of violating the candidate MMPA criterion. Thus, to be fully specified, the MMPA criterion also needs to include a risk tolerance. That is, a complete criterion would identify a target value for $P_{<M N P L}$ that would have allowed us to calculate corresponding inputs to the state-dependent management framework. Because such guidance does not yet exist, we used a placeholder degree of risk tolerance by inferring an upper limit on $P_{<M N P L}$ based on the candidate ESA criterion. Specifically, this upper limit corresponds to human-caused removals that, absent all other threats, would decrease the probability of persistence to less than 90 percent. We estimated this limit by plotting $\left(1-P_{\text {persist }}\right)$ as a function of $P_{<M N P L}$, selecting a polynomial fit using Akaike's Information Criterion and standard regression methods (Zar, 2010), and identifying the value of $P_{<M N P L}$ for which the upper 95-percent prediction interval corresponded to $\left(1-P_{\text {persist }}\right)=$ 0.10 . We present this placeholder degree of risk tolerance to illustrate how the demographic model can be used to calculate inputs to the state-dependent management framework that achieve a specified conservation goal.

\section{Robustness of the State-Dependent Management Framework}

The goal of the second simulation was to assess the robustness of the state-dependent management framework, using a single set of inputs to equations 1 and 2, under a wide range of conditions including declining $K$. The key outcome was the incremental change in the probability of extirpation $\left(\Delta P_{\text {extirpation }}\right)$, calculated as the difference in $P_{\text {persist }}$ for identical projections with, and without, human-caused removals. Projections were performed for all combinations of the following inputs:

- 400 sets of vital rates, as defined by the parameter space.

- Three rates of change in the proxy for $K$, corresponding to (1) twice the mean temporal trend in $\kappa$, as estimated from sea-ice data for the CS and SB regions; (2) the mean trend in $\kappa$; and (3) no temporal trend (i.e., stable carrying capacity).

- Two approaches to human-caused removals: (1) State-dependent management using $F_{O}=0.75$, $S R=2$, and $\widetilde{N}$ selected as the lower 15 th percentile of the sampling distribution for $N$, with a data precision level of 3; and (2) No removals. 
These combinations of inputs resulted in $400 \times 3 \times 2=2,400$ projections. Other inputs were identical to the first simulation for the candidate MMPA criterion.

\section{Software}

The demographic model was built using the $\mathrm{R}$ computing language (version $\mathrm{R}$ 3.1.0; The $\mathrm{R}$ Project for Statistical Computing; http://www.r-project.org). The package "popbio" was used to analyze matrix models (Stubben and others, 2008). Computations were performed on the Amazon Elastic Compute Cloud (http://aws.amazon.com/ec2/), where we ran R using an Amazon Machine Image for RStudio Server (RStudio, 2014) developed by L. Aslett (http://www.louisaslett.com/RStudio_AMI/).

\section{Results}

Across the 400 sets of vital rates that made up the parameter space, the recruitment metric, defined as the number of $\mathrm{C} 1 \mathrm{~s}$ per adult female, ranged from 0.09 to 0.46 . The recruitment metric was positively correlated with the natural survival rate for adult females and with breeding probability (fig. 3 ). The mean estimate of MNPL was 0.69 (95-percent confidence interval $[\mathrm{CI}]=0.63-0.74$ ). Specifically, hypothetical populations produced maximum sustainable yield at an equilibrium population size that was 69 percent of the population size at carrying capacity. Maximum net productivity level was negatively correlated with survival and recruitment (fig. 4). That is, populations with higher vital rates (and thus higher resilience) produced maximum sustainable yield at smaller equilibrium sizes, compared to populations with low resilience. Values of $r_{M N P L}$ ranged from -0.09 to 0.12 . The mean value of the ratio $r_{M N P L} / r_{\max }$ was $0.82(95$-percent $\mathrm{CI}=0.79-0.84)$. As expected, $r_{M N P L}$ was positively correlated with survival and recruitment (fig. 5). Observed survival and recruitment rates for polar bear subpopulations (double boxplot in fig. 5) provide an orientation to the most relevant portions of the contour plot. Under the assumption that vital rates in table 1 were for harvested subpopulations at densities near MNPL, the corresponding median value of $r_{M N P L}$ would be approximately 0.04 based on the location of the crosshairs in the double boxplot. For comparison, the actual mean estimate of natural (i.e., unharvested) $r$ for the case studies was 0.05 (95-percent CI $=0.02-$ 0.09), as shown by the asterisk. The estimates reported in this paragraph are conditional on several assumptions of the demographic model, particularly the form of our density-dependent functions.

The linear density-dependent functions of the vital rates (fig. 2d), which are not realistic for polar bears and were included for sensitivity analysis, resulted in a mean estimate of MNPL of 0.49 (95percent $\mathrm{CI}=0.48-50)$. The mean value of the ratio $r_{M N P L} / r_{\max }$ also was $0.49(95$-percent $\mathrm{CI}=0.48-$ 0.50). This corresponded closely to the expected behavior of the classic logistic growth model for populations, for which $\mathrm{MNPL}=r_{M N P L} / r_{\max }=0.50$. 


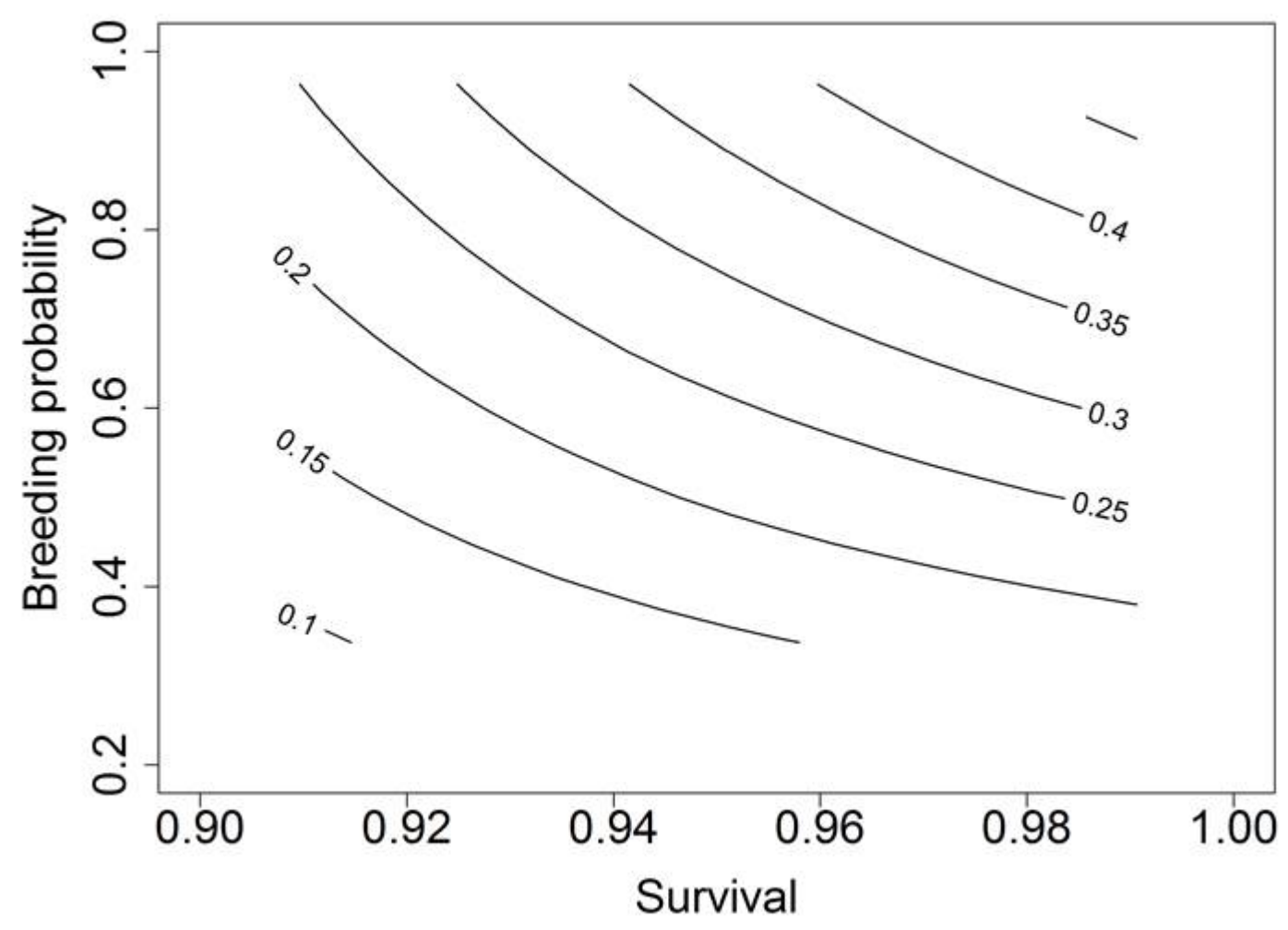

Figure 3. Contour plot of the recruitment metric as a function of survival and breeding probability. Recruitment is the number of yearlings per adult female. Survival is the natural adult female survival rate, averaged over the three adult female stages $(4,5$, and 6$)$ in the life cycle graph. Breeding probability is the parameter $\beta_{4}$, the conditional probability, given survival, of an individual in stage 4 breeding, thereby producing a cub-of-the-year litter with at least one member surviving until the following spring. Vital rates are referenced to population density at maximum net productivity level. 


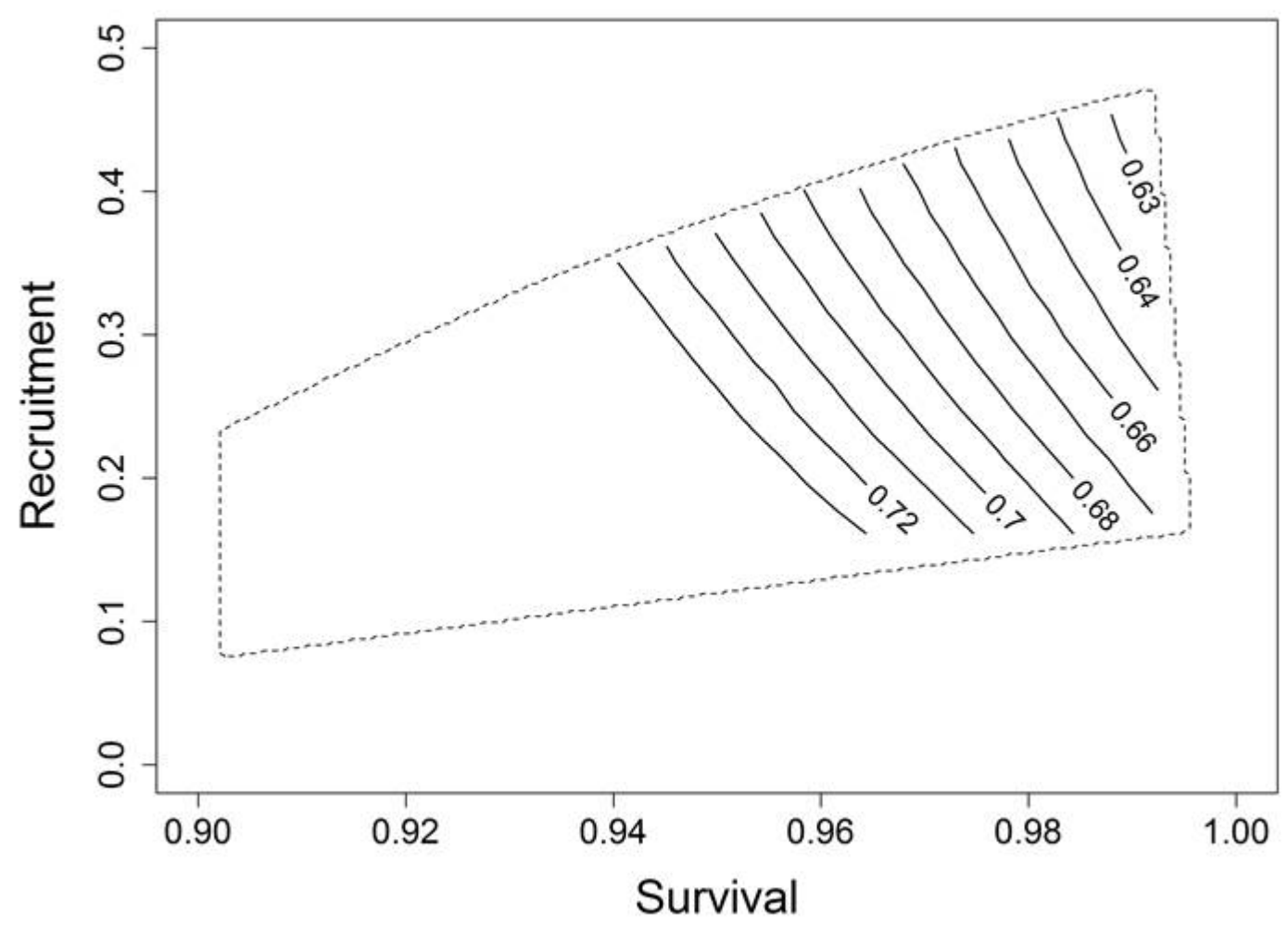

Figure 4. Contour plot of maximum net productivity level (MNPL) as a function of survival and recruitment. Survival is the natural adult female survival rate, averaged over the three adult female stages $(4,5$, and 6$)$ in the life cycle graph. Recruitment is the number of yearlings per adult female. Vital rates are referenced to population density at maximum net productivity level. The dashed region encompasses the combinations of survival and recruitment that are feasible under the demographic model given the life cycle of polar bears (fig. 1), density-dependent functions for the vital rates (fig. 2), and parameter space. 


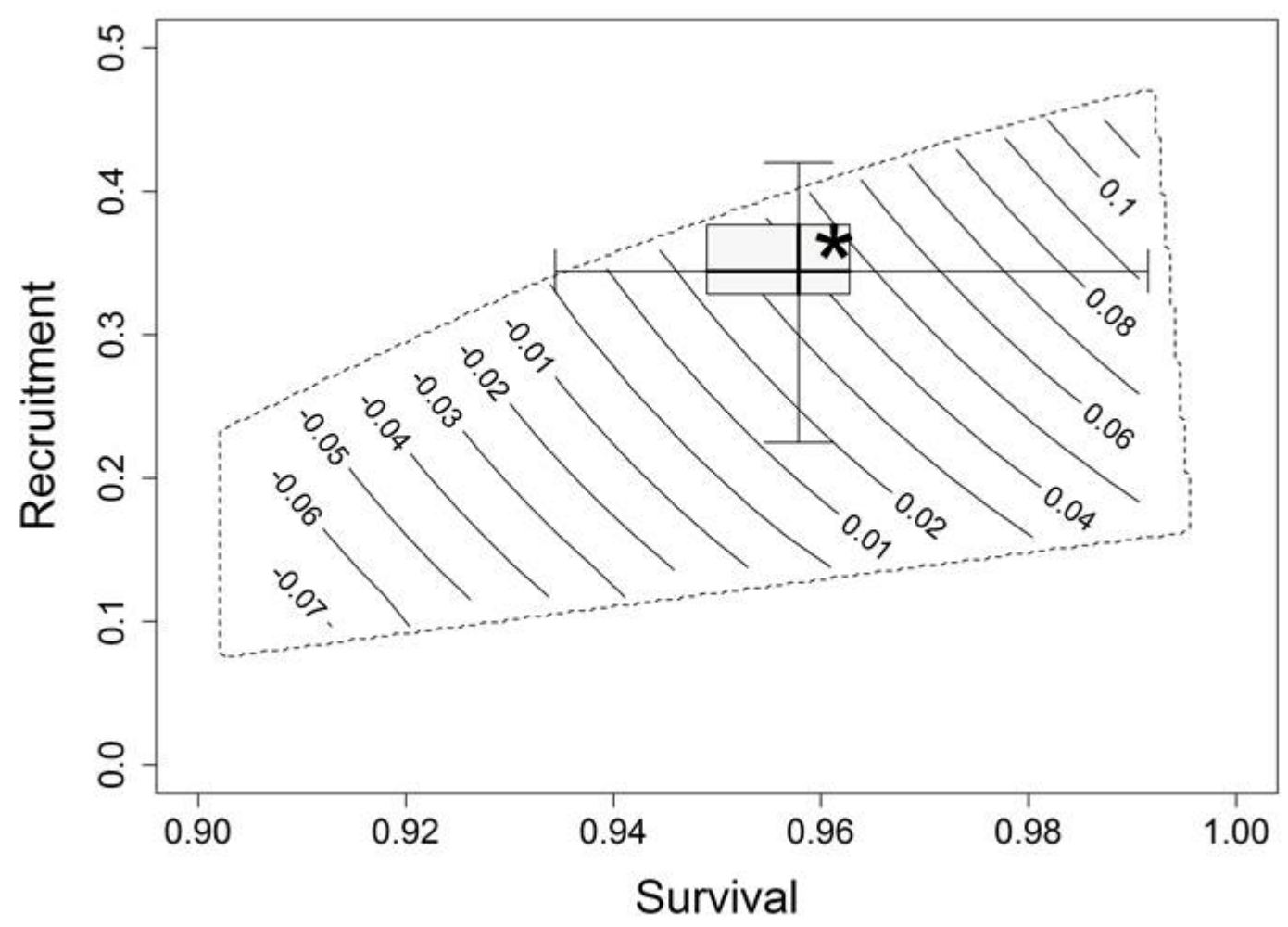

Figure 5. Contour plot of per capita population growth rate at maximum net productivity level $\left(r_{M N P L}\right)$ as a function of survival and recruitment. Survival is the natural adult female survival rate, averaged over the three adult female stages $(4,5$, and 6$)$ in the life cycle graph. Recruitment is the number of yearlings per adult female. Vital rates are referenced to population density at maximum net productivity level. The double boxplot shows the location of survival and recruitment values calculated using vital rates from case studies (table 1). The asterisk is the mean estimated per capita growth rate for case studies. Values for the Northern Beaufort Sea and Southern Hudson Bay subpopulations are not shown because estimates of natural survival were not available. 


\section{ESA Criteria}

We report threshold values of the survival, recruitment, and carrying capacity metrics necessary to achieve a probability of persistence $\left(P_{\text {persist }}\right) \geq 90$ percent over 100 years, which was used as an example of a candidate ESA recovery criterion. For populations subject to human-caused removals at a rate equal to $r_{M N P L}$, natural adult female survival rates from 0.93 to 0.96 , depending on recruitment, are necessary for persistence when $K \geq 1,000$ animals (table 5a and fig. 6). As $K$ decreases to less than approximately 1,000 , the required range of vital rates shifts higher, because the quasi-extinction threshold switched from a proportional value, calculated as 15 percent of starting population size, to a fixed value of 100 animals. Thus, the relative distance between $K$ and the quasi-extinction threshold was reduced. As $K$ decreases to less than approximately 250, the effects of environmental variation become dominant. At such small population sizes, even populations with the capacity for positive growth (i.e., $r_{M N P L}>0$ ) risk crossing below the quasi-extinction threshold due to stochasticity. We note that, for $K=250$, the upper limit on survival required for persistence was approximately 0.97 for most sets of vital rates. For projections with $K=150$, there were no vital rates that resulted in persistence. This is because the equilibrium size of populations subject to human-caused removals was approximately $N_{M N P L}=150 \times 0.69=104$, which was so close to the quasi-extinction threshold that all populations crossed below it due to stochasticity.

Threshold values for the proposed demographic metrics were identical for populations with and without human-caused removals when $K \geq 500$ (table 5). Survival rates necessary for persistence started to differ as $K$ decreased to less than approximately 250 . This is not because human-caused removals were unsustainable in the sense of causing a negative population trend; all removals were implemented at exactly $r_{M N P L}$. Rather, human-caused removals resulted in lower equilibrium population sizes that were closer to the quasi-extinction threshold, and, therefore, were more likely to cross below it due to stochasticity (fig. 7). 
Table 5. Range of survival rates that must be maintained, in conjunction with sufficient recruitment, to achieve a 90-percent probability of persistence over 100 years.

[Rates are natural survival of adult females, referenced to maximum net productivity level (MNPL). Panel (a) is for populations subject to human-caused removals at exactly the natural per capita growth rate referenced to MNPL (i.e., $r_{M N P L}$ ). Panel (b) is for populations without human-caused removals. *Asterisks indicate that persistence was not possible even if survival rates were 1.0]

(a)

\begin{tabular}{lccc}
\hline & & \multicolumn{2}{c}{ Survival } \\
\cline { 3 - 4 } $\begin{array}{l}\text { Carrying } \\
\text { capacity }\end{array}$ & $\begin{array}{c}\text { Equilibrium } \\
\text { population size }\end{array}$ & from & to \\
\hline 4000 & 2760 & 0.93 & 0.95 \\
2000 & 1380 & 0.93 & 0.95 \\
1000 & 690 & 0.93 & 0.95 \\
500 & 345 & 0.93 & 0.96 \\
250 & 173 & 0.94 & 0.99 \\
150 & 104 & $*$ & $*$ \\
\hline
\end{tabular}

(b)

\begin{tabular}{lccc}
\hline & & \multicolumn{2}{c}{ Survival } \\
\cline { 3 - 4 } $\begin{array}{l}\text { Carrying } \\
\text { capacity }\end{array}$ & $\begin{array}{c}\text { Equilibrium } \\
\text { population size }\end{array}$ & from & to \\
\hline 4000 & 4000 & 0.93 & 0.95 \\
2000 & 2000 & 0.93 & 0.95 \\
1000 & 1000 & 0.93 & 0.95 \\
500 & 500 & 0.93 & 0.96 \\
250 & 250 & 0.94 & 0.96 \\
150 & 150 & 0.94 & 0.97 \\
\hline
\end{tabular}




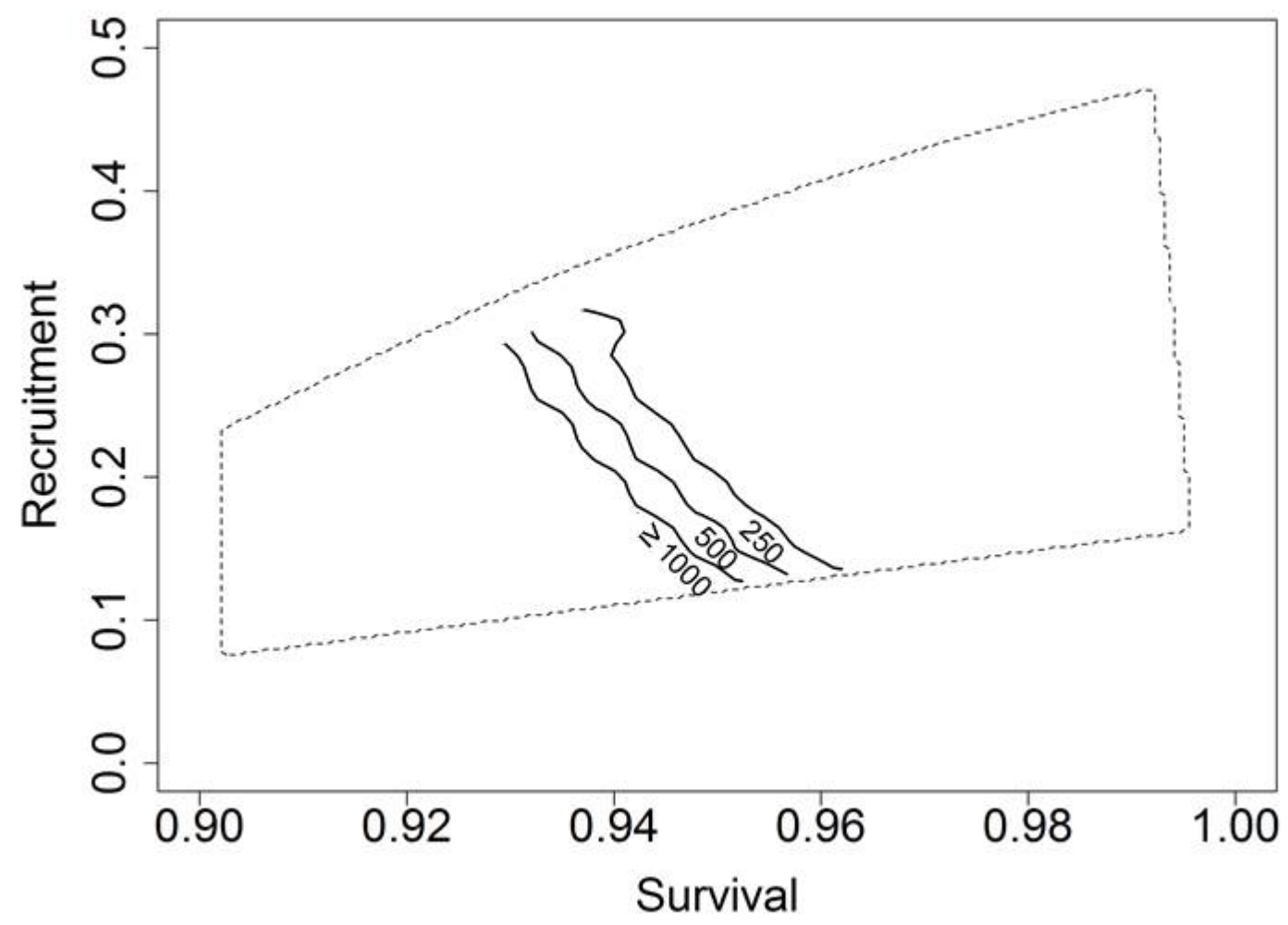

Figure 6. Contour plot of the combinations of survival and recruitment necessary to achieve a 90-percent probability of persistence over 100 years for different levels of carrying capacity. Survival is the natural adult female survival rate, averaged over the three adult female stages $(4,5$, and 6$)$ in the life cycle graph. Recruitment is the number of yearlings per adult female. Vital rates are referenced to population density at maximum net productivity level. The three lines correspond to different levels of carrying capacity. 
(a)

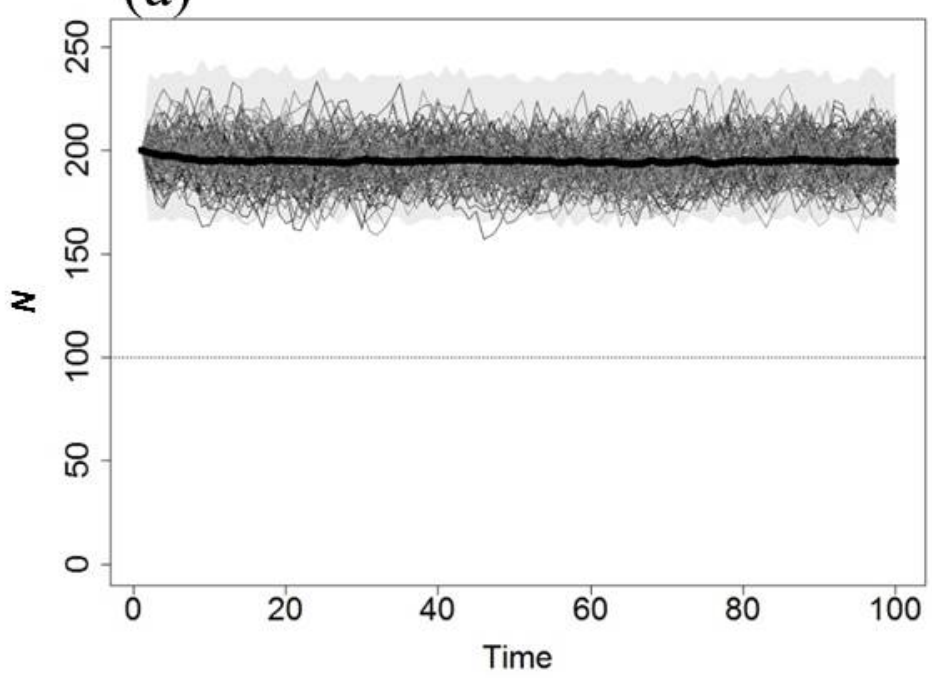

(b)

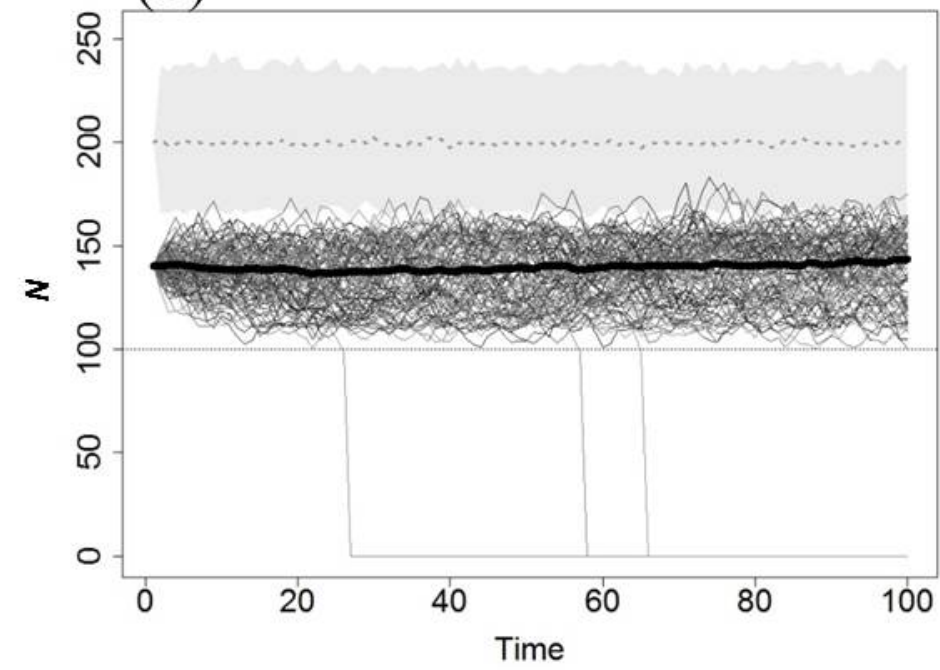

Figure 7. Graphs showing example projections for a small population with and without human-caused removals. The thick solid line is median population size $(N)$. The thin solid lines are the values of $N$ for 100 example iterations. The dotted gray line is the median carrying capacity $(K)$, and the gray shaded area is the 95-percent confidence interval of interannual variation in carrying capacity. The solid gray line is the quasi-extinction threshold of 100 individuals. Sample results are shown for a population with medium resilience and $K=200$ individuals. Panel (a) includes no human-caused removals. The corresponding probability of persistence was 100 percent. Panel (b) includes human-caused removals at a rate exactly equivalent to the per capita population growth rate at maximum net productivity level (i.e., $r_{\text {MNPL }}$ ). The corresponding probability of persistence was 97 percent because $N$ crosses below the quasi-extinction threshold for three iterations. 


\section{MMPA Criteria}

We evaluated the relationships between inputs to the state-dependent management framework and the risk of violating a candidate MMPA criterion, defined as the probability of population size decreasing to less than $N_{M N P L}$ (i.e., $P_{<M N P L}$ ). As expected based on equations 1 and $2, P_{<N M P L}$ was positively correlated with the management factor $F_{O}$ (sample results are shown in fig. 8). Higher values of $F_{O}$ lead to higher human-caused removal rates, which decrease equilibrium population size. The probability $P_{<M N P L}$ was negatively correlated with data precision (sample results are shown in fig. 8). That is, if management decisions are made using more precise information on population status, it is possible to implement a higher value of $F_{O}$, and, therefore, a higher removal rate, without increasing the risk of negative outcomes.

The placeholder degree of risk tolerance with respect to maintaining populations greater than $N_{M N P L}$ depended on the resilience of the population: upper limits on $P_{<M N P L}$, above which human-caused removals would result in $P_{\text {persist }}<90$ percent, were $0.22,0.36$, and 0.62 for populations with high, medium, and low resilience, respectively (sample are results shown in fig. 9). Threshold values for $F_{O}$, defined as the values necessary to remain below these upper limits on $P_{<M N P L}$, were a function of population resilience, data precision, and the approach used to select $\widetilde{N}$ from its sampling distribution (table 6).

Human-caused removals that are implemented using the state-dependent management framework, with a 10-year management interval and values of $F_{O}$ less than those in table 6, would be expected to achieve the candidate MMPA criterion using the placeholder degree of risk tolerance. These findings were relatively insensitive to the model used for density dependence. For example, for a population with medium resilience, threshold values for $F_{O}$ generated using the linear density-dependent functions for vital rates were, on average, only 1.2 percent lower than the values in table $6 \mathrm{~b}$, which incorporated the more realistic density-dependent functions for polar bears.

The relationships between $F_{O}$ and $P_{<M N P L}$ demonstrate a common tradeoff in wildlife management (sample results are shown in fig. 8). When there is uncertainty in the population data used to inform management decisions, increasing removals toward the maximum sustainable level also will increase the risk of population size decreasing to less than $N_{M N P L}$, which can lead to negative population outcomes and reduce future yield. The methods presented here can be used to inform this tradeoff, to concurrently meet conservation goals for persistence and provide for long-term sustainable use. For example, annual yield is shown in figure 10 as a function of time, for biological and management conditions under which the upper limit on $F_{O}$ is 0.86 (table 6). In this example, removal levels calculated using $F_{O}>0.86$ increase current yield, but result in smaller equilibrium population sizes or extirpation, and, therefore, reduce future yield. 
Table 6. Threshold values of the management factor $\left(F_{0}\right)$ used to calculate human-caused removals under the state-dependent management framework, which meet conservation goals based on a placeholder degree of risk tolerance.

[Population resilience is defined in terms of the natural per capita population growth rate referenced to maximum net productivity level (i.e., $\left.r_{M N P L}\right)$. Data precision levels are defined in table 4. Population size $(N)$ was selected from its sampling distribution using the lower 5 th, 15 th, or 50 th percentiles. Values of $F_{O}$ were evaluated within the range of $\left.0.5-1.25\right]$

(a)

\begin{tabular}{cccc}
\hline \multicolumn{4}{c}{ Low resilience $\left(\boldsymbol{r}_{\text {MNPL }}=\mathbf{1 . 5 \%}\right)$} \\
\hline $\begin{array}{c}\text { Data precision } \\
\text { level }\end{array}$ & $\begin{array}{c}\boldsymbol{N}^{\text {lower }} \mathbf{5}^{\text {th }} \\
\text { percentile }\end{array}$ & $\begin{array}{c}\boldsymbol{N}^{\text {lower }} \mathbf{1 5}^{\text {th }} \\
\text { percentile }\end{array}$ & $\boldsymbol{N}$ 50 $^{\text {th }}$ percentile \\
\hline true & 1.18 & 1.18 & 1.19 \\
1 & $>1.25$ & $>1.25$ & 1.15 \\
2 & 1.13 & 1.07 & 0.99 \\
3 & 0.82 & 0.72 & 0.61 \\
4 & $<0.50$ & $<0.50$ & $<0.50$ \\
\hline
\end{tabular}

(b)

\begin{tabular}{lccc}
\hline \multicolumn{4}{c}{ Medium resilience $\left(\boldsymbol{r}_{\mathrm{MNPL}}=\mathbf{4 . 3 \%}\right)$} \\
\hline $\begin{array}{c}\text { Data precision } \\
\text { level }\end{array}$ & $\begin{array}{c}\boldsymbol{N} \text { lower } 5^{\text {th }} \\
\text { percentile }\end{array}$ & $\begin{array}{c}\boldsymbol{N} \text { lower } 15^{\text {th }} \\
\text { percentile }\end{array}$ & $\boldsymbol{N}$ 50 $^{\text {th }}$ percentile \\
\hline true & $>1.25$ & $>1.25$ & $>1.25$ \\
1 & $>1.25$ & $>1.25$ & $>1.25$ \\
2 & 1.21 & 1.15 & 1.07 \\
3 & 0.96 & 0.86 & 0.72 \\
4 & 0.95 & 0.76 & 0.56 \\
\hline
\end{tabular}

(c)

\begin{tabular}{llcc}
\hline \multicolumn{4}{c}{ High resilience $\left(\boldsymbol{r}_{\text {MNPL }}=\mathbf{8 . 5 \%}\right)$} \\
\hline $\begin{array}{l}\text { Data precision } \\
\text { level }\end{array}$ & $\begin{array}{l}\boldsymbol{N} \text { lower } 5^{\text {th }} \\
\text { percentile }\end{array}$ & $\begin{array}{c}\boldsymbol{N} \text { lower } \mathbf{1 5}^{\text {th }} \\
\text { percentile }\end{array}$ & $\boldsymbol{N}$ 50 $^{\text {th }}$ percentile \\
\hline true & $>1.25$ & $>1.25$ & $>1.25$ \\
1 & $>1.25$ & $>1.25$ & 1.23 \\
2 & $>1.25$ & 1.22 & 1.12 \\
3 & $>1.25$ & 1.17 & 1.00 \\
4 & $>1.25$ & 1.11 & 0.82 \\
\hline
\end{tabular}




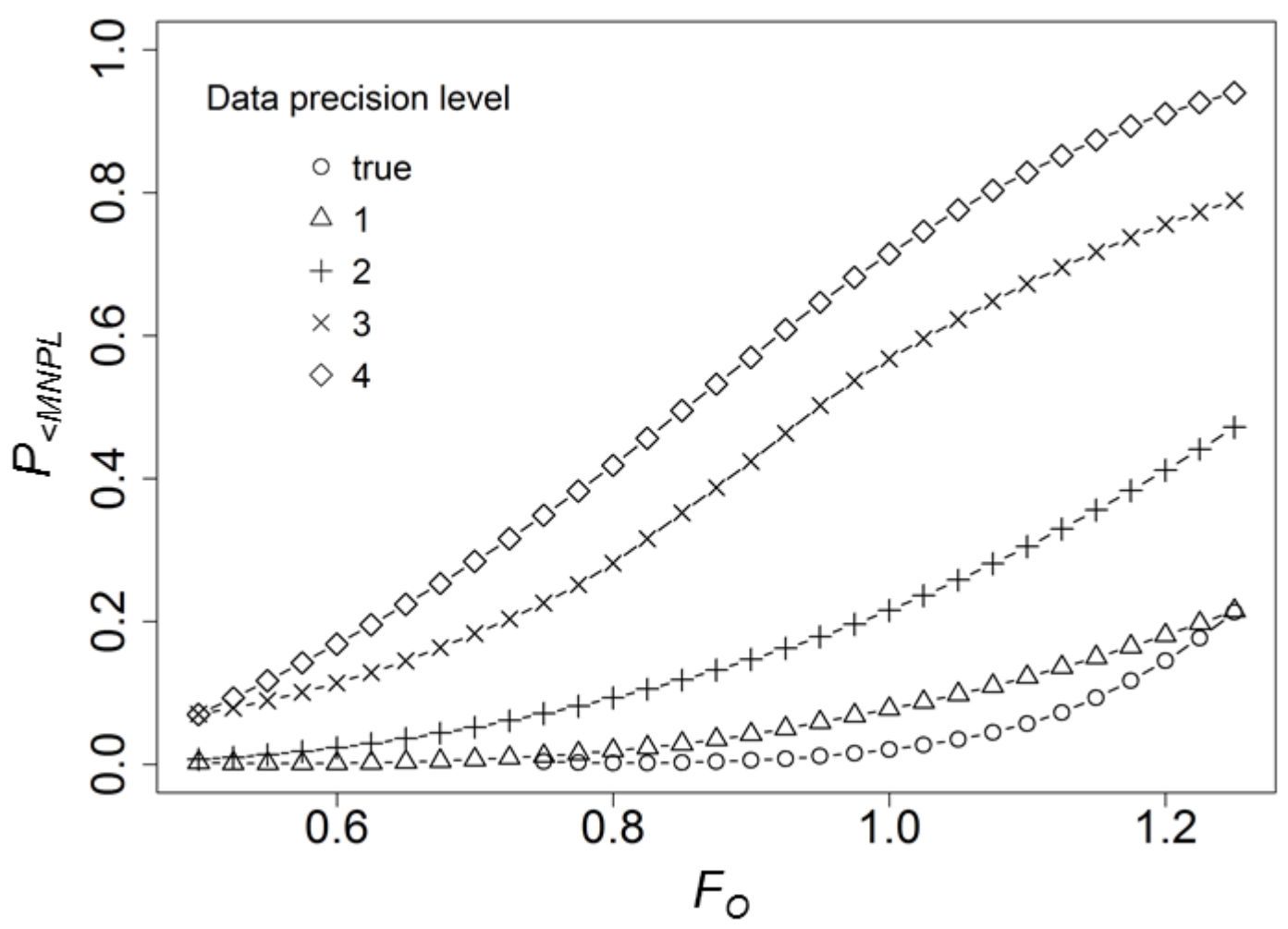

Figure 8. Graph showing probability of population size decreasing to less than $N_{M N P L}\left(P_{<M N P L}\right)$ as a function of the management factor $\left(F_{0}\right)$, for different levels of data precision. The equilibrium population size $N_{\text {MNPL }}$ corresponds to a population density at maximum net productivity level. Sample results are shown for a population with medium resilience. The estimate of population size used to calculate human-caused removals $(\widetilde{N})$ was selected as the lower 15th percentile of the sampling distribution for $N$. Data precision levels are defined in table 4. 


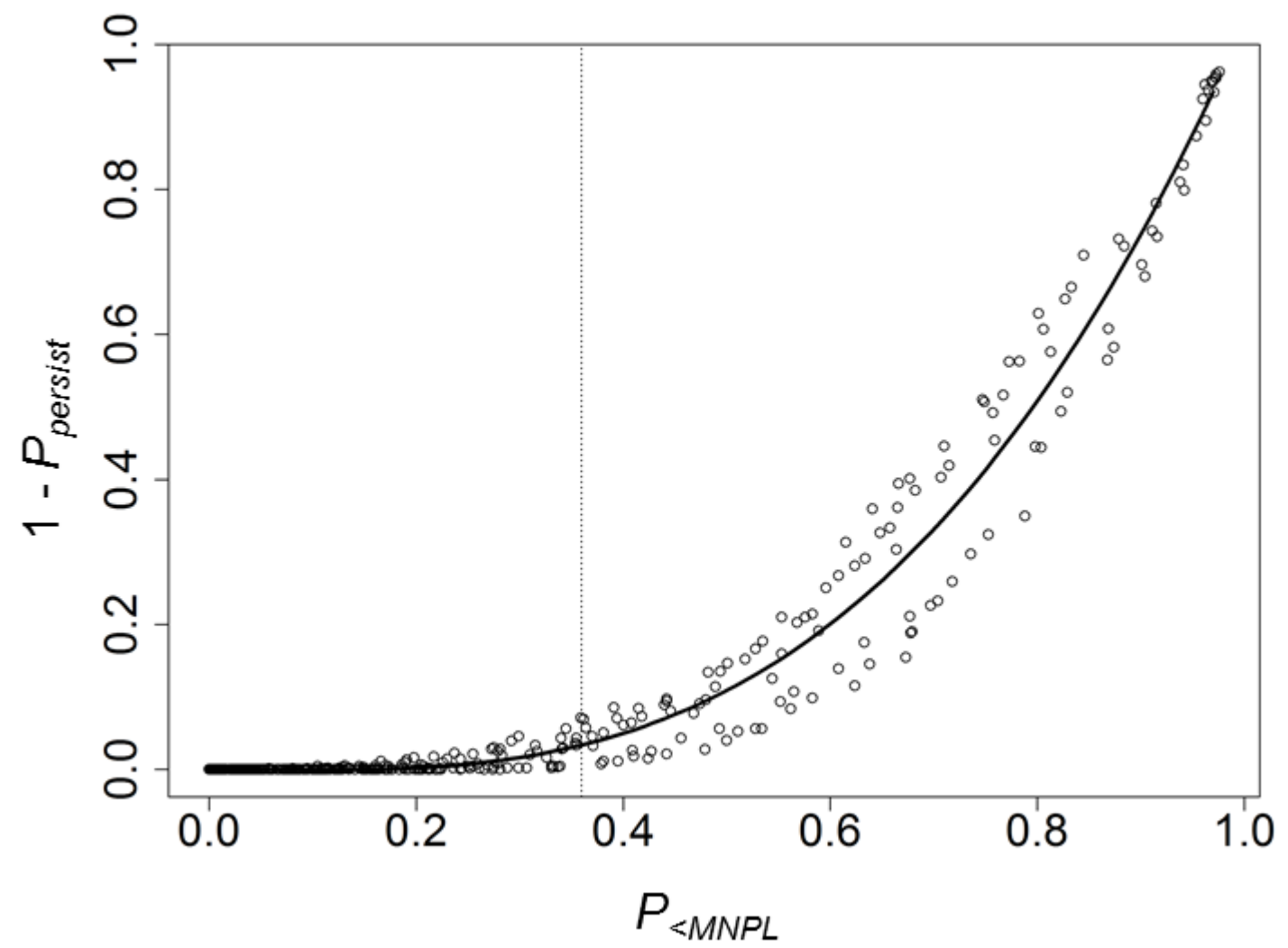

Figure 9. Graph showing relationship between the probability of extirpation $\left(1-P_{\text {persist }}\right)$ and the probability of population size decreasing to less than $N_{M N P L}\left(P_{<M N P L}\right)$. The equilibrium population size $N_{M N P L}$ corresponds to a population density at maximum net productivity level. Sample results are shown for a population with medium resilience. The solid black line represents the best polynomial fit between values of $\left(1-P_{\text {persist }}\right)$ and $P_{<\text {MNPL }}$ estimated from the simulation to evaluate inputs to the state-dependent management framework. The vertical dotted line corresponds to an upper limit on $P_{<M N P L}$ of 0.36 , above which human-caused removals alone would result in a probability of persistence $\left(P_{\text {persist }}\right)$ less than 90 percent. 


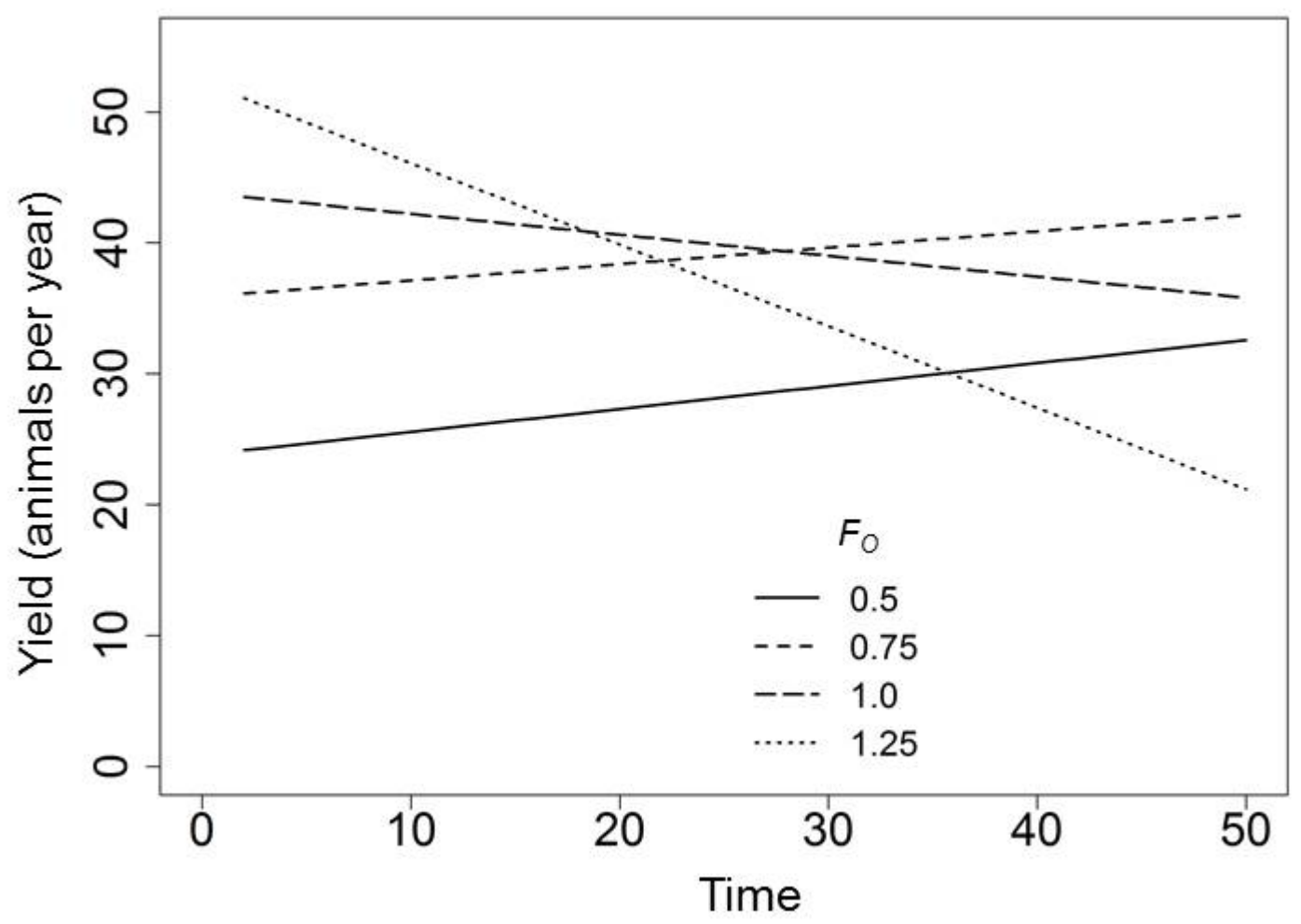

Figure 10. Graph showing annual yield as a function of time, for different levels of the management factor $\left(F_{0}\right)$. Sample results are shown for a population with medium resilience, stable carrying capacity of 1,000 animals, and simulated population assessments performed on a 10-year management interval using a data precision level of 3 (table 4). The estimate of population size used to calculate human-caused removals $(\widetilde{N})$ was selected as the lower 15th percentile of the sampling distribution for $N$. The upper limit on $F_{0}$ for these conditions was 0.86 using the placeholder risk tolerance presented here (table 6 ). At higher values of $F_{0}$, removals lead to reduced future annual yield, as demonstrated by lines with negative slopes. Yield is shown as fitted linear regression lines to demonstrate relative trends. 
A sample application of the state-dependent management framework with $F_{O}=0.75, S R=2$, and a data precision level of 3 , was robust over a wide range of biological conditions (table 7). Increased risk of extirpation compared to no human-caused removals (i.e., $\Delta P_{\text {extirpation }}$ ) was greatest for populations with $r_{M N P L}$ in the range of $-0.05-0$. Populations with $r_{M N P L}<0$ have zero capacity for positive growth; they can do nothing but decline and any human-caused mortality will be additive and serve to accelerate population declines. Although the combination of $r_{M N P L}<0$ and stable $K$ is probably not biologically realistic for polar bears under current conditions, it is included to illustrate the potential risks of humancaused removals under severe density-independent limitation. The increased risk of extirpation for populations with human-caused removals largely was due to sampling error - the chance of a positively biased estimate of $r_{M N P L}$ leading to an overestimate of the sustainable removal rate. For populations with $r_{M N P L}$ in the range 0 to 0.025 , values of $\Delta P_{\text {extirpation }}$ ranged from 4 to 8 percent, depending on the trend in $K$. These values are consistent with the placeholder degree of risk tolerance (i.e., that removals alone not result in $P_{\text {persist }}<90$ percent). Compared to populations with stable carrying capacity, values of $\triangle P_{\text {extirpation }}$ were similar for populations that experienced the mean estimated decline of 7 percent per decade in the proxy for $K$ developed using sea-ice data for the CS and SB regions. This is because human-caused removals conducted at a sustainable rate tend to result in an equilibrium population size that declines in parallel to $K$, but not at an accelerated rate compared to $K$ (figs. $11 \mathrm{a}-11 \mathrm{c}$ ). Values of $\Delta P_{\text {extirpation }}$ were higher for populations that experienced a 14-percent decline per decade in $K$, especially if those populations had low or medium resilience (table 7). This is because $K$ declined so quickly that small-population effects became important toward the end of the projection. Human-caused removals led to smaller equilibrium population sizes and increased relative variance, which together put populations at greater risk of declining below the quasi-extinction threshold due to stochasticity. At a 14-percent decline rate per decade in $K$, any population would be headed for extirpation in the next 100 years. Populations with human-caused removals, even if conducted at a sustainable rate, would be expected to face extirpation slightly sooner (figs. 11c and 11f).

The state-dependent management framework can be placed in the context of historical polar bear harvests by using a sample value of $F_{O}$ to derive sustainable removal rates for different subpopulations. We continue the previous example using $F_{O}=0.75, S R=2$, and assuming that estimates of $r$ derived from the vital rates for case studies (table 1) are equivalent to $r_{M N P L}$. Application of equations 1 and 2 with these inputs and assumptions would suggest a mean sustainable removal rate of 5.3 percent (95percent $\mathrm{CI}=1.7-9.7$ percent). 
Table 7. Increased risk of extirpation compared to no human-caused removals ( $\left.\Delta P_{\text {extirpation }}\right)$, under a sample application of the state-dependent management framework, for different rates of declining carrying capacity.

[Population resilience is defined in terms of the natural per capita population growth rate referenced to maximum net productivity level (i.e., $\left.r_{M N P L}\right)$. Increased risk of extirpation is derived as the probability of persistence $\left(P_{\text {persist }}\right)$ for populations with no human-caused removals, minus $P_{\text {persist }}$ for populations with removals. Removals were calculated using an example application of the state-dependent management framework with a management factor $\left(F_{O}\right)$ of 0.75 , a male-to-female sex ratio $(S R)$ of 2 , and simulated population assessments with a data precision level of 3 (table 4). Populations with moderate negative resilience (e.g., $-0.05<r_{M N P L}<-0.025$ ) have the greatest increased risk of extirpation, because using population data with low precision can lead to the spurious conclusion that there is a sustainable harvest rate, when in fact no removals were sustainable. In this example, populations with strong negative resilience (e.g., $\left.r_{M N P L}<-0.05\right)$ do not have an increased risk of extirpation, because the intrinsic growth rate was low enough that there was little risk of reaching the spurious conclusion that there was a sustainable harvest rate]

\begin{tabular}{lrrr}
\hline & \multicolumn{3}{c}{$\begin{array}{c}\text { Percent change in carrying } \\
\text { capacity per decade }\end{array}$} \\
\cline { 2 - 4 } $\begin{array}{c}\text { Population resilience } \\
\left.\text { ( } \boldsymbol{M}_{\text {MNPL }}\right)\end{array}$ & $0 \%$ & $-7 \%$ & $-14 \%$ \\
\hline$<-0.05$ & $0 \%$ & $0 \%$ & $0 \%$ \\
-0.05 to -0.025 & $11 \%$ & $10 \%$ & $10 \%$ \\
-0.025 to 0 & $6 \%$ & $6 \%$ & $7 \%$ \\
0 to 0.025 & $4 \%$ & $5 \%$ & $8 \%$ \\
0.025 to 0.05 & $1 \%$ & $1 \%$ & $4 \%$ \\
$>0.05$ & $0 \%$ & $0 \%$ & $2 \%$ \\
\hline
\end{tabular}


(a)

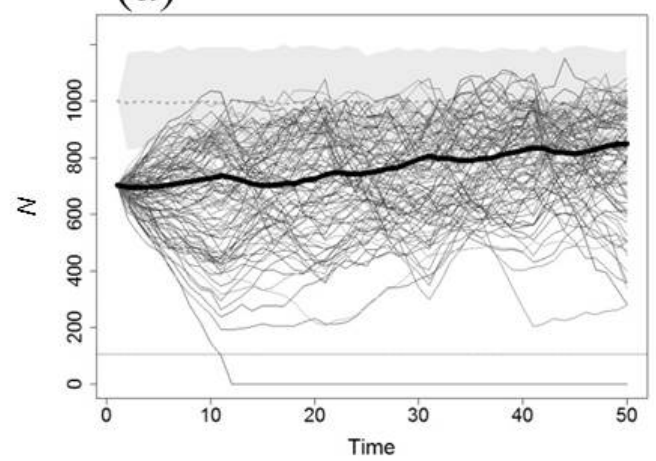

(b)

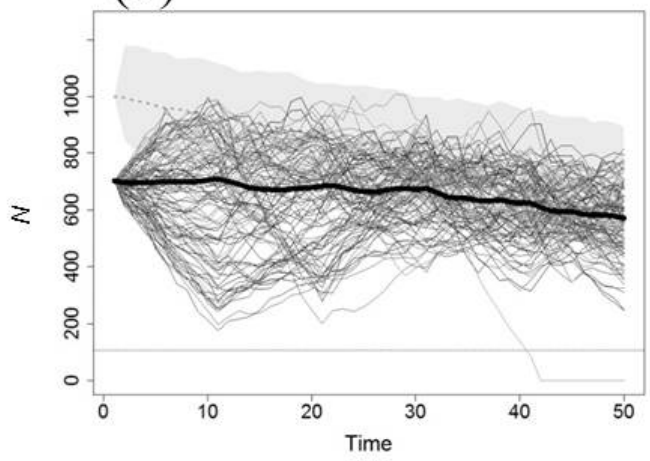

(c)

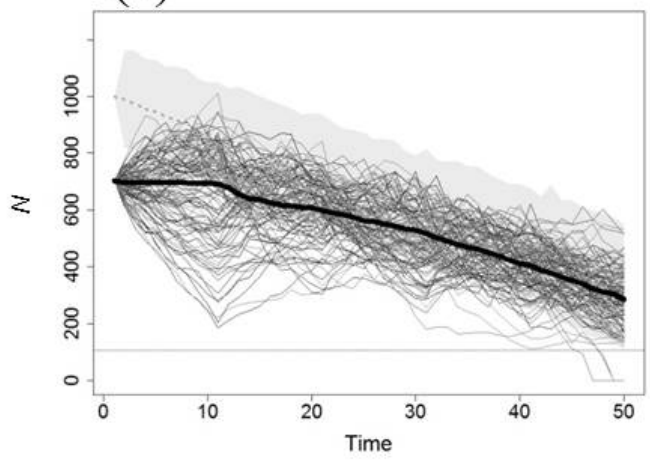

(d)

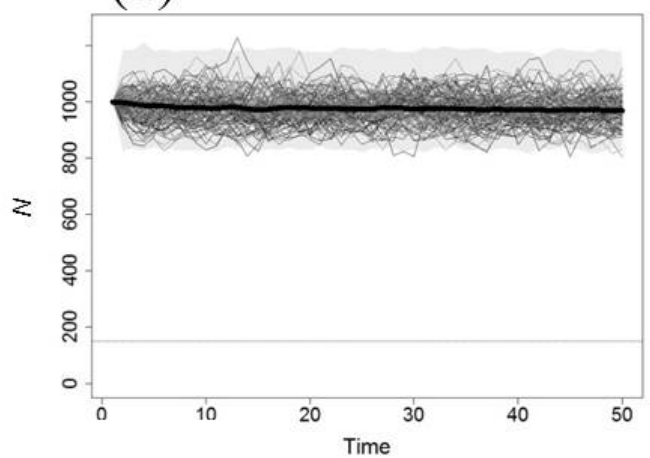

(e)

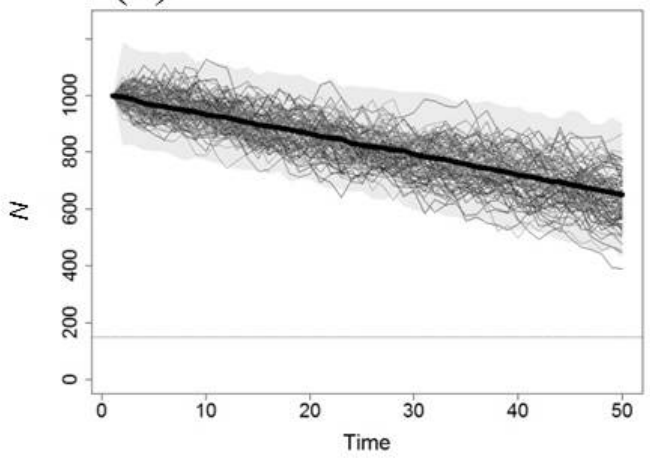

(f)

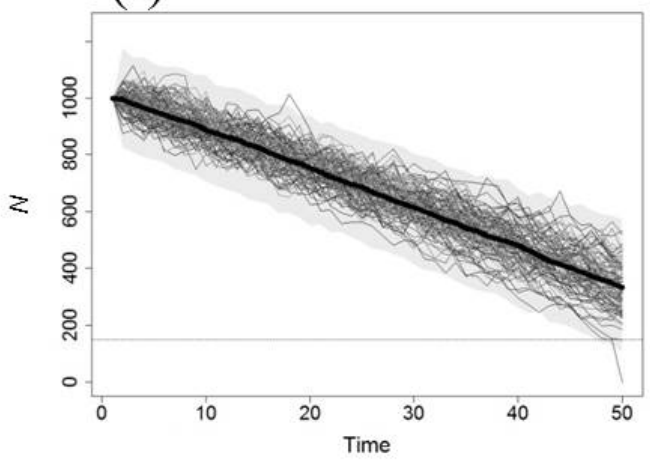

Figure 11. Graphs showing example population projections with and without human-caused removals for stable and declining carrying capacity. The thick solid line is median population size $(N)$. The thin solid lines are the values of $N$ for 100 example iterations. The dotted gray line is the median carrying capacity $(K)$, and the gray shaded area is the 95-percent confidence interval of interannual variation in carrying capacity. The solid gray line is the quasiextinction threshold. Sample results are shown for a population with medium resilience and $K(t=1)=1,000$ individuals. The left column of panels represent populations with human-caused removals using the statedependent management framework with management factor $\left(F_{0}\right)=0.75$, a male-to-female sex ratio $(S R)$ of 2 , and simulated population assessments performed on a 10-year management interval using a data precision level of 3 (table 4). The estimate of population size used to calculate human-caused removals $(\widetilde{N})$ was selected as the lower 15th percentile of the sampling distribution for $N$. The right column of panels has no human-caused removals. Carrying capacity was stable for panels (a) and (d), declined by 7 percent per decade for panels (b) and (e), or declined by 14 percent per decade for panels (c) and (f). 


\section{Discussion}

We developed a demographic model that builds upon existing PVA frameworks for polar bears (e.g., Taylor and others, 2005; Hunter and others, 2010). We used the model to estimate conditions that maintain polar bear populations with a 90 -percent probability of persistence over 100 years. We also developed a state-dependent management framework by linking the demographic model to simulated population assessments. This linkage is useful because management decisions are informed by infrequent estimates of population parameters that include uncertainty and possible bias (Nichols and Williams, 2006). Although we focused on human-caused removals, our methods could be applied to other management issues, such as quantifying the effects of reproductive failures (e.g., due to den disturbance; Amstrup, 1993). Future use of the demographic model could be integrated with decision analysis methods (Williams and Johnson, 2013) to help focus on key uncertainties or optimize tradeoffs in conservation planning.

\section{Demographic Model}

Density dependence has not been included in previous matrix-based models for polar bears (Hunter and others, 2010; Lunn and others, 2014). This is justifiable if projections are for short time horizons over which density is constant (Taylor and others, 2002) or if projections are based on estimated relationships between vital rates and the environment that reflect the full range of densitydependent behaviors. However, inclusion of density dependence is necessary if a PVA will be used to evaluate changes in environmental carrying capacity, human-caused removals, and interactions between these two factors (Guthery and Shaw, 2013).

How density dependence is represented can affect estimates of population persistence (Mills and others, 1996) and, therefore, should be based on the biology of the species (Henle and others, 2004). For large mammals with long life expectancy and low reproductive rates, density-dependent effects occur mostly at population sizes close to $K$ (Fowler, 1987). The density-dependent functions in our demographic model led to behaviors consistent with theory and empirical observations. Our estimate of MNPL was within the range of 0.5-0.85 suggested for marine mammals (Taylor and DeMaster, 1993), and similar to the range of $0.75-0.90$ suggested for polar bears (Taylor, 1994). Fowler (1988) derived an empirical equation to estimate MNPL based on population data for a wide range of taxonomic groups. Using that equation with reasonable inputs for polar bears (generation length from 10 to 15 years, $r_{\max }$ from 5 to 10 percent) would estimate $\mathrm{MNPL}=0.65$ (95-percent $\mathrm{CI}=0.57-0.74$ ), also similar to our range of estimates. The upper limits on the management factor $\left(F_{O}\right)$ in the state-dependent management framework, necessary to meet conservation goals, were insensitive to the alternative, linear densitydependent functions for the vital rates. We did not evaluate the hypothesis of no density dependence because it is not biologically plausible for polar bears. Although the details of density dependence are difficult to estimate from field data (Dennis and Taper, 1994), its presence is necessary to explain that populations do not naturally increase without limit (Caughley and Sinclair, 1994) and can be exploited without being extirpated (McGowan and others, 2011). 
For polar bears, the demographic effects of sea-ice loss could occur through both densitydependent mechanisms (e.g., increased competition for limited resources) and density-independent mechanisms (e.g., insufficient temporal availability of resources, regardless of competition), although the details of such effects and their interactions are poorly understood. Within the demographic model, density-dependent processes are represented through variation in $K$, and we have illustrated how sea-ice data could be used to derive a proxy for $K$. The demographic model allows for density-independent limitation in two ways. First, populations can have different maximum vital rates, and thus different values of $r_{\max }$, which represents the capacity for growth at very low densities and in the absence of human-caused removals. Conceptually, the demography of populations with low resilience (e.g., $r_{M N P L}=$ 0.015 ) is relevant both to current subpopulations in less-productive regions of the Arctic, and to future subpopulations that experience density-independent reductions in $r_{\max }$ due to ecological change. Second, the nonlinear density-dependent functions for the vital rates resulted in growth curves that were nearly horizontal for densities less than $0.5 \times N / K$ (fig. 2c), meaning that population responses at low densities were effectively density-independent. Because the demographic model includes both density-dependent and density-independent processes, it is sufficiently general to include a range of mechanisms by which climate change might affect populations and their ability to sustain human-caused removals. For example, if the primary effect of sea-ice loss is to reduce $K$, then the sustainable harvest rate would not change, but the harvest level (i.e., the number of animals removed per year) would decline with declining $N$. Additionally, if the primary effect of sea-ice loss is to reduce $r_{\text {max }}$, then the sustainable harvest rate would decline to the point that, if $r_{\max }$ approached 0 , any human-caused mortality would be additive. The demographic model also allows the dynamic properties of compensation for humancaused mortality (Péron, 2013) to be adjusted through the density-dependent functions of the vital rates. As currently implemented, the ratio $r_{\mathrm{MNPL}} / r_{\max }=0.82$ indicates the potential for fairly strong compensation. Note that the mechanism for compensation takes place across years. That is, humancaused removals are not immediately compensated by an increase in survival and reproductive rates in the current year, but rather in the following year.

To our knowledge, this is the first time that energetic requirements have been incorporated into a demographic model for a species of bear. Our approach considered theoretical relationships between population dynamics and individual energetic requirements (Savage and others, 2004). In conjunction, the effects of metabolic energetic equivalents, removals at a 2:1 male-to-female sex ratio, and agespecific harvest vulnerabilities led to population sex ratios skewed toward females, and equilibrium population sizes greater than the expected value based on asymptotic population dynamics. For example, the projection in figure $11 \mathrm{a}$ had a starting population size of $N_{M N P L}=690$, and subsequently experienced a period of transient dynamics (Caswell, 2007) during which the proportion of females increased from 0.52 to 0.68 , and the median population size increased from 690 to approximately 814 . Due to this behavior, the upper limits on $F_{O}$ that still met the example conservation goals were greater than 1.0 under some conditions (table 6). This departs from the theoretical expectation that $F_{O}=1$ will lead to populations at exactly $N_{M N P L}$, which in turn would result in a high probability of temporarily decreasing to less than $N_{M N P L}$ because of stochastic variation. A similar phenomenon of higher abundance, relative to a given resource base, has been suggested for female-skewed populations of ungulates that result from sexual selection, resource partitioning, and higher energetic requirements of males (McCullough, 1999). 
We defined population persistence relative to a quasi-extinction threshold (Dennis and others, 1991) below which small-population effects may become significant. The threshold was based on demographic rather than genetic considerations due to the relatively low genetic diversity of polar bears (Peacock and others, 2015), their high mobility and potential for exchange among subpopulations (Amstrup and others, 2004), and the assumed presence of more than one subpopulation in each ecoregion within the timeframes considered. The proportional component of the quasi-extinction threshold (i.e., 15 percent of starting population size) is tentative, but is based on the work of Molnár and others (2008) suggesting that reductions in population density, along with the depletion of males due to sex-selective removals, could lead to Allee effects in the mating system. Future refinements of the demographic model could incorporate a mechanistic model for Allee effects (Molnár and others, 2014), which could have the added benefit of representing the demographic effects of skewed population sex ratios at normal densities. For polygynous species, the male segment of the population can become quite small before fecundity is affected (Caughley and Sinclair, 1994; Derocher and others, 1997). Taylor and others (2008c) suggested that, for polar bear populations harvested at maximum sustainable yield, a 3:1 male-to-female sex ratio in the harvest can lead to a 0.25 proportion of males in the population, with a young male distribution, and most males harvested as 2 -year-olds. Our evaluation of human-caused removals, which included the effects of imperfect information and time lags, suggested that this degree of reduction in the male segment is possible at a 2:1 male-to-female removal ratio. For example, for populations with medium resilience subject to removals using the combinations of $F_{O}$ and other parameters in table $6 \mathrm{~b}$, the mean proportion of females after 50 years was 0.75 (95percent $\mathrm{CI}=0.70-0.80$ ). Monitoring the proportion of females in a population may be a useful indicator of overharvest when removals are sex-selective (Millspaugh and others, 2009).

The use of matrix-based PVA models (Morris and Doak, 2002) is a preferred approach for addressing quantitative questions in wildlife management (Milner-Gulland and Akcakaya, 2001). Nonetheless, PVAs come with multiple assumptions and caveats (Pe'er and others, 2013), and may be susceptible to negative bias when assessing population trends (Weinbaum and others, 2013). In this report, we focused on developing metrics for candidate ESA and MMPA criteria, and demonstrated use of the demographic model to estimate threshold values for these metrics. We also focused on estimating relative risks rather than absolute risks (Akcakaya and Sjogren-Gulve, 2000). If the demographic model is used in the future to prescribe a specific management approach, or to forecast the status of a specific subpopulation, additional issues will have to be investigated and justified because such analyses can be sensitive to sampling uncertainty and potential bias in estimated vital rates (Hunter and others, 2010), and to uncertain or non-stationary relations between vital rates and the environment (Bromaghin and others, in press).

\section{ESA Criteria}

We suggest that natural adult female survival, recruitment defined as the number of $\mathrm{C} 1 \mathrm{~s}$ per adult female, and carrying capacity, are useful demographic metrics that collectively serve as a proxy for population persistence. We evaluated these metrics at the scale of an individual subpopulation, for two reasons. First, in the near- and mid-term, polar bear management and conservation will likely continue to focus on subpopulations. Second, variation in the status of subpopulations within an ecoregion could make metapopulation dynamics (Brook and others, 2009), which the demographic model does not include, an important factor at larger spatial scales. 
Natural adult female survival rates of at least 0.93 to 0.96 , in conjunction with sufficient recruitment, are necessary to achieve a 90-percent probability of persistence over 100 years. These values are within the range necessary to maintain bear populations (Eberhardt, 1990) and are similar to survival rates associated with stable or positive population growth in case studies (Regehr and others, 2010; Lunn and others, 2014). Estimates of the recruitment metric, derived from the vital rates in table 1, were toward the upper end of the plausible range for polar bears, and toward the high end of the range necessary for persistence (fig. 5). Direct observations of the recruitment metric from capture samples include values of 0.24 for the SB subpopulation (Regehr and others, 2006) and 0.32 for the Davis Strait subpopulation (Peacock and others, 2013). If environmental change affects polar bears primarily through increased competition for nutritional resources, declining recruitment may serve as a leading indicator of declines in adult survival as competition increases (Stirling and others, 1999; Regehr and others, 2007).

In addition to survival and recruitment, which determine population resilience, long-term persistence requires a certain level of abundance to buffer against stochastic variation. In our simulations, a carrying capacity of approximately 250 animals (for an isolated subpopulation) was necessary to reduce the risk of crossing below the quasi-extinction threshold of 100 animals. At more than 250 animals, human-caused removals implemented at exactly the sustainable rate $r_{M N P L}$ did not have a negative effect on persistence. At fewer than 250 animals, removals decreased the probability of persistence because smaller equilibrium sizes, for harvested populations, led to increased vulnerability to stochastic events. In practice, increased caution in implementation of human-caused removals would be necessary for small and isolated subpopulations because management imperfections could be expected to result in increased relative variance in population size, and thus increased risk of extirpation, compared to the best-case scenario of removals implemented at exactly $r_{M N P L}$.

We referenced the proposed survival and recruitment metrics to a population density at MNPL. This was practical for polar bears because many subpopulations are thought to be harvested near maximum sustainable yield (Obbard and others, 2010). If that is the case, the equilibrium size of harvested populations will be close to $N_{M N P L}$, and estimates of natural survival from multistate models (Lebreton and others, 2009) or live recapture-dead recovery models (Barker, 1997) can be used to directly estimate a value of $r$ which, in turn, will be close to $r_{M N P L}$. The approach taken here is to infer population density relative to $K$ (i.e., $N / K$ ) based on knowledge of the removal rate, rather than based on an independent estimate of carrying capacity, which generally is not available (Gerrodette and Demaster, 1990).

Several assumptions of the demographic model may have underestimated persistence, and are listed here for future consideration. First, we assumed that density-independent temporal variation in vital rates constituted 25 percent of total uncertainty from case studies (Taylor and others, 2002, 2006). The results were similar to an estimated coefficient of variation of 0.017 , obtained by applying variance components methods (White, 2000) to 27 annual estimates of adult female survival for the western Hudson Bay subpopulation (Lunn and others, 2014). However, our approach of including variation in the proxy for $K$, additive to density-independent temporal variation, may have overstated the amount of environmental variation that polar bears generally experience. Second, sampling covariances and the structure of capture-recapture models used to estimate vital rates for the SB subpopulation (Regehr and others, 2010) could have introduced positive bias into the estimated correlation coefficients among vital rates. This would tend to overstate the negative effects of density-independent variation on the longterm population growth rate (Fieberg and Ellner, 2001). Third, the model did not allow individual variation in demographic parameters. Although the potential effects of individual variation are not understood for polar bears, persistence can be bolstered if animals with lower fitness are preferentially 
removed from a population subjected to stress (White, 2000). Other assumptions may have overestimated persistence. For example, we did not include potential autocorrelation in the ice-based proxy for $K$ (Rockwell and others, 2011), which under some conditions can exacerbate the risk of extirpation (Ripa and Heino, 1999). We also did not evaluate the potential effects of catastrophic habitat loss or mortality events (Derocher and others, 2013).

We estimated threshold values for the proposed demographic metrics relative to a specific probability of persistence, timeframe, and quasi-extinction threshold. These metrics can serve as initial indicators for monitoring but should be interpreted with caution. First, we report true process mean values for the metrics. In reality, sampling variation will lead to uncertainty around the process mean, and bias could lead to "non-true" estimates (e.g., negative bias in estimates of survival and population size from capture-recapture studies, when there is unexplained individual heterogeneity in recapture probabilities; Devineau and others, 2006). Uncertainty and bias are particular challenges when evaluating adult female survival, which is a strong determinant of the population growth rate and can be difficult to estimate with sufficient accuracy to differentiate between biologically significant outcomes (McLellan and others, 1999). Second, the demographic model assumed a certain covariance structure among vital rates. Departures from this structure (e.g., a large decline in the survival of subadult males) could lead to low probabilities of persistence regardless of other vital rates. Third, the magnitude and form of temporal variation in vital rates can be expected to vary among subpopulations, and we did not evaluate the sensitivity of persistence to such variation. For example, vital rates from case studies for polar bears (table 1) suggest that most subpopulations currently have sufficient natural survival rates to persist, provided those rates are maintained over the next 100 years. This is not surprising given that future negative effects of habitat loss are the primary concern for polar bears (Amstrup and others, 2008). However, the status of some subpopulations may be different than would be expected on the basis of these metrics alone. Time-invariant estimates of adult female survival for the SB subpopulation, for 2001-06, were approximately 0.95 (Regehr and others, 2010). Although this rate seems high enough to achieve persistence, projected growth rates for the SB population were negative due to high temporal variation in vital rates, and correlation between vital rates and declining environmental conditions (Hunter and others, 2010).

\section{MMPA Criteria}

We developed a state-dependent management framework that can be used to estimate the sustainable rate of human-caused removals for polar bears, including subsistence harvest. Our approach is state dependent with respect to both $N$ and $r_{M N P L}$, which is appropriate given the potential for ecological change in the Arctic to affect polar bears through both density-dependent and densityindependent mechanisms. Although our simulated population assessments used a single management interval of 10 years, actual intervals vary among subpopulations (Obbard and others, 2010), and it can be expected that the upper limits on $F_{O}$, associated with a particular risk tolerance, would increase for shorter management intervals. Our simulations demonstrated clearly that the risk associated with human-caused removals is due in large part to imprecise data on population status, which emphasizes the importance of scientific studies and collection of traditional knowledge (TK; Voorhees and others, 2014). Our simulations also demonstrate that, as long as $K$ remains positive for the timeframe of interest, maintaining current harvest within sustainable limits will serve to safeguard both population 
persistence and the opportunity for future sustainable use. Future application of the demographic model could be expanded to evaluate tradeoffs between current harvest rates, long-term cumulative yield, and various population outcomes (e.g., probability of persistence, expected time to extirpation) under different scenarios such as declining $K$ followed by stabilization (e.g., due to a stabilized climate system) and declining $K$ to 0 .

We determined that sustainable harvest rates were positively correlated with population resilience because more resilient populations have a higher net productivity and the capacity to rebound following periods of overexploitation. Our simulations also demonstrate the importance of accounting for sex, age, and reproductive status. Young bears, especially males, are most often killed in conflict situations (Dyck, 2006). Furthermore, most subsistence harvests select for males (Taylor and others, 2008c), and national laws and international agreements discourage the removal of adult females that are near maternal dens or have dependent young (Obbard and others, 2010). Across the 400 sets of vital rates in the parameter space, the mean ratio of the reproductive value (Caswell, 2001) for adult females with C1s (stage 6) compared to single adult females (stage 4) was 1.23 (95-percent CI $=1.16-1.30)$. The ratio for stage 6 females compared to 2-year-old females (stage 1) was 2.03 (95-percent CI $=1.83-$ 2.28). In combination, the increased vulnerability of young bears to being removed by humans, and the decreased reproductive value of young bears, lead to a lower risk for a given removal level than would be predicted using a naïve model that did not account for such variation. The differences in reproductive value also emphasize the importance of protecting adult females, a common management goal for bears (Taylor and others, 1987).

Several assumptions may have overestimated the potential negative effects of human-caused removals on population persistence, and are listed here for future consideration. First, changes in population density at time step $t$ acted on vital rates at time step $t+1$. If multiyear time lags exist between declines in $K$ and reductions in vital rates, under conditions of rapidly declining $K$ it is possible that human-caused mortality would be more compensatory than in our projections (Péron, 2013), effectively moving populations toward $K$ while having a limited effect on persistence. Second, during simulations to evaluate the candidate MMPA criterion, populations started with a stable stage distribution and subsequently underwent a period of transient dynamics due to selective removals. This resulted in a trend toward higher values of per capita growth rate and equilibrium population size, compared to the starting values of $r_{M N P L}$ and $N_{M N P L}$, respectively. Future applications of the demographic model could include a "burn-in" period prior to $t=1$, especially if the goal is to evaluate human-caused removals over a shorter timeframe. Third, when evaluating harvest in relation to data precision, the simulated population assessments assumed a correlation coefficient of 1.0 among estimated population parameters. Thus, if sampling variation happened to result in positively biased values for the vital rates, it also would require a positively biased value for $N$. For a given replicate, this could have overstated the risk of positive bias in both $\widetilde{N}$ and $\tilde{r}_{M N P L}$, which would have led to excessive removals.

Other assumptions may have underestimated the negative effects of human-caused removals, under certain conditions. First, although we evaluated the state-dependent management framework under a wide range of conditions, including different maximum vital rates and temporal trends in $K$, we did not include temporal trends in $r_{\max }$. If $r_{\max }$ were to decline between population assessments (e.g., due to negative density-independent effects of climate change), the sustainable harvest rate estimated at the beginning of the management interval could become unsustainable toward the end of the interval. Second, in the simulated population assessments, we did not consider uncertainty in how close estimated values of $r$ were to the desired parameter $r_{M N P L}$. For polar bears, the expense and logistical challenges of conducting population assessments make it difficult to obtain accurate estimates of vital 
rates and population size (Vongraven and others, 2012). Furthermore, knowledge of population density is necessary to interpret estimates of vital rates. For example, if population density is less than MNPL (e.g., due to high harvest or increasing $K$ ), direct estimates of $r$ from population assessments will be between $r_{M N P L}$ and $r_{\text {max }}$. In the context of the state-dependent management framework, using direct estimates of $r$ in equations 1 and 2 could overestimate the sustainable harvest rate. The potential for such overestimation does not seem substantial for polar bears because nonlinear density dependence results in $r_{M N P L} / r_{\max } \approx 0.82$. Conversely, if population density is greater than MNPL (e.g., due to low harvest or declining $K$ ), estimates of $r$ will be between $r_{M N P L}$ and 0 . Under these conditions, using direct estimates of $r$ in equations 1 and 2 could significantly underestimate sustainable harvest rate, especially if $K$ is declining rapidly. In practice, it may be difficult to obtain valid estimates of $r_{M N P L}$, unless $r$ can be estimated during a period of population stability. In some instances, it may be preferable or necessary to base inference for $r_{M N P L}$ on other demographic or ecological indicators, rather than on direct estimates of $r$, and to account for this additional uncertainty in management decisions.

Although the state-dependent management framework is an extension of the PBR method, our approach differed from other applications of PBR that viewed take of marine mammals (e.g., due to fisheries by-catch) as a negative outcome to be avoided, rather than a positive outcome with value to humans as in the case of subsistence harvest. We demonstrated how to apply the state-dependent management framework based on a placeholder degree of risk tolerance. The resulting estimates of $F_{O}$, and thus sustainable removal rate, represent the upper limits that still achieved consistency with an ESA criterion for persistence. Future applications should be based on clear conservation goals that reflect statutory and stakeholder values. Although linking fundamental goals to demographic criteria is mostly a scientific process, subtle forms of risk tolerance can arise there as well. For example, the threshold values of $F_{O}$ in the current example were influenced by the regression methods used to establish upper limits on $P_{<M N P L}$ as a function of $P_{\text {persist }}$. Furthermore, we evaluated $P_{<M N P L}$ at a single point in time (i.e., at $t=50$ years), rather than at each year $t=1,2, \ldots 50$, which likely underestimated the risk of populations decreasing to less than $N_{M N P L}$ in the near term.

Our results suggest that human-caused removals conducted at a sustainable rate are unlikely to accelerate population declines that may result from climate change, provided that climate change affects polar bears primarily through density-dependent mechanisms or that negative density-independent effects occur at a slow rate relative to the management interval. It follows that a well-managed subsistence harvest seems unlikely to have negative effects on persistence beyond those deemed acceptable when setting values of $F_{O}$ and other inputs to the state-dependent framework. For this to hold true requires periodic assessments of population status, and a management system that provides accurate and timely harvest reporting and that can adjust removal levels. Under conditions of ecological change, information obtained from TK (e.g., Voorhees and others, 2014) and other sources on polar bear distribution, human-bear interactions, and patterns of subsistence use, will likely become increasingly important to responsive management.

The state-dependent management framework implements harvest as a fraction of current population size, which generally is a robust strategy (Quinn and Deriso, 1999). A consequence of this approach is that, if populations are declining due to declining $K$, the level of human-caused removals will decline as well. Thus, implementation of subsistence harvest under this framework requires an ability to decrease future use if populations get smaller due to climate change or other factors. We suggest that the following considerations also are important to mitigating risk if environmental conditions are deteriorating rapidly (i.e., such that large declines in $K$ or $r_{\max }$ occur between population assessments): (1) performing more regular population assessments and shortening the management interval, (2) planning a stopgap measure to reduce removals if a lower population threshold is crossed, 
and (3) evaluating the statistical power to detect whether the lower population threshold has been crossed. Threshold harvest strategies, for which there are no human-caused removals below a specified population size, are an effective method of minimizing the incremental risk of extirpation due to humancaused removals, while maintaining the opportunity for sustainable use if populations rebound in the future (Lande and others, 1997).

\section{Comparison with Current Polar Bear Harvest Management}

The sample demonstration of the state-dependent management framework led to a removal rate higher than the standard 4.5 percent, which has a history of application to polar bear populations (Taylor and others, 1987). However, the 4.5-percent rate usually has been applied to the best estimate (i.e., mean value) of population size, whereas we used the more robust approach of applying removal rates to a lower percentile of the sampling distribution for $N$ (Wade, 1998). For the purpose of demonstration, we can adjust for this difference by assuming a normal distribution for estimates of $N$ with a coefficient of variation equal to 0.15 (this corresponds to data precision level 3 in the simulations; table 4). The lower 15 th percentile of such a distribution is approximately 0.85 of the mean value. Thus, the sustainable removal rate from the state-dependent management framework would be adjusted as follows: 5.3 percent $\times 0.85=4.5$ percent. This suggests that application of the state-dependent management framework using $F_{O}=0.75$, a moderately conservative input under most conditions (table 6 ), would be broadly consistent with historical harvest rates for polar bear subpopulations. That the 4.5-percent rates align exactly is an artifact of using $F_{O}=0.75$ in this example. In practice, either lower or higher values of $F_{O}$ could be appropriate based on population resilience, data precision, and risk tolerance. Furthermore, our analyses suggest that under certain conditions, polar bears can support removal rates higher than 4.5 percent. This is consistent with (1) the suggestion in Eberhardt (1990) that populations of brown bears (Ursus arctos) and polar bears can support higher human-caused mortality than recommended by Taylor and others (1987); (2) with observations that polar bear populations harvested at a 4.5 percent rate have not experienced long-term declines when environmental conditions are stable (Obbard and others, 2010); and (3) with evidence that brown bears, which have a similar life history to polar bears, can support removal rates of 6-10 percent under favorable conditions (Bunnell and Tait, 1981; Hovey and McLellan, 1996; VanDaele, 2007; Krofel and others, 2012). Thus, our analyses suggest that a 4.5-percent harvest rate is not a theoretical maximum, but rather a reasonable approach for populations with moderate resilience in light of imperfect information on population status and time lags in management.

\section{Definition of Sustainability for Polar Bear Harvest Management}

There are conflicting interpretations of "sustainability" in wildlife management (Sutherland, 2001), yet ensuring that harvests are sustainable is a common goal. We suggest a general definition that may be useful for polar bear management: removals conducted at a sustainable rate will (1) result in population sizes at or greater than $N_{M N P L}$ with respect to current conditions, and (2) have a limited negative effect on population persistence. The degree of risk tolerance for both conditions must be determined based on management objectives, the costs and benefits of use, and statutory and stakeholder values. This definition is well-suited for 21 st-century conservation challenges. It acknowledges that carrying capacity can change with time (e.g., due to sea-ice loss) and that whether human-caused removals are sustainable depends on current conditions. Because populations produce maximum sustainable yield near $N_{M N P L}$, this definition allows managers to maximize long-term returns while seeking to avoid excessive near-term removals that could reduce opportunities for future 
generations. Finally, this definition uses objective methods to estimate risk, and acknowledges that other factors must be considered when deciding how much risk is acceptable. This is intended to improve transparency and does not preclude application of the "precautionary principle" or any other conservation standard. It also is consistent with definitions of "sustainable use" according to the Convention on Biological Diversity (2004) and International Union for Conservation of Nature (2000), and with the growing recognition that balancing preservation and human needs is an integral part of long-term conservation (Kareiva and Marvier, 2012).

\section{Acknowledgments}

Primary support for this analysis was provided by U.S. Fish and Wildlife Service (USFWS) and U.S. Geological Survey (USGS). Advice on the modeling framework and analytical approach was provided by members of the Science and Traditional Ecological Knowledge Working Group of the Polar Bear Recovery Team, including T. Atwood, P. Boveng, D. Douglas, K. Johnson, M. Pederson, R. Sparks, K. Titus, and A. Von Duyke. We thank H. Stern (University of Washington) for providing seaice data. We thank T. Atwood, P. Conn, A. Von Duyke, K. Oakley, G. Pendleton, and R. Sparks for comments that improved the report. The findings and conclusions in this report are those of the authors and do not necessarily represent the views of the USFWS. This report was reviewed and approved by USGS under their Fundamental Science Practices policy (http://www.usgs.gov/fsp/).

\section{References Cited}

Akcakaya, H.R., and Sjogren-Gulve, P., 2000, Population viability analyses in conservation planningAn overview: Ecological Bulletins, v. 48, p. 9-21.

Amstrup, S.C., 1993, Human disturbances of denning polar bears in Alaska: Arctic, v. 46, no. 3, p. 246-250.

Amstrup, S.C., 2003, Polar Bear (Ursus maritimus), in Feldhamer, G.A., Thompson, B.C., and Chapman, J.A., eds., Mammals of North America-Biology, management, and conservation: (2d ed.): Baltimore, Maryland, John Hopkins University Press, p. 587-610.

Amstrup, S.C., and Durner, G.M., 1995, Survival rates of radio-collared female polar bears and their dependent young: Canadian Journal of Zoology, v. 73, no. 7, p. 1,312-1,322.

Amstrup, S.C., Marcot, B.G., and Douglas, D.C., 2008, A Bayesian network modeling approach to forecasting the 21 st century worldwide status of polar bears, in DeWeaver, E.T., Bitz, C.M., and Tremblay, L.-B., eds., Arctic sea ice decline-Observations, projections, mechanisms, and implications.: Washington, D.C., American Geophysical Union, Geophysical Monograph 180, p. 213-268.

Amstrup, S.C., McDonald, T.L., and Durner, G.M., 2004, Using satellite radiotelemetry data to delineate and manage wildlife populations: Wildlife Society Bulletin, v. 32, no. 3, p. 661-679.

Barker, R.J., 1997, Joint modeling of live-recapture, tag-resight, and tag-recovery data: Biometrics, v. 53, p. 666-677.

Beissinger, S.R., and McCullough, D.R., 2002, Population viability analysis: Chicago and London, The University of Chicago Press, $577 \mathrm{p}$.

Born, E.W., Heilmann, A., Holm, L.K., and Laidre, K.L., 2011, Polar bears in northwest GreenlandAn interview survey about the catch and the climate: Meddelelser om Grønland, v. 351, 250 p. Boyce, M.S., Haridas, C.V., and Lee, C.T., 2006, Demography in an increasingly variable worldTrends in ecology and evolution: v. 21, no. 3, p. 141-148. 
Bromaghin, J.F., McDonald, T.L., Stirling, I., Derocher, A.E., Richardson, E.S., Regehr, E.V., Douglas, D.C., Durner, G.M., Atwood, T., and Amstrup, S.C., in press, Polar bear population dynamics in the southern Beaufort Sea during a period of sea ice decline: Ecological Applications, http://dx.doi.org/10.1890/14-1129.1.

Brook, B.W., Akcakaya, H.R., Keith, D.A., Mace, G.M., Pearson, R.G., and Araujo, M.B., 2009, Integrating bioclimate with population models to improve forecasts of species extinctions under climate change: Biology Letters, v. 5, no. 6, p. 723-725.

Brower, C.D., Carpenter, A., Branigan, M.L., Calvert, W., Evans, T., Fischbach, A.S., Nagy, J.A., Schliebe, S., and Stirling, I., 2002, The Polar Bear Management Agreement for the Southern Beaufort Sea-An Evaluation of the first ten years of a unique conservation agreement: Arctic, v. 55, no. 4, p. 362-372.

Bunnell, F.L., and Tait, D.E.N., 1981, Population dynamics of bears-Implications, in Fowler, C.W., and Smith, T.D., eds., Dynamics of large mammal populations: New York, John Wiley and Sons, p. 75-98.

Cameron, M.F., Bengtson, J.L., Boveng, P.L., Jansen, J.K., Kelly, B.P., Dahle, S.P., Logerwell, E.A., Overland, J.E., Sabine, C.L., Waring, G.T., and Wilder, J.M., 2010, Status review of the bearded seal (Erignathus barbatus): National Oceanic and Atospheric Administration Technical Memorandum NMFS-AFSC, v. 211, p. i-xvi, 1-246.

Capellini, I., Venditti, C., and Barton, R.A., 2010, Phylogeny and metabolic scaling in mammals: Ecology, v. 91, no. 9, p. 2,783-2,793.

Caswell, H., 2001, Matrix population models (2d ed.): Sunderland, Massachusetts, Sinauer Associates Inc., $722 \mathrm{p}$.

Caswell, H., 2007, Sensitivity analysis of transient population dynamics: Ecology Letters, v. 10, no. 1, p. $1-15$.

Caughley, G., and Sinclair, A.R.E., 1994, Wildlife ecology and management: Cambridge, Massachusetts, Blackwell Science.

Cherry, S.G., Derocher, A.E., Hobson, K.A., Stirling, I., and Thiemann, G.W., 2011, Quantifying dietary pathways of proteins and lipids to tissues of a marine predator: Journal of Applied Ecology, $\mathrm{v}$. 48, no. 2, p. 373-381.

Convention on Biological Diversity, 2004, Addis Ababa principles and guidelines for the sustainable use of biodiversity: United Nations Environment Program, 9-20 and 27 Feb., 2004, Conference of the Parties to the Convention on Biological Diversity, Seventh meeting, Kuala Lumpur.

Convey, P., Aitken, S., di Prisco, G., Gill, M.J., Coulson, S.J., Barry, T., Jonsdottir, I.S., Dang, P.T., Hik, D., Kulkarni, T., and Lewis, G., 2012, The impacts of climate change on circumpolar biodiversity: Ottawa, Canada, Biodiversity, v. 13, nos. 3-4, p. 134-143.

Czetwertynski, S.M., Boyce, M.S., and Schmiegelow, F.K., 2007, Effects of hunting on demographic parameters of American black bears: Ursus, v. 18, no. 1, p. 1-18.

Dennis, B., Munholland, P.L., and Scott, J.M., 1991, Estimation of growth and extinction parameters for endangered species: Ecological Monographs, v. 61, no. 2, p. 115-143.

Dennis, B., and Taper, M.L., 1994, Density dependence in time-series observation of natural populations-Estimation and testing: Ecological Monographs, v. 64, no. 2, p. 205-224.

Derocher, A.E., Aars, J., Amstrup, S.C., Cutting, A., Lunn, N.J., Molnár, P.K., Obbard, M.E., Stirling, I., Thiemann, G.W., Vongraven, D., Wiig, O., and York, G., 2013, Rapid ecosystem change and polar bear conservation: Conservation Letters, v. 6, no. 5, p. 368-375.

Derocher, A.E., and Stirling, I., 1996, Aspects of survival in juvenile polar bears: Canadian Journal of Zoology, v. 74, p. 1,246-1,252. 
Derocher, A.E., Stirling, I., and Calvert, W., 1997, Male-biased harvesting of polar bears in western Hudson Bay: Journal of Wildlife Management, v. 61, no. 4, p. 1,075-1,082.

Devineau, O., Choquet, R., and Lebreton, J.D., 2006, Planning capture-recapture studiesStraightforward precision, bias, and power calculations: Wildlife Society Bulletin, v. 34, no. 4, p. $1,028-1,035$.

Doak, D.F., Morris, W.F., Pfister, C., Kendall, B.E., and Bruna, E.M., 2005, Correctly estimating how environmental stochasticity influences fitness and population growth: American Naturalist, v. 166, no. 1, p. E14-E21.

Dowsley, M., 2009, Community clusters in wildlife and environmental management-Using TEK and community involvement to improve co-management in an era of rapid environmental change: Polar Research, v. 28, no. 1, p. 43-59.

Dyck, M.G., 2006, Characteristics of polar bears killed in defense of life and property in Nunavut, Canada, 1970-2000: Ursus, v. 17, no. 1, p. 52-62.

Eberhardt, L.L., 1990, Survival rates required to sustain bear populations: Journal of Wildlife Management, v. 54, p. 587-590.

Eberhardt, L.L., 2002, A paradigm for population analysis of long-lived vertebrates: Ecology, v. 83, no. 10 , p. 2,841-2,854.

Fieberg, J., and Ellner, S.P., 2001, Stochastic matrix models for conservation and management-A comparative review of methods: Ecology Letters, v. 4, no. 3, p. 244-266.

Flather, C.H., Hayward, G.D., Beissinger, S.R., and Stephens, P.A., 2011, Minimum viable populations - Is there a 'magic number' for conservation practitioners?: Trends in Ecology and Evolution, v. 26, no. 6, p. 307-316.

Fowler, C.W., 1987, A review of density dependence in populations of large mammals: Current Mammalogy, v. 1, p. 401-441.

Fowler, C.W., 1988, Population dynamics as related to rate of increase per generation: Evolutionary Ecology, v. 2, no. 3, p. 197-204.

Gerrodette, T., and Demaster, D.P., 1990, Quantitative determination of optimum sustainable population level: Marine Mammal Science, v. 6, no. 1, p. 1-16.

Groffman, P.M., Kareiva, P., Carter, S., Grimm, N.B., Lawler, J., Mack, M., Matzek, V., and Tallis, H., 2014, chap. 8-Ecosystems, biodiversity, and ecosystem services, in Melillo, J.M., Richmond, T.C., and Yohe, G.W., eds., Climate change impacts in the United States - The third national climate assessment: Washington, D.C., U.S. Global Change Research Program, p. 195-219.

Guthery, F.S., and Shaw, J.H., 2013, Density dependence-Applications in wildlife management: Journal of Wildlife Management, v. 77, no. 1, p. 33-38.

Henle, K., Sarre, S., and Wiegand, K., 2004, The role of density regulation in extinction processes and population viability analysis: Biodiversity and Conservation, v. 13, no. 1, p. 9-52.

Hinzman, L.D., Deal, C.J., McGuire, A.D., Mernild, S.H., Polyakov, I.V., and Walsh, J.E., 2013, Trajectory of the Arctic as an integrated system: Ecological Applications, v. 23, no. 8, p. 1,837-1,868. Hovey, F.W., and McLellan, B.N., 1996, Estimating population growth of grizzly bears from the Flathead River drainage using computer simulations of reproduction and survival rates: Canadian Journal of Zoology-Revue Canadienne De Zoologie, v. 74, no. 8, p. 1,409-1,416.

Hunter, C.M., Caswell, H., Runge, M.C., Amstrup, S.C., Regehr, E.V., and Stirling, I., 2007, Polar bears in the southern Beaufort Sea II-Demography and population growth in relation to sea ice conditions: U.S. Geological Survey Administrative Report, U.S. Geological Survey Alaska Science Center, Anchorage. 
Hunter, C.M., Caswell, H., Runge, M.C., Regehr, E.V., Amstrup, S.C., and Stirling, I., 2010, Climate change threatens polar bear populations-A stochastic demographic analysis: Ecology, v. 91, no. 10, p. 2,883-2,897.

Intergovernmental Panel on Climate Change, 2013, Summary for policymakers, climate change 2013The physical science basis - Contribution of Working Group I to the Fifth Assessment Report of the Intergovernmental Panel on Climate Change: Cambridge, United Kingdom, and New York, Cambridge University Press.

International Union for Conservation of Nature, 2000, IUCN policy statement on sustainable use of wild living resources, in IUCN World Conservation Congress, International Union for Conservation of Nature.

Kareiva, P., and Marvier, M., 2012, What Is conservation xcience?: Bioscience, v. 62, no. 11, p. 962-969.

Kelly, B.P., Bentson, J.L., Boveng, P.L., Cameron, M.F., Dahle, S.P., Jansen, J.K., Logerwell, E.A., Overland, J.E., Sabine, C.L., Waring, G.T., and Wilder, J.M., 2010, Status review of the ringed seal (Phoca hispida): National Oceanic and Atmospheric Administration Technical Memorandum NMFSAFSC, v. 212, p. i-xiv, 1-250.

Kovacs, K.M., Lydersen, C., Overland, J.E., and Moore, S.E., 2011, Impacts of changing sea-ice conditions on Arctic marine mammals: Marine Biodiversity, v. 41, no. 1, p. 181-194.

Krofel, M., Jonozovic, M., and Jerina, K., 2012, Demography and mortality patterns of removed brown bears in a heavily exploited population: Ursus, v. 23, no. 1, p. 91-103.

Laidre, K.L., Stern, H., Kovacs, K.M., Lowry, L., Moore, S.E., Regehr, E.V., Ferguson, S.H., Wiig, Ø., Boveng, P., Angliss, R.P., Born, E.W., Litovka, D., Quakenbush, L., Lydersen, C., Vongraven, D., and Ugarte, F., 2015, A circumpolar assessment of Arctic marine mammals and sea ice loss, with conservation recommendations for the 21st century: Conservation Biology.

Laidre, K.L., Stirling, I., Lowry, L.F., Wiig, O., Heide-Jorgensen, M.P., and Ferguson, S.H., 2008, Quantifying the sensitivity of Arctic marine mammals to climate-induced habitat change: Ecological Applications, v. 18, no. 2, p. S97-S125.

Lande, R., Saether, B.E., and Engen, S., 1997, Threshold harvesting for sustainability of fluctuating resources: Ecology, v. 78, no. 5, p. 1,341-1,350.

Lebreton, J.-D., Nichols, J.D., Barker, R.J., Pradel, R., and Spendlow, J.A., 2009, Modeling individual animal histories with multistate capture-recapture models, in Caswell, H., ed., Advances in ecological research, Volume 41: New York, Academic Press.

Lunn, N.J., Servanty, S., Regehr, E.V., Converse, S.J., Richardson, E., and Stirling, I., 2014, Demography and population status of polar bears in western Hudson Bay, Canada: Environment Canada Research Report, 55 p.

Lyons, J.E., Runge, M.C., Laskowski, H.P., and Kendall, W.L., 2008, Monitoring in the context of structured decision-making and adaptive management: Journal of Wildlife Management, v. 72, no. 8, p. 1,683-1,692.

Maslanik, J.A., Fowler, C., Stroeve, J., Drobot, S., Zwally, J., Yi, D., and Emery, W., 2007, A younger, thinner Arctic ice cover-Increased potential for rapid, extensive sea-ice loss: Geophysical Research Letters, v. 34, no. 24.

McCullough, D.R., 1999, Density dependence and life-history strategies of ungulates: Journal of Mammalogy, v. 80, no. 4, p. 1,130-1,146.

McGowan, C.P., Ryan, M.R., Runge, M.C., Millspaugh, J.J., and Cochrane, J.F., 2011, The role of demographic compensation theory in incidental take assessments for endangered species: Biological Conservation, v. 144, no. 2, p. 730-737. 
McLellan, B.N., Hovey, F.W., Mace, R.D., Woods, J.G., Carney, D.W., Gibeau, M.L., Wakkinen, W.L., and Kasworm, W.F., 1999, Rates and causes of grizzly bear mortality in the interior mountains of British Columbia, Alberta, Montana, Washington, and Idaho: Journal of Wildlife Management, v. 63, no. 3, p. 911-920.

Miller, S.D., Sellers, R.A., and Keay, J.A., 2003, Effects of hunting on brown bear cub survival and litter size in Alaska: Knoxville, Tennessee, Ursus, v. 14, no. 2, p. 130-152.

Mills, L.S., Hayes, S.G., Baldwin, C., Wisdom, M.J., Citta, J., Mattson, D.J., and Murphy, K., 1996, Factors leading to different viability predictions for a grizzly bear data set: Conservation Biology, v. 10 , no. 3, p. 863-873.

Millspaugh, J.J., Skalski, J.R., Townsend, R.L., Diefenbach, D.R., Boyce, M.S., Hansen, L.P., and Kammermeyer, K., 2009, An evaluation of sex-age-kill (SAK) model performance: Journal of Wildlife Management, v. 73, no. 3, p. 442-451.

Milner-Gulland, E.J., 2011, Integrating fisheries approaches and household utility models for improved resource management: Proceedings of the National Academy of Sciences of the United States of America, v. 108, no. 4, p. 1,741-1,746.

Milner-Gulland, E.J., and Akcakaya, H.R., 2001, Sustainability indices for exploited populations: Trends in Ecology and Evolution, v. 16, no. 12, p. 686-692.

Mitchell, M.S., Pacifici, L.B., Grand, J.B., and Powell, R.A., 2009, Contributions of vital rates to growth of a protected population of American black bears: Ursus, v. 20, no. 2, p. 77-84.

Molnár, P.K., Derocher, A.E., Lewis, M.A., and Taylor, M.K., 2008, Modelling the mating system of polar bears - A mechanistic approach to the Allee effect: Proceedings of the Royal Society BBiological Sciences, v. 275, no. 1,631, p. 217-226.

Molnár, P.K., Lewis, M.A., and Derocher, A.E., 2014, Estimating Allee dynamics before they can be observed-Polar bears as a case study: Plos One, v. 9, no. 1.

Morris, W.F., and Doak, D.F., 2002, Quantitative conservation biology - Theory and practice of population viability analysis: Sunderland, Massachusetts, Sinauer Associates, Inc.

Nichols, J.D., and Williams, B.K., 2006, Monitoring for conservation-Trends in ecology and evolution, v. 21, no. 12, p. 668-673.

Noyce, K.V., and Garshelis, D.L., 1994, Body size and blood characteristics as indicators of condition and reproductive performance in black bears: International Conference of Bear Research and Management, v. 91, no. 1, p. 481-496.

Obbard, M.E., McDonald, T.L., Howe, E.J., Regehr, E.V., and Richardson, E.S., 2007, Polar bear population status in southern Hudson Bay, Canada: U.S. Geological Survey Administrative Report, Reston, Virginia, p. 32.

Obbard, M.E., Thiemann, G.W., Peacock, E., and DeBruyn, T.D., 2010, Polar bears: Proceedings of the 15th working meeting of the International Union for Conservation of Nature/Species Survival Commission Polar Bear Specialist Group, June 29-July, 3, 2009, Copenhagen, Denmark: Gland, Switzerland, and Cambridge, United Kingdom, International Union for Conservation of Nature, p. vii $+235 \mathrm{p}$.

Overland, J.E., and Wang, M., 2013, When will the summer Arctic be nearly sea ice free?: Geophysical Research Letters, v. 40, no. 10, p. 2,097-2,101.

Paetkau, D., Amstrup, S.C., Born, E.W., Calvert, W., Derocher, A.E., Garner, G.W., Messier, F., Stirling, I., Taylor, M.K., Wiig, O., and Strobeck, C., 1999, Genetic structure of the world's polar bear populations: Molecular Ecology, v. 8, p. 1,571-1,584. 
Peacock, E., Derocher, A.E., Thiemann, G.W., and Stirling, I., 2011, Conservation and management of Canada's polar bears (Ursus maritimus) in a changing Arctic: Canadian Journal of Zoology-Revue Canadienne De Zoologie, v. 89, no. 5, p. 371-385.

Peacock, E., Sonsthagen, S.A., Obbard, M.E., Boltunov, A., Regehr, E.V., Ovsyanikov, N., Aars, J., Atkinson, S.N., Sage, G.K., Hope, A.G., Zeyl, E., Bachmann, L., Ehrich, D., Scribner, K.T., Amstrup, S.C., Belikov, S., Born, E.W., Derocher, A.E., Stirling, I., Taylor, M.K., Wiig, Ø., Paetkau, D., and Talbot, S.L., 2015, Implications of the circumpolar genetic structure of polar bears for their conservation in a rapidly warming Arctic: Plos One, 10(1): e112021, doi:10.1371/journal.pone.0112021.

Peacock, E., Taylor, M.K., Laake, J., and Stirling, I., 2013, Population ecology of polar bears in Davis Strait, Canada and Greenland: Journal of Wildlife Management, v. 77, no. 3, p. 463-476.

Pe'er, G., Matsinos, Y.G., Johst, K., Franz, K.W., Turlure, C., Radchuk, V., Malinowska, A.H., Curtis, J.M.R., Naujokaitis-Lewis, I., Wintle, B.A., and Henle, K., 2013, A protocol for better design, application, and communication of population viability analyses: Conservation Biology, v. 27, no. 4, p. 644-656.

Péron, G., 2013, Compensation and additivity of anthropogenic mortality-Life-history effects and review of methods: Journal of Animal Ecology, v. 82, no. 2, p. 408-417.

Pfister, C.A., 1998, Patterns of variance in stage-structured pPopulations-Evolutionary predictions and ecological implications: Proceedings of the National Academy of Sciences of the United States of America, v. 95, no. 1, p. 213-218.

Post, E., Forchhammer, M.C., Bret-Harte, M.S., Callaghan, T.V., Christensen, T.R., Elberling, B., Fox, A.D., Gilg, O., Hik, D.S., Hoye, T.T., Ims, R.A., Jeppesen, E., Klein, D.R., Madsen, J., McGuire, A.D., Rysgaard, S., Schindler, D.E., Stirling, I., Tamstorf, M.P., Tyler, N.J.C., van der Wal, R., Welker, J., Wookey, P.A., Schmidt, N.M., and Aastrup, P., 2009, Ecological dynamics across the Arctic associated with recent climate change: Science, v. 325, no. 5,946, p. 1,355-1,358.

Quinn, T.J., and Deriso, R.B., 1999, Quantitative fish dynamics: New York, Oxford University Press.

Regehr, E.V., Amstrup, S.C., and Stirling, I., 2006, Polar bear population status in the southern Beaufort Sea: U.S. Geological Survey Open-File Report 2006-1337, 20 p.

Regehr, E.V., Hunter, C.M., Caswell, H., Amstrup, S.C., and Stirling, I., 2010, Survival and breeding of polar bears in the southern Beaufort Sea in relation to sea ice: Journal of Animal Ecology, v. 79, no. 1, p. 117-127.

Regehr, E.V., Lunn, N.J., Amstrup, S.C., and Stirling, I., 2007, Effects of earlier sea ice breakup on survival and population size of polar bears in western Hudson Bay: Journal of Wildlife Management, v. 71, no. 8, p. 2,673-2,683.

Ripa, J., and Heino, M., 1999, Linear analysis solves two puzzles in population dynamics-The route to extinction and extinction in coloured environments: Ecology Letters, v. 2, no. 4, p. 219-222.

Robbins, C.T., Ben-David, M., Fortin, J.K., and Nelson, O.L., 2012, Maternal condition determines birth date and growth of newborn bear cubs: Journal of Mammalogy, v. 93, no. 2, p. 540-546.

Rockwell, R.F., Gormezano, L.J., and Koons, D.N., 2011, Trophic matches and mismatches - Can polar bears reduce the abundance of nesting snow geese in western Hudson Bay?: Oikos, v. 120, no. 5, p. 696-709.

Rode, K.D., Peacock, E., Taylor, M., Stirling, I., Born, E.W., Laidre, K.L., and Wiig, O., 2012, A tale of two polar bear populations - Ice habitat, harvest, and body condition: Population Ecology, v. 54, no. 1, p. 3-18. 
Rode, K.D., Regehr, E.V., Douglas, D.C., Durner, G., Derocher, A.E., Thiemann, G.W., and Budge, S.M., 2014, Variation in the response of an Arctic top predator experiencing habitat loss-Feeding and reproductive ecology of two polar bear populations: Global Change Biology, v. 20, no. 1, p. 7688.

Ross, J.V., 2009, A note on density dependence in population models: Ecological Modelling, v. 220 , no. 23 , p. 3,472-3,474.

RStudio, 2014, RStudio-Integrated development environment for R (0.98.1060 ed.): Boston, RStudio.

Ruhl, J.B., 2008, Climate change and the Endangered Species Act-Building bridges to the no-analog future: Boston, Boston University Law Review, v. 88, no. 1, p. 1-62.

Runge, M.C., Langtimm, C.A., and Kendall, W., 2004, A stage-based model of manatee population dynamics: Marine Mammal Science, v. 20, no. 3, p. 361-385.

Runge, M.C., Sauer, J.R., Avery, M.L., Blackwell, B.F., and Koenff, M.D., 2009, Assessing allowable take of migratory birds: Journal of Wildlife Management, v. 73, no. 4, p. 556-565.

Savage, V.M., Gillooly, J.F., Brown, J.H., West, G.B., and Charnov, E.L., 2004, Effects of body size and temperature on population growth: American Naturalist, v. 163, no. 3, p. 429-441.

Schliebe, S., Evans, T., Johnson, K., Roy, M., Miller, S., Hamilton, C., Meehan, R., and Jahrsdoerfer, S., 2006, Range-wide status review of the polar bear (Ursus maritimus), in Service: U.S. Fish andWildlife Service, Anchorage, Alaska, $262 \mathrm{p}$.

Schliebe, S., Rode, K.D., Gleason, J.S., Wilder, J., Proffitt, K., Evans, T.J., and Miller, S., 2008, Effects of sea ice extent and food availability on spatial and temporal distribution of polar bears during the fall open-water period in the southern Beaufort Sea: Polar Biology, v. 31, no. 8, p. 999-1,010.

Schwartz, C.C., Haroldson, M.A., White, G.C., Harris, R.B., Cherry, S., Keating, K.A., Moody, D., and Servheen, C., 2006, Temporal, spatial, and environmental influences on the demographics of grizzly bears in the greater Yellowstone ecosystem: Wildlife Monographs, no. 161, p. 1-68.

Seney, E.E., Rowland, M.J., Lowery, R.A., Griffis, R.B., and McClure, M.M., 2013, Climate change, marine environments, and the U.S. Endangered Species Act: Conservation Biology, v. 27, no. 6, p. $1,138-1,146$.

Stapleton, S., Peacock, E., Garshelis, D., and Atkinson, S., 2012, Foxe Basin polar bear aerial survey, 2009 and 2010, final report: Nunavut Wildlife Research Trust, Government of Nunavut, Igloolik, $17 \mathrm{p}$.

Stirling, I., and Derocher, A.E., 2012, Effects of climate warming on polar bears-A review of the evidence: Global Change Biology, v. 18, no. 9, p. 2,694-2,706.

Stirling, I., and Lunn, N.J., 1997, Environmental fluctuations in Arctic marine ecosystems as reflected by variability in reproduction of polar bears and ringed seals, in Woodin, S.J., and Marquiss, M., eds., Ecology of Arctic environments: Oxford, United Kingdom, Blackwell Scientific Publications, p. $167-181$.

Stirling, I., Lunn, N.J., and Iacozza, J., 1999, Long-term trends in the population ecology of polar bears in western Hudson Bay in relation to climatic change: Arctic, v. 52, no. 3, p. 294-306.

Stirling, I., McDonald, T.L., Richardson, E.S., Regehr, E.V., and Amstrup, S.C., 2011, Polar bear population status in the northern Beaufort Sea, Canada, 1971-2006: Ecological Applications, v. 21, no. 3 , p. 859-876.

Stirling, I., and Oritsland, N.A., 1995, Relationships between estimates of ringed seal (Phoca hispida) and polar bear (Ursus maritimus) populations in the Canadian Arctic: Canadian Journal of Fisheries and Aquatic Sciences, v. 52, no. 12, p. 2,594-2,612.

Stirling, I., and Smith, T.G., 2004, Implications of warm temperatures and an unusual rain event for the survival of ringed seals on the coast of southeastern Baffin Island: Arctic, v. 57, no. 1, p. 59-67. 
Stroeve, J.C., Kattsov, V., Barrett, A., Serreze, M., Pavlova, T., Holland, M., and Meier, W.N., 2012, Trends in Arctic sea ice extent from CMIP5, CMIP3 and observations: Geophysical Research Letters, v. 39.

Stubben, C., Milligan, B., and Nantel, P., 2008, The popbio package-Construction and analysis of matrix population models, Version 1.1.11: Vienna, Austria, The R Project for Statistical Computing. [Also available at $h t t p: / / w w w . r-p r o j e c t . o r g /$.

Taylor, M., 1994, Density-dependent population regulation in black, brown, and polar bears, Ninth International Conference on Bear Research and Management, February 23-28, 1992, Missoula, Montana: International Association for Bear Research and Management, Monogaph. Series No. 3, p. 43p.

Taylor, B.L., and DeMaster, D.P., 1993, Implications for non-linear density dependence: Marine Mammal Science, no. 9, p. 360-371.

Taylor, M.K., DeMaster, D.P., Bunnell, F.L., and Schweinsburg, R.E., 1987, Modeling the sustainable harvest of female polar bears: Journal of Wildlife Management, v. 51, no. 4, p. 811-820.

Taylor, M.K., Laake, J., Cluff, H.D., Ramsay, M., and Messier, F., 2002, Managing the risk from hunting for the Viscount Melville Sound polar bear population: Ursus, v. 13, p. 185-202.

Taylor, M.K., Laake, J., McLoughlin, P.D., Born, E.W., Cluff, H.D., Ferguson, S.H., Rosing-Asvid, A., Schweinsburg, R., and Messier, F., 2005, Demography and viability of a hunted population of polar bears: Arctic, v. 58, no. 2, p. 203-214.

Taylor, M. K., Laake, J., McLoughlin, P.D., Cluff, H.D., Born, E.W., Rosing-Asvid, A., and Messier. F., 2008a, Population parameters and harvest risks for polar bears (Ursus maritimus) of Kane Basin, Canada and Greenland: Polar Biology, v. 31, p.491-499.

Taylor, M. K., Laake, J., Mcloughlin, P.D., Cluff, H.D., and Messier, F., 2006, Demographic parameters and harvest-explicit population viability analysis for polar bears in M'clintock Channel, Nunavut, Canada: Journal of Wildlife Management, v. 70, p. 1667-1673.

Taylor, M.K., Laake, J., McLoughlin, P.D., Cluff, H.D., and Messier, F., 2008b, Mark-recapture and stochastic population models for polar bears of the high Arctic: Arctic, v. 61, no. 2, p. 143-152.

Taylor, M.K., Laake, J., McLoughlin, P.D., Cluff, H.D., and Messier, F., 2009, Demography and population viability of polar bears in the Gulf of Boothia, Nunavut: Marine Mammal Science, v. 25, no. 4, p. 778-796.

Taylor, M.K., McLoughlin, P.D., and Messier, F., 2008c, Sex-selective harvesting of polar bears Ursus maritimus: Wildlife Biology, v. 14, no. 1, p. 52-60.

Thiemann, G.W., Iverson, S.J., and Stirling, I., 2008, Polar bear diets and Arctic marine food websInsights from fatty acid analysis: Ecological Monographs, v. 78, no. 4, p. 591-613.

Towns, L., Derocher, A.E., Stirling, I., Lunn, N.J., and Hedman, D., 2009, Spatial and temporal patterns of problem polar bears in Churchill, Manitoba: Polar Biology, v. 32, no. 10, p. 1,529-1,537.

U.S. Fish and Wildlife Service, 2008, Endangered and threatened wildlife and plants; determination of threatened status for the polar bear (Ursus maritimus) throughout its range; final rule: Federal Register, v. 72, p. 28212.

U.S. Fish and Wildlife Service, 2013, Endangered and threatened wildlife and plants; special rule for the polar bear under section 4(d) of the Endangered Species Act: Federal Register, v. 78, p. 11766-11788.

VanDaele, L.J., 2007, Population dynamics and management of brown bears on Kodiak Island, Alaska: Moscow, University of Idaho, Ph.D. dissertation, $81 \mathrm{p}$. 
Vongraven, D., Aars, J., Amstrup, S., Atkinson, S.N., Belikov, S., Born, E.W., DeBruyn, T., Derocher, A.E., Durner, G., Gill, M., Lunn, N., Obbard, M., Omelak, J., Ovsyanikov, N., Peacock, E., Richardson, E., Sahanatien, V., Stirling, I., and Wiig, O., 2012, A circumpolar monitoring framework for polar bears: Ursus Monograph Series, v. 5, p. 1-66.

Voorhees, H., Sparks, R., Huntington, H.P., and Rode, K.D., 2014, Traditional knowledge about polar bears (Ursus maritimus) in northwestern Alaska: Arctic, v. 67, no. 4, p. 523-536.

Wade, P.R., 1998, Calculating limits to the allowable human-caused mortality of cetaceans and pinnipeds: Marine Mammal Science, v. 14, no. 1, p. 1-37.

Wade, P.R., and Angliss, R., 1997, Guidelines for assessing marine mammal stocks-Report of the GAMMS Workshop, April 3-5, 1996, Seattle, Washington: National Oceanic and Atmospheric Administration, $93 \mathrm{p}$.

Walsh, J.E., 2008, Climate of the Arctic marine environment: Ecological Applications, v. 18, no. 2, p. S3-S22.

Weinbaum, K.Z., Brashares, J.S., Golden, C.D., and Getz, W.M., 2013, Searching for sustainabilityAre assessments of wildlife harvests behind the times?: Ecology Letters, v. 16, no. 1, p. 99-111.

White, C.R., and Seymour, R.S., 2003, Mammalian basal metabolic rate is proportional to body mass (2/3): Proceedings of the National Academy of Sciences of the United States of America, v. 100, no. 7, p. 4,046-4,049.

White, G.C., 2000, Population viability analysis — Data requirements and essential analyses, in Biotani, L., and Fullers, T.K., eds., Research techniques in animal ecology_Controversies and consequences: New York, Cambridge University Press.

Wieglus, R.B., Sarrazin, F., Ferriere, R., Clobert, J., 2001, Estimating effects of adult male mortality on grizzly bear population growth and persistence using matrix models: Biological Conservation, v. 98, p. 293-303.

Williams, B.K., and Johnson, F.A., 2013, Confronting dynamics and uncertainty in optimal decision making for conservation: Environmental Research Letters, v. 8, no. 2.

Williams, C.K., 2013, Accounting for wildlife life-history strategies when modeling stochastic densitydependent populations-A review: Journal of Wildlife Management, v. 77, no. 1, p. 4-11.

Zar, J.H., 2010, Biostatistical analysis (5th ed.): Upper Saddle River, New Jersey, Pearson Prentice Hall, $960 \mathrm{p}$.

Zedrosser, A., Dahle, B., and Swenson, J.E., 2006, Population density and food conditions determine adult female body size in brown bears: Journal of Mammalogy, v. 87, no. 3, p. 510-518. 


\section{Appendix A. Methods to Adapt Published Vital Rates to the Polar Bear Life Cycle Graph}

If a study did not report C1 (polar bear yearling) survival, we assumed it to be equivalent to the reported value of subadult (independent polar bear aged 2-4 years) survival. If a study reported survival for a combined $\mathrm{C} 1$ and subadult age class, we assumed it to be equivalent to subadult survival as defined in the life cycle graph (fig. 1). We used estimates of litter production rate for females $>6$ years (Obbard and others, 2010, table 3 ) as the vital rate $\beta_{4}$, and as the vital rate $\beta_{3}$ if a separate estimate of $\beta_{3}$ was not available. Recruitment parameters in the life cycle graph $\left(\sigma_{L 0}, \sigma_{L 1}\right.$, and $\left.f\right)$ were calculated from $\mathrm{C} 0$ (cub-of-the year) litter sex ratio, $\mathrm{C} 0$ litter size, $\mathrm{C} 0$ survival, and $\mathrm{C} 1$ survival as described in Hunter and others (2007, appendix B). All projections used a constant value of 0.5 for the proportion of females in C0 litters because this is the mean estimate across subpopulations (Obbard and others, 2010, table 3) and we did not have a biological expectation for variation in this parameter. All population projections used a constant value of 0.10 for $\beta_{5}$ (Regehr and others, 2010) because this parameter is relatively unimportant to population growth (Hunter and others, 2007) and has not been estimated in most polar bear studies. 


\section{Appendix B. Methods to Generate Density-Dependent Functions for the Vital Rates}

We defined relationships between vital rates and density using a form of the logistic equation:

$$
y=(\mu-h f)+(2 h f) /\{1+\exp [-m(x-c)]\}
$$

where $y \quad$ is a vital rate;

$x \quad$ is a dimensionless measure of density, calculated as the ratio of population size to carrying capacity (i.e., $N / K)$;

$\mu \quad$ is the median value of the vital rate;

$h f \quad$ is the half range of the vital rate, calculated as twice its standard deviation;

$m \quad$ is a slope coefficient; and

$c \quad$ is a location coefficient denoting the value of $x$ at which the median (i.e., inflection point) occurs.

We calculated the median value $(\mu)$ for each vital rate from its maximum value and its half range $(h f)$. The maximum of each vital rate (i.e., the value in the absence of density effects) was a specified input for any given population projection. We used a half range $(h f)$ of 0.05 for the vital rates $\sigma_{4}, \sigma_{6}$, and $\sigma_{6}$, which was calculated as twice the standard deviation of point estimates of adult female survival from case studies (table 1). This approach assumed that total variation in survival for adult females, as estimated across polar bear populations that exist under different densities and different environmental conditions, was a reasonable approximation of the amount of plasticity in this parameter. The true amount of plasticity likely was somewhat lower due to the presence of sampling error in estimates of survival, which in future analyses could be delineated using variance components.

Adult female survival is the most important determinant of population growth for many longlived species (Eberhardt, 2002). For polar bears, it is also estimated with higher precision than other demographic parameters. We estimated the value of $h f$ for other vital rates from the value for adult females, using a linear relationship on the log-log scale between a vital rate's coefficient of variation and elasticity as calculated from the matrix model (Caswell, 2001). This was a quantitative way to incorporate the hypothesis of demographic buffering, or negative correlation between the variance of a vital rate and its importance to population growth (Pfister, 1998), into the density-dependent functions. Elasticity values were not available for male survival because the life cycle graph did not reflect the role of males in reproduction. Therefore, we set $h f$ for male survival equal to $h f$ for female survival within the same age class.

We used a slope coefficient $(m)$ of -7.25 in equation B1. This produced convex vital rate versus density curves for which most density-related changes occurred in the range $0.5<N / K<1.5$. It also led to functional responses that were consistent with population dynamics theory (see section, "Results"). We adjusted the location coefficient $c$ for each vital rate, relative to the others, so that density dependence would begin to affect vital rates in the following order: subadult (independent polar bear aged 2-4 years) survival, C0 (cub-of-the year) survival, breeding probability, and finally C1 (polar bear yearling) survival and adult (polar bear aged 5 or more years) survival (Eberhardt, 2002). With the location coefficient set to $c$ for adult survival, we set the location coefficient to $0.8 c$ for the vital rates $\sigma_{1}, \sigma_{2}, \sigma_{3}$, $\sigma_{7}, \sigma_{8}$, and $\sigma_{9}$. This reflected the hypothesis that, as $N / K$ increases, density effects will first show up in subadult survival because subadults are inexperienced hunters that have high energetic demands and generally are in poorer nutritional condition than other bears (Noyce and Garshelis, 1994; Eberhardt, 2002; Schwartz and others, 2006). We set the location coefficient to $0.85 c$ for $\sigma_{L 0}$, reflecting the 
hypothesis that $\mathrm{C} 0$ litter survival is the next vital rate affected. Body size and survival for $\mathrm{C} 0$ s are related to maternal nutritional condition, which depends on food availability (Derocher and Stirling, 1996) and declines in C0 survivorship have been suggested as one of the first responses to density effects (Miller and others, 2003). Finally, we set the location coefficient to $0.975 \mathrm{c}$ for $\beta_{3}$ and $\beta_{4}$, reflecting the hypothesis that changes in breeding probability may be delayed (Noyce and Garshelis, 1994) because studies of several subpopulations thought to be experiencing density effects suggest that the threshold for maternal nutritional condition, below which females fail to give birth, is low (Robbins and others, 2012). This potentially can lead to successful $\mathrm{C} 0$ litter production (i.e., relatively high $\beta_{4}$ ) followed by $\mathrm{C} 0$ litter loss (i.e., relatively low $\sigma_{L 0}$ ).

The density-dependent functions generated by equation B1 were constrained to the range $[0,1]$. Equation B1 was applied to all vital rates in the life cycle graph (fig. 1) except for the parameter $f$, the expected number of 2-year-olds arriving in stages 1 and 7. This is because $f$ was not independent but rather was calculated as a function of $\mathrm{C} 0$ litter sex ratio, $\mathrm{C} 0$ litter size, $\mathrm{C} 0$ survival, and $\mathrm{C} 1$ survival (Hunter and others, 2010, appendix B). We used a time-constant value of C0 litter size; therefore, the demographic model did not allow for potential density-dependent effects on C0 litter size. 


\section{Appendix C. Methods to Generate a Sea Ice-Based Proxy for Carrying Capacity}

We obtained passive microwave satellite imagery of daily sea-ice concentration for 1979-2013 (data source, National Snow and Ice Data Center, Boulder, Colorado; http://nsidc.org; data provided by H. Stern, University of Washington) within the Chukchi Sea and Southern Beaufort Sea polar bear subpopulation boundaries (Obbard and others, 2010). The sea ice concentrations were generated using the National Aeronautics and Space Administration Team algorithm and were provided in a polar stereographic projection with a nominal grid cell size of $25 \times 25 \mathrm{~km}$. Within each subpopulation boundary, we first determined the mean area covered by sea ice during March of each year (i.e., the sea ice maximum), for 1979-2013. Area covered by sea ice was calculated as the sum of grid cell area multiplied by grid cell concentration, over all grid cells with greater than 15 -percent sea ice concentration. Next, we determined the number of days each year when the area of ice cover was greater than 50 percent of the March area, hereafter referred to as "ice-covered days." We then used linear regression to estimate the trend in the number of ice-covered days (trend) and the standard deviation of the trend (sd.trend). The standard deviation of the residuals (sd.annual) provided a measure of interannual variability. Finally, we calculated the mean number of ice-covered days for the period 1994-2013 (ndays94-13) to serve as a baseline for projections. Based on these results (table C1), we projected the number of ice-covered days forward in time using a gamma distribution to ensure that values were greater than zero:

$$
\text { ndays }_{t} \sim \text { Gamma }\left(\text { shape }=\frac{\left(\text { ndays }_{94-13}+t \overline{\text { ren }} d \times t\right)^{2}}{\text { sd.annual }^{2}}, \text { rate }=\frac{\left(\text { ndays }_{94-13}+t \widehat{\text { rend }} \times t\right)}{\text { sd.annual }^{2}}\right)
$$

where ndays $_{t} \quad$ is the number of ice-covered days in year $t$;

$t \quad$ is the number of years from the beginning of the projection; and

$\widehat{t r e n d}$ is a random draw, at the beginning of each projection, from a normal distribution with mean trend and standard deviation sd.trend.

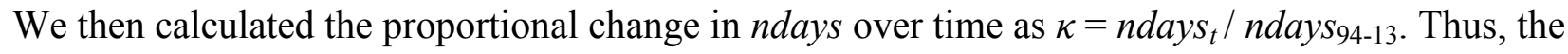
dimensionless metric $\kappa$ reflects proportional changes in the duration of the ice-covered period.

Table C1. Parameters for linear regressions fit to the number of ice-covered days for 1979-2013.

[Regression parameters were used to project the number of ice-free days forward in time using equation C1]

\begin{tabular}{lcccc}
\hline \multicolumn{1}{c}{ Subpopulation } & $\begin{array}{c}\text { trend } \\
\text { (days / year) }\end{array}$ & $\begin{array}{c}\text { sd.trend } \\
\text { (days / year) }\end{array}$ & $\begin{array}{c}\text { sd.annual } \\
\text { (days) }\end{array}$ & $\begin{array}{c}\text { ndays94-13 } \\
\text { (days) }\end{array}$ \\
\hline Chukchi Sea & -0.9 & 0.3 & 15.3 & 188 \\
Southern Beaufort Sea & -2.1 & 0.4 & 24.4 & 252 \\
\hline
\end{tabular}




\section{Appendix D. Methods to Estimate Parameters Using Simulated Population Assessments}

For the purpose of evaluating the state-dependent management framework, human-caused removals were calculated using equations 1 and 2 and were specified at a constant level for 10-year management intervals. At the beginning of each management interval, we simulated a population assessment to generate the input parameters for equations 1 and 2. Per capita population growth rate at maximum net productivity level (i.e., $r_{M N P L}$ ) was estimated from correlated random vital rates, selected from a multivariate beta distribution using methods described in section, "Density-Independent Variation." The mean values in the multivariate beta distribution were the true vital rates at a population density equal to MNPL, as determined from the density-dependent functions for the vital rates. A random value for $N$ was selected from a normal distribution. The mean value in the normal distribution was the average true value of $N$ for the projected population over the preceding five time steps. Random draws were performed using a correlation coefficient of 1 across the vital rates and $N$. The amount of sampling error in the simulated population assessment (i.e., the variances in the beta and normal distributions) was based on 75 percent of total uncertainty in parameter estimates from case studies (table 4). This was complementary to the previous assumption that process variation constituted 25 percent of total uncertainty in estimates of vital rates. Uncertainty in estimates of $N$ was obtained from the most recent case studies for each polar bear subpopulation as summarized in the Status Table published by the Polar Bear Specialist Group of the International Union for Conservation of Nature (http://pbsg.npolar.no/en/status/status-table.html, accessed July 10, 2014). The four levels of data precision considered in the simulated population assessments (table 4) were based on the 1st, 10th, 50th, and 99th percentiles of estimated sampling uncertainty. Thus, our simulated population assessments broadly reflected the observed range of data precision in case studies for polar bears. 
Publishing support provided by the U.S. Geological Survey Science Publishing Network, Tacoma Publishing Service Center

For more information concerning the research in this report, contact the Director, Alaska Science Center

U.S. Geological Survey

4210 University $\mathrm{Dr}$

Anchorage, Alaska 99508-4560

http://alaska.usgs.gov 
